\title{
REDUCING RISK IN LOW-PERMEABILITY GAS FORMATIONS: UNDERSTANDING THE ROCK/FLUID CHARACTERISTICS OF ROCKY MOUNTAIN LARAMIDE BASINS
}

\author{
Final Technical Progress Report
}

Reporting Period Start Date: October 1, 2001

Reporting Period End Date: September 30, 2003

Dr. Ronald C. Surdam

Project Manager and Principal Investigator

\section{D.O.E. Award No. DE-FC26-01NT41325}

Department of Energy Contracting Officer: Delia E. Ball

Ronald C. Surdam, Zunsheng Jiao, and Yuri Ganshin Innovative Discovery Technologies, LLC 1275 N. 15th St., Suite 121

Laramie, WY 82072 


\section{Disclaimer}

This report was prepared as an account of work sponsored by an agency of the United States Government. Neither the United States Government, nor any agency thereof, nor any of their employees, makes any warranty, express or implied, or as-sumes any legal liability or responsibility for the accuracy, completeness, or usefulness of any information, apparatus, product, or process disclosed, or represents that its use would not infringe on privately owned rights. Reference herein to any specific commercial product, process, or service by trade name, trademark, manufacturer, or otherwise does not necessarily constitute or imply its endorsement, recommendation, or favoring by the United States Government or any agency thereof. The views and opinions of the authors expressed herein do not necessarily state or reflect those of the United States Government of any agency thereof. 


\section{Abstract}

An anomalous velocity model was constructed for the Wind River Basin (WRB) based on $2000 \mathrm{mi}$ of 2-D seismic data and 175 sonic logs, for a total of 132,000 velocity/depth profiles. Ten cross sections were constructed through the model coincident with known gas fields. In each cross section, an intense, anomalously slow velocity domain coincided with the gasproductive rock/fluid interval. The anomalous velocity model:

1. Easily isolates gas-charged rock/fluid systems characterized by anomalously slow velocities and water-rich rock/fluid systems characterized by normal velocities; and

2. Delineates the regional velocity inversion surface, which is characterized by steepening of the $\mathrm{R}_{\mathrm{o}}$ /depth gradient, a significant increase in capillary displacement pressure, a significant change in formation water composition, and acceleration of the reaction rate of smectiteto-illite diagenesis in mixed-layer clays.

Gas chimneys are observed as topographic highs on the regional velocity inversion surface. Beneath the surface are significant fluid-flow compartments, which have a gas-charge in the fluid phase and are isolated from meteoric water recharge. Water-rich domains may occur within regional gas-charged compartments, but are not being recharged from the meteoric water system (i.e., trapped water).

The WRB is divided into at least two regionally prominent fluid-flow compartments separated by the velocity inversion surface: a waterdominated upper compartment likely under strong meteoric water drive and a gas-charged, anomalously pressured lower compartment. Judging from cross sections, numerous gascharged subcompartments occur within the regional compartment. Their geometries and boundaries are controlled by faults and lowpermeability rocks. Commercial gas production results when a reservoir interval characterized by enhanced porosity/permeability intersects one of these gas-charged subcompartments.

The rock/fluid characteristics of the Rocky Mountain Laramide Basins (RMLB) described in this work determine the potential for significant, relatively unconventional, so-called "basincenter" hydrocarbon accumulations. If such accumulations occur, they will be characterized by the following critical attributes:

1. Location beneath a regional velocity inversion surface that typically is associated with low-permeability lithologies;

2. Anomalous pressure, both over- and underpressure, and when, less commonly, they appear to be normally pressured, they are not in contact with the meteoric water system;

3. A significant gas component in the regional multiphase fluid-flow system (water-gas-oil) that occurs beneath the regional velocity inversion surface;

4. Domains of intense gas charge (i.e., high gas saturation) within the regional multiphase fluid-flow system;

5. Compartmentalization of the rock/fluid system to a far greater extent beneath the regional velocity inversion surface than above it (i.e., convection of fluids across the regional velocity inversion surface is reduced or eliminated depending on the nature of the capillary properties of the low-permeability rocks associated with the inversion surface);

6. Commercial gas accumulations occurring at the intersection of reservoir intervals characterized by enhanced porosity and permeability and gascharged domains;

7. Productive intersections of reservoir intervals and gas-charged domains, which are controlled by the structural, stratigraphic, and diagenetic elements 
affecting the rock/fluid system; and

8. No apparent meteoric water connection with the gas accumulations and gas columns up to several thousand feet in height.

Because some of these critical attributes are not associated with conventional hydrocarbon accumulations, a new set of diagnostic tools are required in order to explore for and exploit these types of gas prospects efficiently and effectively. Some of these new diagnostic tools have been discussed in this report; other have been described elsewhere (Surdam et al., 1994; Heasler et al, 1994; Chen et al., 1994; MacGowan et al, 1994; Surdam et al, 1997; Maucione and Surdam, 1997; Surdam, 1997; Surdam et al, 200; Surdam, 2001a,b,c; and Surdam, 2003a,b). In order to maximize risk reduction, it is recommended when exploring for these types of gas accumulations in the RMLB - or for that matter, anomalously pressured gas accumulations anywhere in the world — that highest priority be given to:

1. Evaluating gas distribution in the fluid system, and

2. Predicting enhanced porosity and permeability in the rock system. 


\section{Table of Contents}

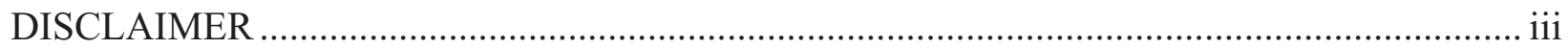

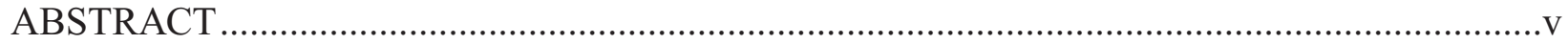

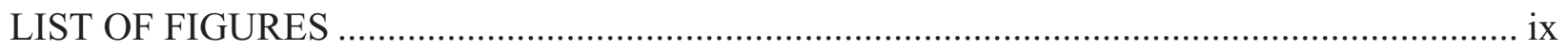

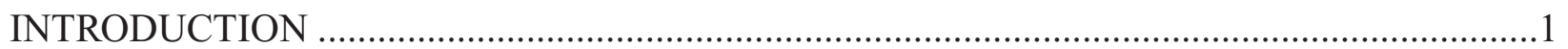

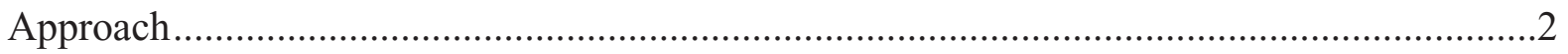

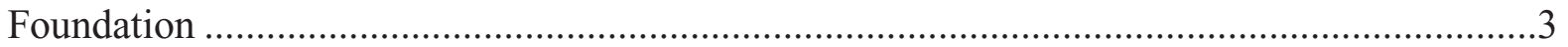

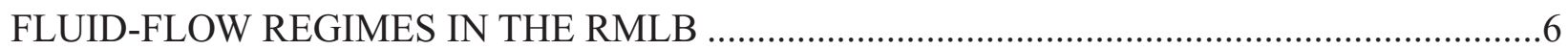

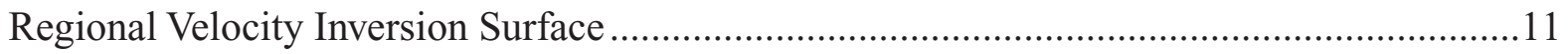

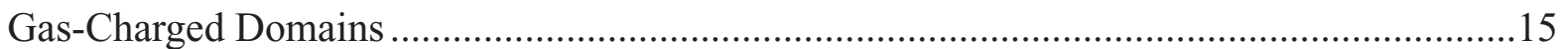

Basinwide Rock/Fluid Systems: Wind River Basin........................................................ 17

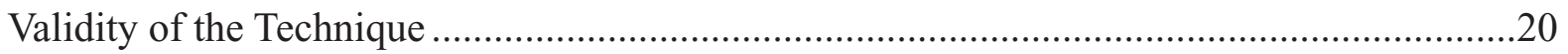

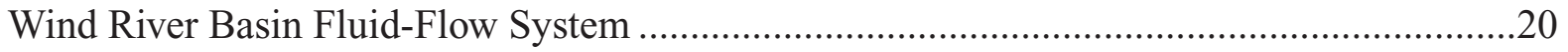

COMMERCIAL GAS-CHARGED RESERVOIR TARGETS ..............................................24

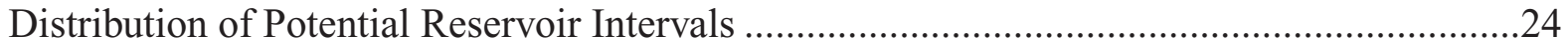

Seismic Frequency and Lithologic Correlations .......................................................26

Intersection of Gas-Charged Domains and Sandstone-Rich Reservoir Intervals ............29

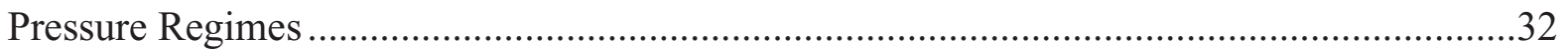

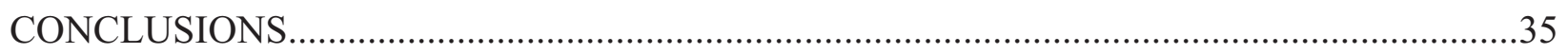

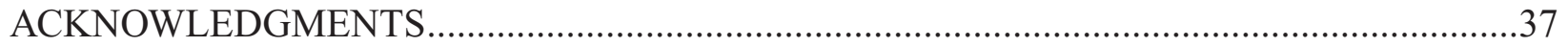

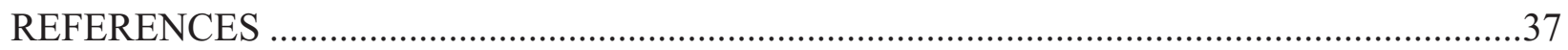




\section{List of Figures}

Figure

page

1 Map showing anomalously pressured gas fields near basin margin in the Washakie Basin, WY ..... 1

anomalous velocity profile for the San Juan Basin based on 20 sonic $\log$ profiles .......................... 3

anomalous velocity volume for the Wind River Basin .................................................................. 4

Summary of velocity-composition relationships of demonstrated by Timur (1987), Lazaratos and

Marion (1997), and Knight et al. (1998) .................................................................................. 5

5 Diagram illustrating correlation between anomalous velocity and EUR for the Lance Fm. ........... 6

6 Left : observed sonic velocity profile and constructed ideal regional velocity/depth function. Right:

observed sonic velocity profile after removel of ideal regional velocity/depth function ................. 7

7 Left: seismic velocity field across Jonah field superimposed on seismic stack. Right: anomalous

velocity profile

8

Typical anomalous seismic interval velocity panel for the Powder River Basin 8

$9 \quad$ Typical anomalous seismic interval velocity panel for the Washakie Basin .................................. 9

10 Typical anomalous seismic interval velocity panel for the Hanna Basin .................................... 9

11 Typical anomalous seismic interval velocity (i.e., slow) panel for the Piceance Basin ................. 10

12 Typical anomalous seismic interval velocity (i.e., slow) panel for the Sand Wash Basin............... 10

13 Index map of the Rocky Mountain Laramide Basins (RMLB) ................................................... 11

14 Typical observed sonic velocity/depth (left) and anomalous sonic velocity (right) profiles in the

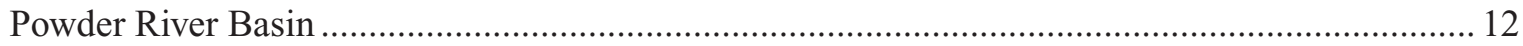

15 PI vs. depth (left), Ro vs. depth (middle), and illite/smectite vs. depth (right) for organic-rich rocks from the Powder River, Bighorn, Wind River, and Washakie basins ............................................. 13

16 TDS in formation water from the Muddy Ss vs. depth in the Powder River Basin, WY ...14

17 Displacement pressure vs. depth (left) and sealing capacity vs. depth (right) for samples from the Cretaceous Mowry Shale from the Powder River Basin ......................................14

18 Index map from the distribution of the Echo Geophysical Wind River seismic data set....15 anomalous velocity model for the Wind River Basin .................................................16

20 Section of the Wind River Basin velocity model that falls on the ideal regional velocity/ depth trend

21 Inclined view of the top of the regional velocity inversion surface and the anomalously slow velocity portion or the Wind River Basin anomalous velocity model .......................17

22 Inclined view of a 3-D anomalous velocity model for the Upper Fort Union stratigraphic volume 18

23 Inclined view of a 3-D anomalous velocity model for the Lower Fort Union stratigraphic volume 18

24 Inclined view of a 3-D anomalous velocity model for the Lance stratigraphic volume .....19

25

26 Inclined view of a 3-D anomalous velocity model for the Meeteetse stratigraphic volume19 Inclined view of a 3-D anomalous velocity model for the Mesaverde stratigraphic volume 20

27 N-S anomalous velocity profile through the Upper Cretaceous portion of the Madden gas field 21

$28 \quad$ N-S anomalous velocity profile through the Frenchie Draw field .21 N-S anomalous velocity profile through the Dinty Moore field .......................................22 N-S anomalous velocity profile through the Squaw Butte field....................................22 $\mathrm{N}-\mathrm{S}$ anomalous velocity profile through the Kanson Draw field ....................................23 $\mathrm{N}-\mathrm{S}$ anomalous velocity profile through the Pavillion field............................................23 Schematic diagram illustrating that gas production sweets pots typically are defined spatially by the intersection of gas-charged fluid domains with reservoir rock domains characterized by enhanced porosity and permeability ................................................25

$34 \quad \mathrm{~N}-\mathrm{S}$ seismic frequency panel from the Greater Green River Basin ................................26

35 Panel showing a frequency/depth profile and a gamma ray log trace/depth profile from a coincident seismic CMP and a well log from the Frenchie Draw field, Wind River Basin27 
$36 \quad$ N-S seismic frequency panel through the Frenchie Draw field

$\mathrm{N}-\mathrm{S}$ anomalous velocity panel for the same seismic data as those shown in Figure $38 . . . .29$

38 Seismic data display showing the results of superimposing Figure 36 (seismic frequency attributes) and 37 (anomalous velocity profile)

39 Seismic frequency attribute panel for a prospective area in the Wind River Basin .............31

Figure

40 anomalous velocity panel for the same seismic data as those shown in Figure 39............32

41 Seismic display illustrating the overlap between the frequency panel (Figure 39) and the anomalous velocity panel (Figure 40)....

42 ISIP (left) and FSIP (right) vs. depth for the Lower Fort Union, Lance, and Mesaverde stratigraphic units from the Wind River Basin..............................................................34

43 Pressure profile for the major Cretaceous gas reservoirs in the Powder River Basin .........35

44 Schematic diagram illustrating the typical transition from overpressured to underpressured ock/fluid systems in the RMLB that have undergone regional uplift

\section{List of Tables}

Table

page

1 List of basins in which the IDT exploration strategy and associated technologies have been successfully applied

\section{List of Acronyms/Symbols}

$\begin{array}{ll}\text { BCGS } & \text { Basin center gas system } \\ \text { CMP } & \text { Common midpoint } \\ \text { FSIP } & \text { Final shut-in pressure } \\ \text { ISIP } & \text { Initial shut-in pressure } \\ \text { PI } & \text { Production index } \\ \text { RMLB } & \text { Rocky Mountain Laramie Basins } \\ \mathrm{R}_{\mathrm{o}} & \text { Vitrinite reflectance } \\ \text { TDS } & \text { Total dissolved solids } \\ \text { TWTT } & \text { Two-way traveltime } \\ \text { WRB } & \text { Wind River Basin }\end{array}$




\section{Reducing Risk in Low-Permeability Gas Formations: Understanding the Rock/Fluid Characteristics of Rocky Mountain Laramide Basins}

\section{INTRODUCTION}

The authors of this paper have studied socalled "basin-center" gas systems (BCGS) in more than 30 basins located in North and South America, Asia, southeastern Asia, Africa, and Australia (Table 1). In addition, Law (2002) has documented the existence of BCGS in Europe, New Zealand, and the Middle East. Thus, the distribution of the class of gas accumulations commonly referred to as BCGS occurs worldwide in a variety of basin types and in rock/fluid systems ranging in age from Precambrian to Tertiary (Law, 2002). These BCGS have been denoted "basin-center," "deep basin, and "continuous" gas accumulations. Recently, they have been further subdivided into "direct and indirect basin-center gas accumulations" based on source rock maturation history (Law, 2002). Most recently, Camp et al. (2003) have suggested that many of the previously designated BCGSs are low-permeability, conventional gas traps. Unfortunately, the development of all of this nomenclature has added confusion and uncertainty to the efforts to better understand and exploit this relatively unconventional, but very important gas resource.

Clearly, BCGS do not always occur in basincenter configurations; they are not necessarily

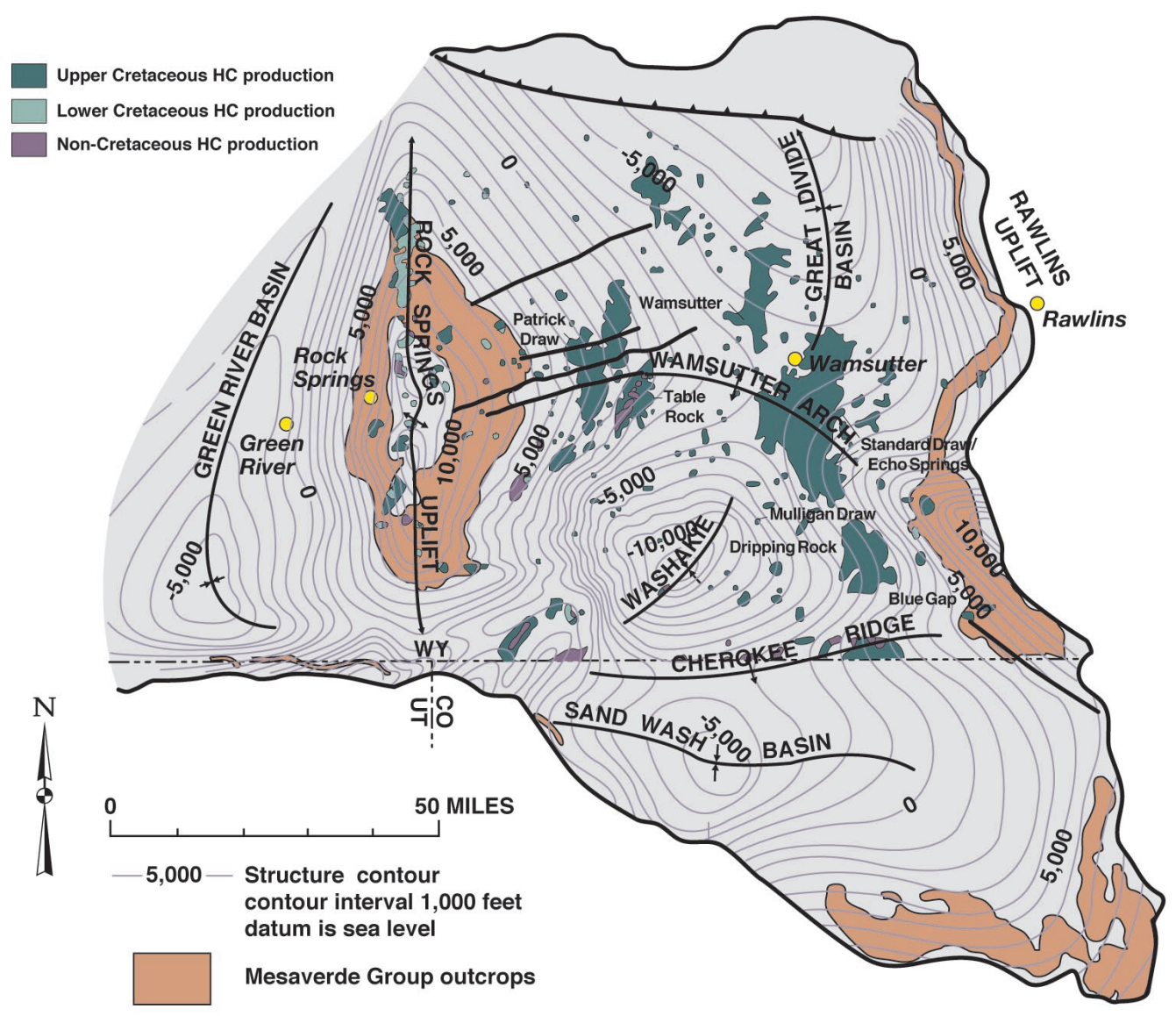

Figure 1. Map showing some of the anomalously pressured gas fields, such as Table Rock, Standard Draw, and Echo Springs located closer to the basin margin than the basin center of the Washakie subbasin (Greater Green River Basin of Wyoming). Structure contour is on the top of the Mesaverde Group. 
deep; and many of them are certainly not continuous. For example, the Table Rock and giant Echo Springs-Standard Draw gas fields in the Greater Green River Basin of Wyoming are near the basin edge (Figure 1); the BCGS in the San Juan Basin of New Mexico are not deep (the top of the anomalously pressured gas accumulations is at 3000 to $4000 \mathrm{ft}$ present-day depth; Figure 2); and the BCGS in the Wind River Basin of Wyoming are not continuous (Figure 3). Subdividing these gas accumulations based on maturation scenarios can be counterproductive because detailed maturation sequences are unknown or are unattainable in many basins. The question confronting earth scientists today can be framed as follows: are BCGS a unique class of petroleum systems characterized by a set of unusual attributes that separate them from conventional hydrocarbon accumulations, or, as Shanley et al (2003) suggest, are they "an end-member within well-understood petroleum systems and should be evaluated in a manner similar to, and consistent with conventional hydrocarbon systems"? The answer to this question will determine how efficiently and effectively these gas resources will be converted to energy reserves.

\section{Approach}

This report will focus generally on the rock/ fluid system characteristics of Rocky Mountain Laramide Basins (RMLB), and specifically on the Wind River Basin of Wyoming for a more detailed evaluation of basinwide rock/fluid attributes. This approach - focusing mainly on the RMLB is used because much of the defining work completed on BCGS originated in these basins (see, among others, Law, 1984; Law and Dickinson, 1985; Law and Spencer, 1989; Law et al., 1980; Masters, 1979; Masters, 1984; McPeek, 1981; Spencer, 1985, 1987, 1989; Surdam, 1997; Surdam et al., 1994, 1997). The work presented in this report work emphasizes descriptions of the rock/fluid system characteristics of the RMLB based on observations. As such, the report will keep speculation regarding BCGS to a minimum and label such speculation when it occurs. If

\section{ROCKY MOUNTAIN BASINS}

Powder River Basin, WY
Bighorn Basin, WY
Wind River Basin, WY
Badger Basin, WY
Washakie Basin, WY
Green River Basin, WY
Hanna Basin, WY
Hoback Basin, WY
Great Divide Basin, WY
Sand Wash Basin, WY, CO
Denver Basin, CO
Piceance Basin, CO
South Park Basin, CO
Uinta Basin, UT
San Juan Basin, NM
West Canada (Alberta) Basin, Canada
Other North American Basins
Western Anadarko Basin, OK
Sacramento Basin, CA

\section{INTERNATIONAL}

Mahakam Delta (East Kalimantan), Indonesia
Kiru Trough (Sumatra), Indonesia
Waropen Basin, Indonesia
Offshore Camaroons (West Africa), Cameroons
Bohai Bay, China
South China Sea, China
Yellow River Delta, East China
Cooper Basin, Australia
San Jorge Basin, Argentina
Neuquen Basin, Argentina
Maturin Basin, Venezuela
Cauca Valley, Colombia

Table 1. List of basins in which the IDT exploration strategy and associated technologies have been successfully applied. 


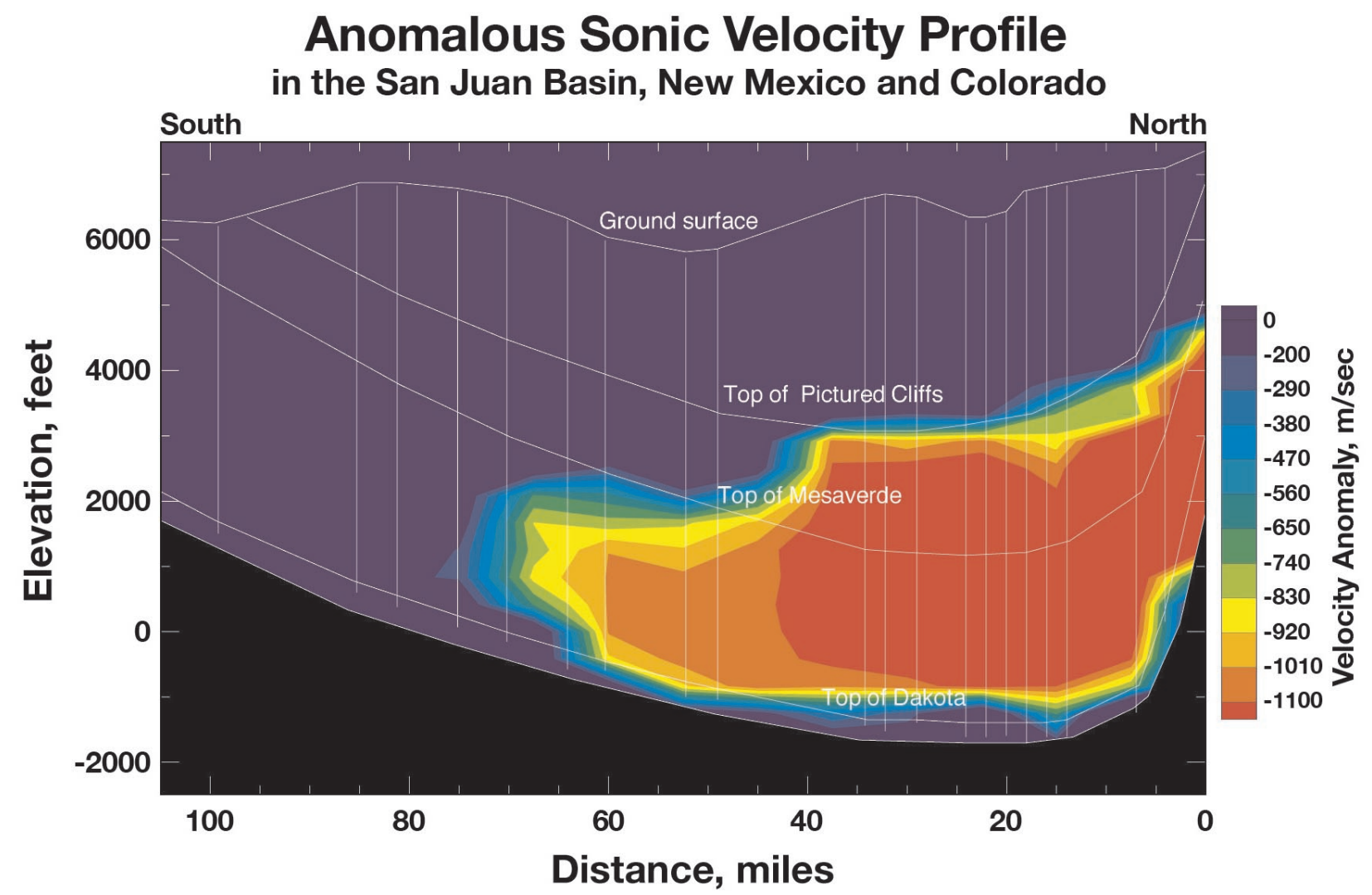

Figure 2. anomalous velocity profile for the San Juan Basin based on 20 sonic log profiles. Yellow to red areas represent rock/fluid systems characterized by significantly slower velocities than would be predicted at that depth by the ideal velocity/depth gradient. These rock/fluid systems typically contain a multiphase fluid-flow regime (water-gas-oil) and are anomalously pressured (in the San Juan Basin, the rock/fluid systems shown in yellow to red are underpressured). The top of the anomalously pressured rock/fluid systems in the San Juan Basin is at 3000 to $4000 \mathrm{ft}$ present-day depth.

this task can be accomplished, future discussions of BCGS can begin with a set of observations relative to rock/fluid characteristics in the RMLB, instead of a discussion of nomenclature.

\section{Foundation}

The relationship between gas saturation and velocity is the foundation for evaluating gas distribution in this report. This relationship is of interest because the presence of a significant gas component in the fluid phase can cause decreases in both sonic and seismic interval velocity. The correlation between fluid composition and sonic and seismic velocity is a well-established fact. Among others, Timur (1987) demonstrated that at 15 to $20 \%$ gas saturation, there is a notable decrease in velocity (Figure 4). Lazaratos and Marion (1997), in well-to-well seismic tomography experiments, demonstrated a 10 to $20 \%$ decrease in velocity resulted from the injection of a significant $\mathrm{CO}_{2}$ gas component into the fluid phase (Figure 4). Most importantly, Knight et al. (1998) established a relationship between saturation distribution and velocity.

In the rock/fluid systems described in Knight et al. (1998), the saturation distribution can be characterized as heterogeneous ("patchy"), which is similar to the lithologic heterogeneity inherent in many depositional/lithologic systems (e.g., fluvial/deltaic and marginal marine), such as those in the Fort Union, Lance, and Mesaverde stratigraphic units. Saturation heterogeneity occurs in these types of stratigraphic frameworks 
Anomalous Velocity Model, Wind River Basin

$\mathrm{AV}>1600 \mathrm{~m} / \mathrm{s}$, View to South

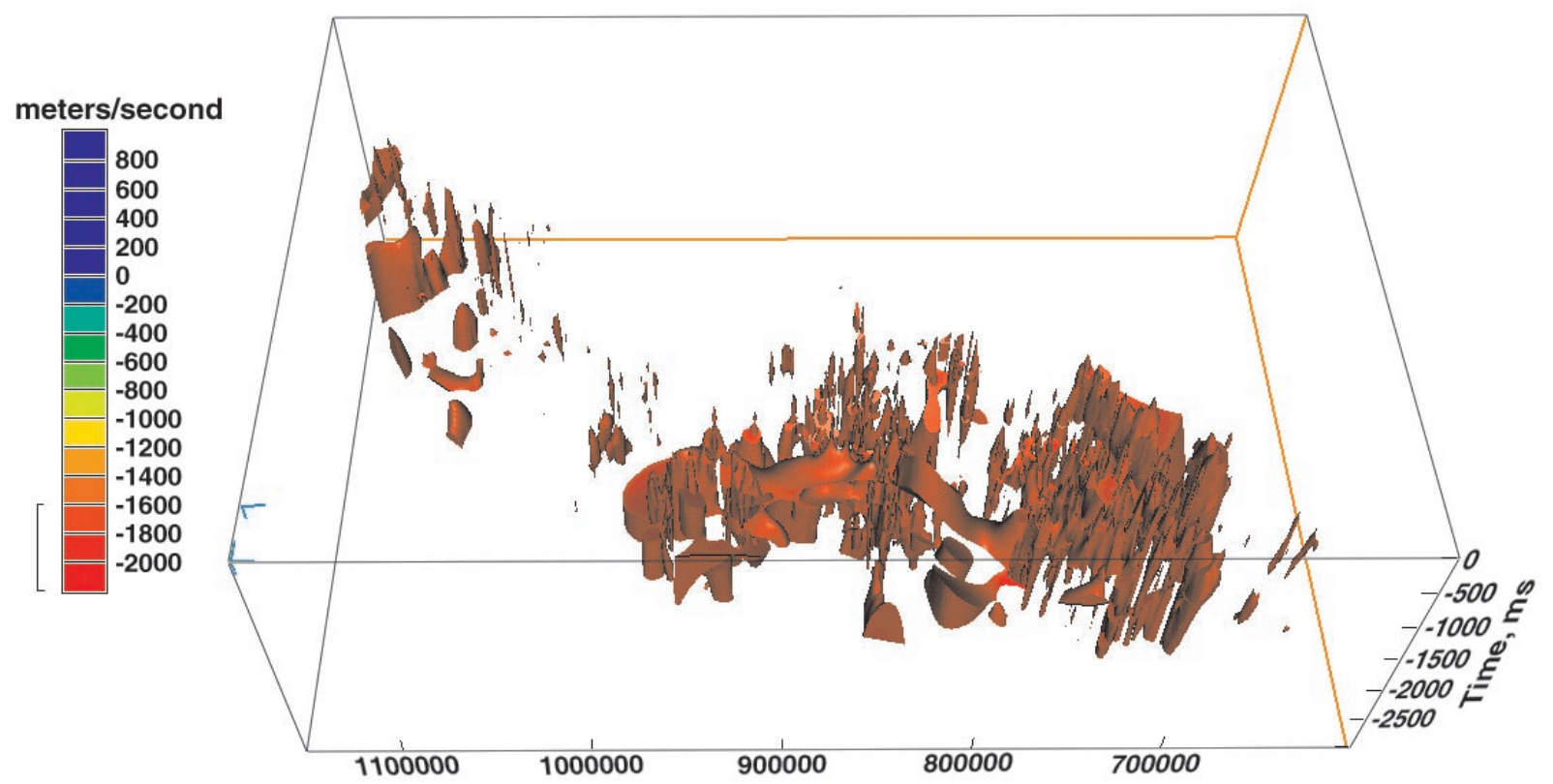

Figure 3. anomalous velocity volume for the Wind River Basin. An anomalous velocity value (AV) of -1600 $\mathrm{m} / \mathrm{sec}$ indicates that, at that point, the velocity is $1600 \mathrm{~m} / \mathrm{sec}$ slower than would be predicted by the ideal velocity/depth function. (Minus sign indicates that the anomalous velocity is slow). Any rock/fluid system characterized by significant anomalous velocity (i.e., >1400 m/sec) is typically gas-charged and anomalously pressured (an intensely gas-charged domain). Note that the intensely gas-charged domains in the Wind River Basin are not laterally continuous.

because, under conditions of capillary equilibrium, different lithologies within a stratigraphic interval can have different saturations depending on their porosities and permeabilities (Knight et al., 1998). Knight et al. (1998) conclude that "in a water-gas saturated reservoir, a patchy distribution of the different lithologic units is found to cause $\mathrm{P}$-wave velocity to exhibit a noticeable and almost continuous velocity variation across the entire saturation range" (p. 132).

These findings are important because they indicate that, in many of the reservoir intervals of interest in the RMLB where the distribution of lithologies is "patchy," a relationship between increasing gas saturation and decreasing velocity occurs across a wide range of gas saturations. This velocity response to gas saturation is different from the response of a homogeneous reservoir, where only a single large drop in velocity occurs in the 15 to $20 \%$ saturation range (Timur,
1987; Knight et al., 1998). The work of Knight et al. (1998) explains why in some relatively thick and heterogeneous reservoir intervals like the Lance Formation, there is a nearly continuous decrease in velocity as the gas-charge (as reflected by the estimated ultimate recovery, or EUR of wells) increases (Figure 5). Thus, the relationship between velocity and gas saturation is the main diagnostic tool used herein to evaluate the distribution of gas in the RMLB.

Although a variety of factors can cause decreases in velocity - including but not limited to decreased stress, variations in lithology, and increased temperature and pressure - none of these others factors compare in the magnitude of effect to the presence of gas in the fluid phase. Certainly, no other single factor can lower seismic velocities to the extent observed in the RMLB (i.e., $>1600 \mathrm{~m} / \mathrm{sec}$ ). Consequently, in the RMLB, the observed significant velocity slowdowns, both 

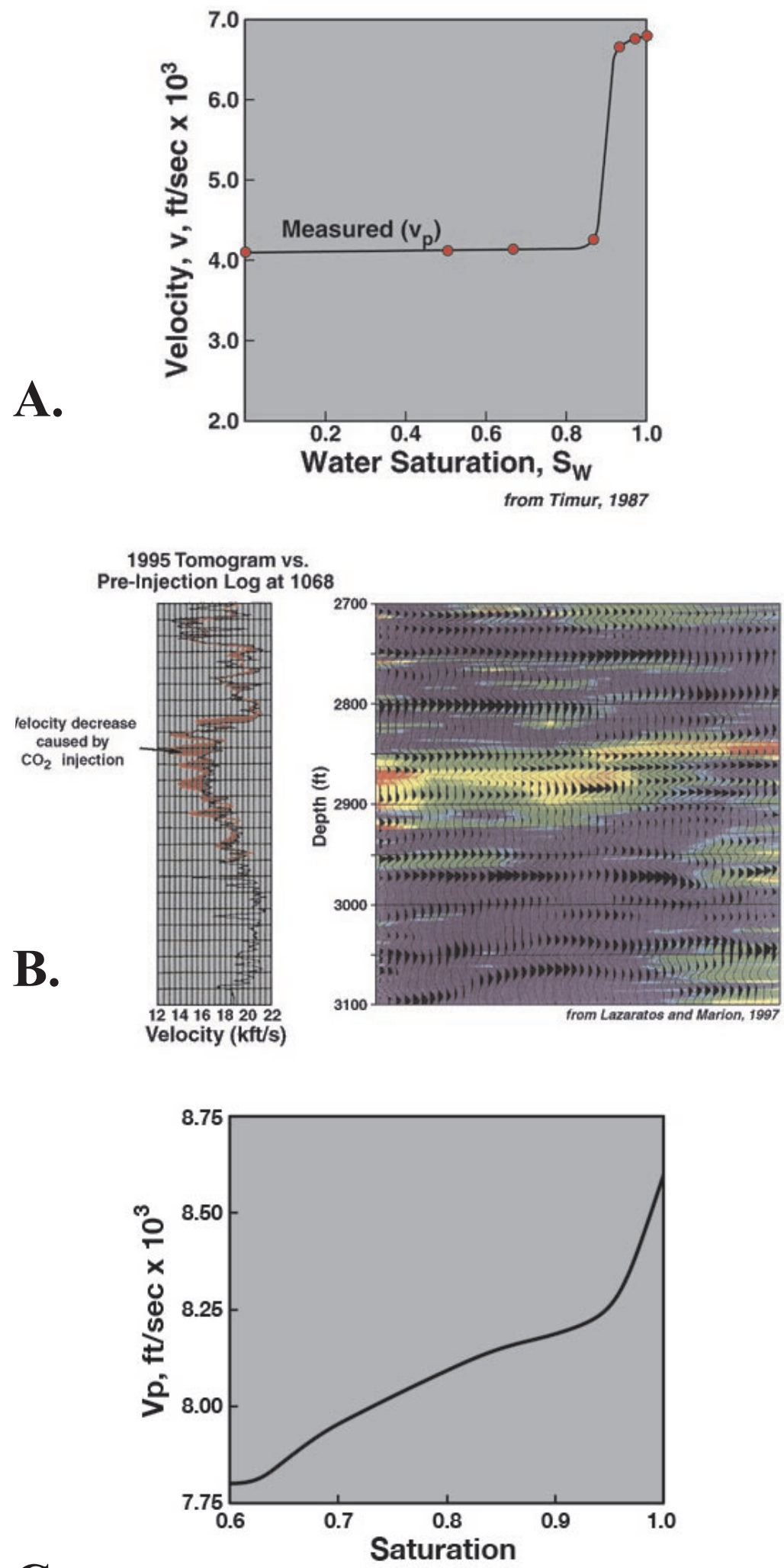

C.
Figure 4A-C. Summary of the velocity-composition relationships demonstrated by Timur (1987), Lazaratos and Marion (1997), and Knight et al. (1998). A. Timur (1987) used a homogeneous solid medium to evaluate the effect of fluid composition on compression velocity and demonstrated that a significant velocity drop (i.e., slowdown) occurs at a gas saturation of 15 to $20 \%$ (red dots). B. Lazaratos and Marion (1997) used cross well tomography to evaluate the velocity effect of a $\mathrm{CO}_{2}$ injection. Right side is a velocity difference profile with injection of a gas phase into the fluid system of a hydrocarbonproducing interval. Left side shows the measured velocity effect resulting from the addition of the $\mathrm{CO}_{2}$ gas phase into the fluid system. The effect of adding the gas phase into the fluid is a 10 to $20 \%$ drop in velocity (i.e., slowdown). C. Knight et al. (1998), using a patchy distribution of 10 lithologies, demonstrated that the P-wave velocity exhibits a continuous velocity variation across the entire saturation range. 
AV Area vs. EUR for Lance wells

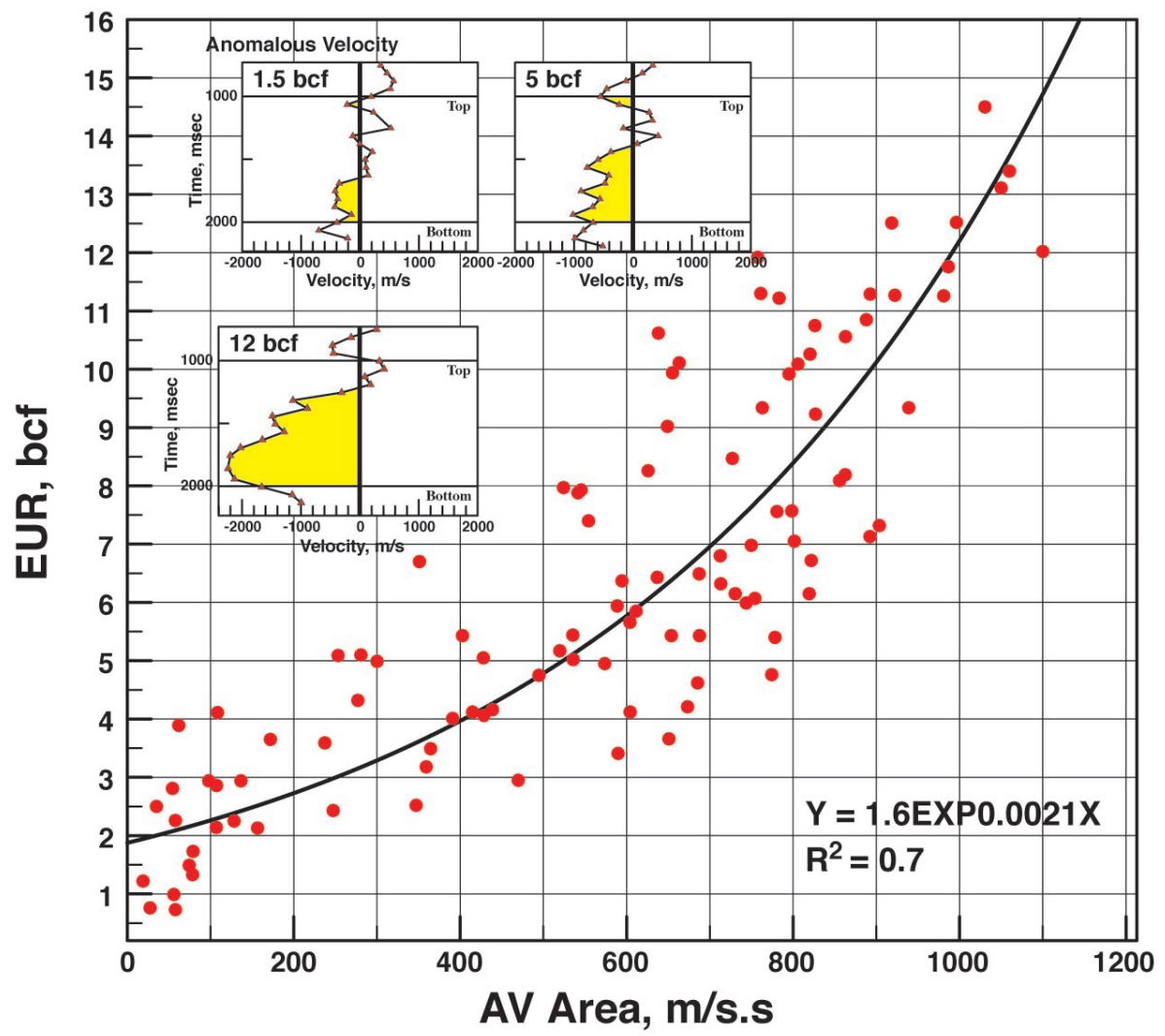

Figure 5. Diagram illustrating the correlation between anomalous velocity (a function of velocity) and estimated ultimate recovery (EUR; a function of gas saturation) for the Lance Formation. The anomalous velocity values (i.e., anomalous velocity area plotted in this figure) are a measure of the area under the AV/depth profile through the Lance Formation (see insert demonstrating the variations of anomalous velocity area, in yellow, for wells with EURS of $1.5,5$, and $12 \mathrm{Bcf}$, respectively). See text for details on how anomalous velocity values are derived. in terms of sonic and seismic interval velocity, are interpreted to result mainly from the presence of a significant gas component in the fluid phase of the rock/fluid system (Surdam, 1997).

The primary goal of the present work is to gain a better understanding of the rock/fluid characteristics of the Rocky Mountain Laramide Basins generally, and the Wind River Basin specifically. Detailed sonic and seismic velocity analyses are the main tools used to evaluate the spatial distribution of both water- and gas-rich fluid-flow domains.

\section{FLUID-FLOW REGIMES IN THE RMLB}

The basinwide fluid-flow regimes in the RMLB were evaluated using the following steps:

1. A detailed velocity model was established from sonic logs, 2-D seismic lines, and, where available, 3-D seismic data.
Automatic picking technology using continuous, statistically-derived interval velocity selection, as well as conventional graphical interactive methodologies were used to construct the seismic interval velocity field (Surdam, 2003a).

2. Next, velocities calculated from the ideal regional velocity/depth function were removed from the observed sonic or seismic velocity/depth profile. The constructed ideal regional velocity/depth function is the velocity/depth trend resulting from the progressive burial of a rock/ fluid system of constant rock/fluid composition, with all other factors remaining constant (Surdam, 2003b).

3. The removal of the ideal regional velocity/depth function isolated the anomalously slow velocities (Figure 6), which allowed evaluation of the following: 


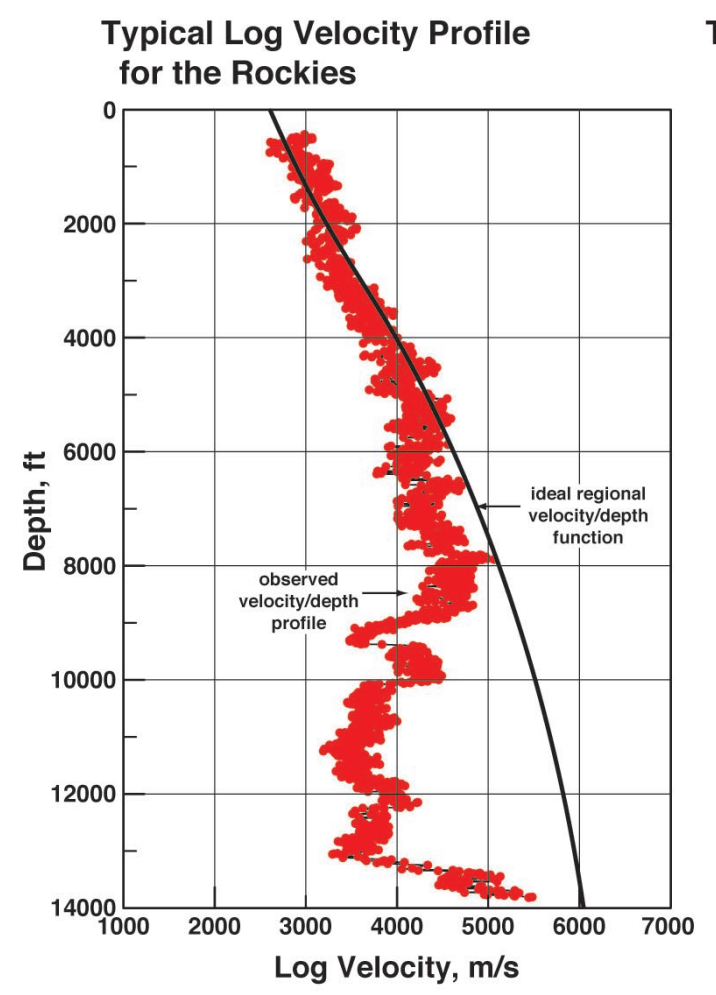

Typical Anomalous Velocity Profile
for the Rockies

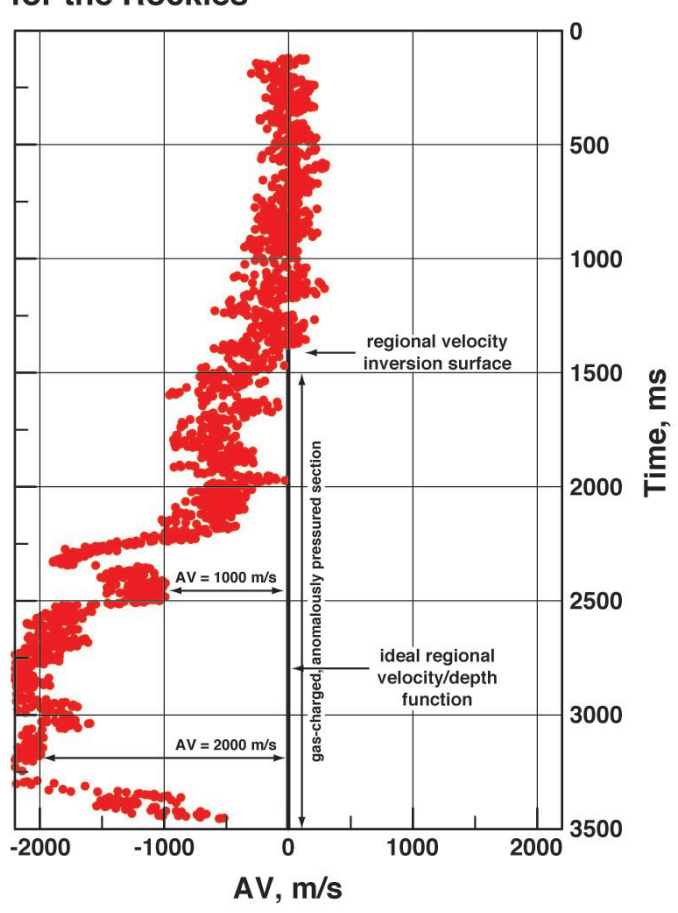

Figure 6. Left panel: observed sonic velocity profile (red) and the constructed ideal regional velocity/depth function (black line). Right panel: the ideal regional velocity/depth trend has been removed from the observed sonic velocity, isolating the domains characterized by anomalously slow velocity values and delineating the regional velocity inversion surface. Vertical solid black line is the ideal regional velocity/depth function.

a. The regional velocity inversion surface (or pressure surface boundary);

b. Detection/delineation of gas-charged domains beneath the velocity inversion surface (i.e., volumes characterized by anomalously slow velocities);

c. Variations within the internal fabric of the velocity anomaly; and

d. Determination of the distribution of single-phase, water-rich fluid-flow regimes under meteoric water drive.

Using this analytical approach facilitated the construction of anomalous velocity profiles. Construction of these profiles is important because it results in the isolation of anomalously slow velocity domains (i.e., gas-charged domains), and delineation of the spatial configuration of the regional velocity inversion surface.
The regional velocity inversion surface is the depth at which the observed velocity begins to become significantly slower than would be predicted at that depth by the ideal regional velocity/ depth function. The regional velocity inversion surface is equivalent to the regional pressure surface boundary, which separates normally pressured, water-dominated fluids above from anomalously pressured, either underpressured or overpressured, gas-charged fluids below.

Figures 7 through 12 are anomalous velocity profiles constructed from conventional 2-D seismic lines from the Green River, Powder River, Washakie, Hanna, Piceance, and Sand Wash basins. Although these anomalous velocity profiles are from six specific basins, they are typical of all the RMLB shown in Figure 13. In constructing these types of anomalous velocity profiles, it is important to obtain seismic data with sufficient offset and CMP (common midpoint) 

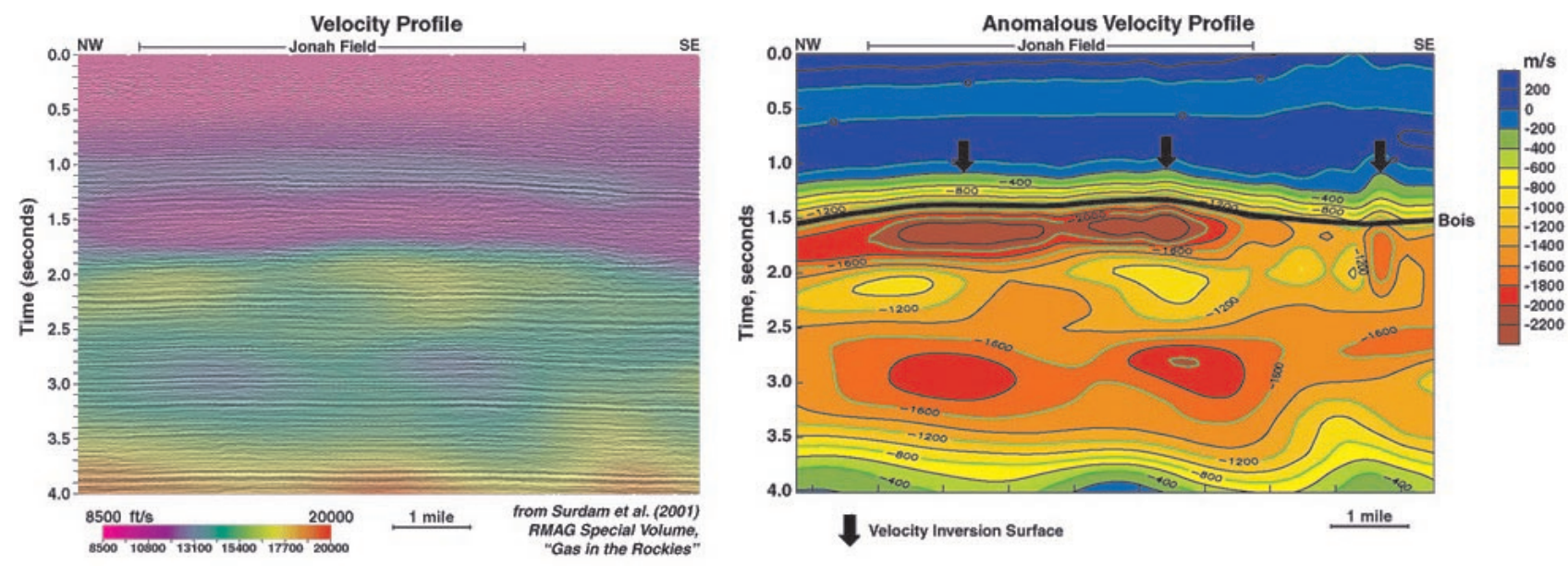

Figure 7. Left panel: a seismic interval velocity profile across Jonah field superimposed on the seismic stack for purposes of illustration. The Lance Fm. is at the time interval of $1.5 \mathrm{sec}$ to $2.0 \mathrm{sec}$ TWTT. Note that a subtle seismic interval velocity inversion occurs at approximately 1.3 to $1.4 \mathrm{sec}$ TWTT, and the anomalously slow velocity interval extends from 1.3-1.4 to 1.8-2.0 sec TWTT (at about the Lance Fm. interval). Right penal: the anomalous velocity profile (i.e., ideal velocity/depth function has been removed). Note the improved resolution with respect to the position of the velocity inversion surface (black arrows) and the isolation of anomalous velocity domains beneath the velocity inversion surface.

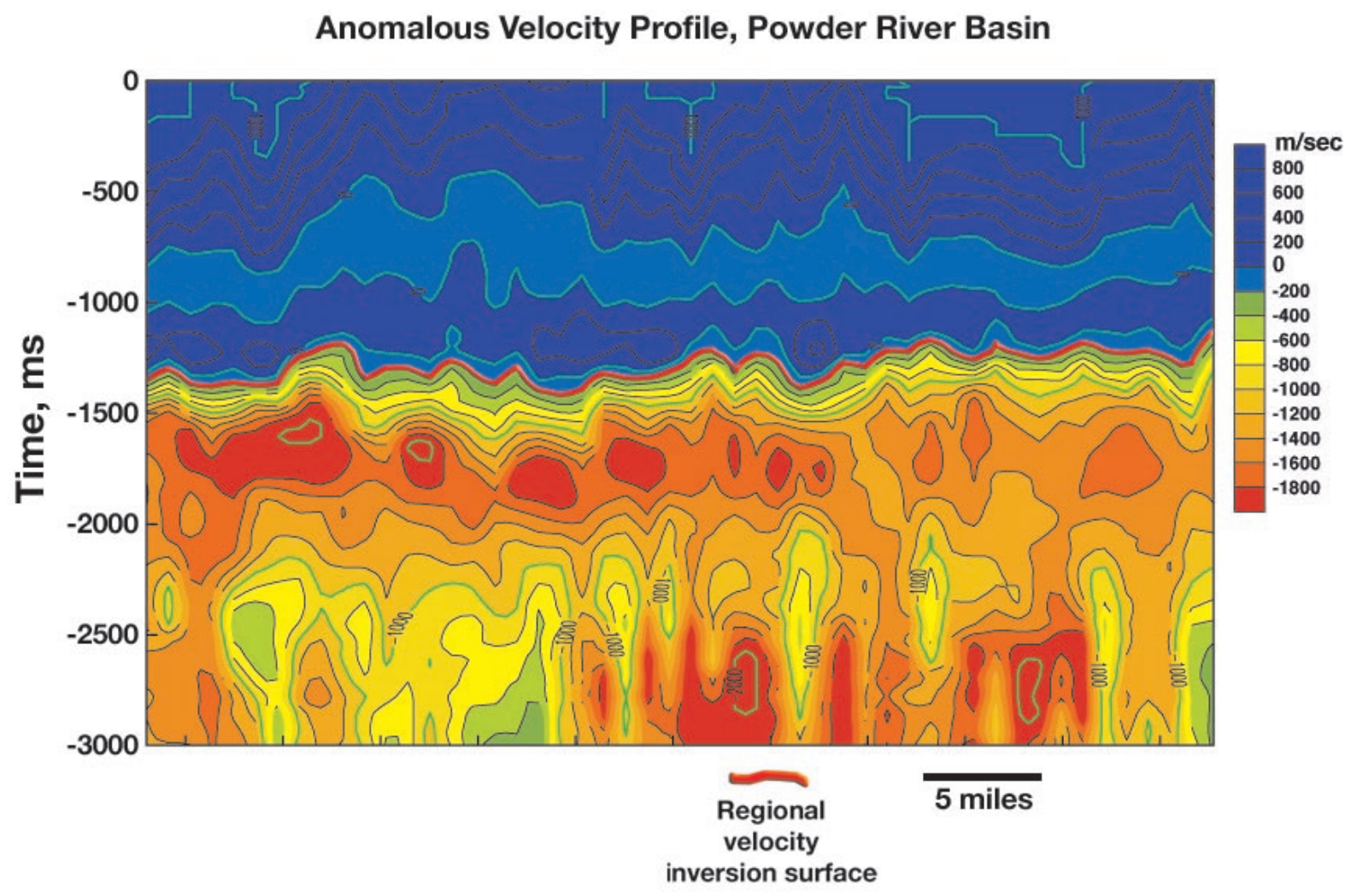

Figure 8. Typical anomalous seismic interval velocity (i.e., slow) panel for the Powder River Basin. Regional velocity inversion surface denoted by red line. The intense anomalous velocity domains (i.e., "highly" gascharged domains) are shown in orange and red. 


\section{Anomalous Velocity Profile, Washakie Basin}

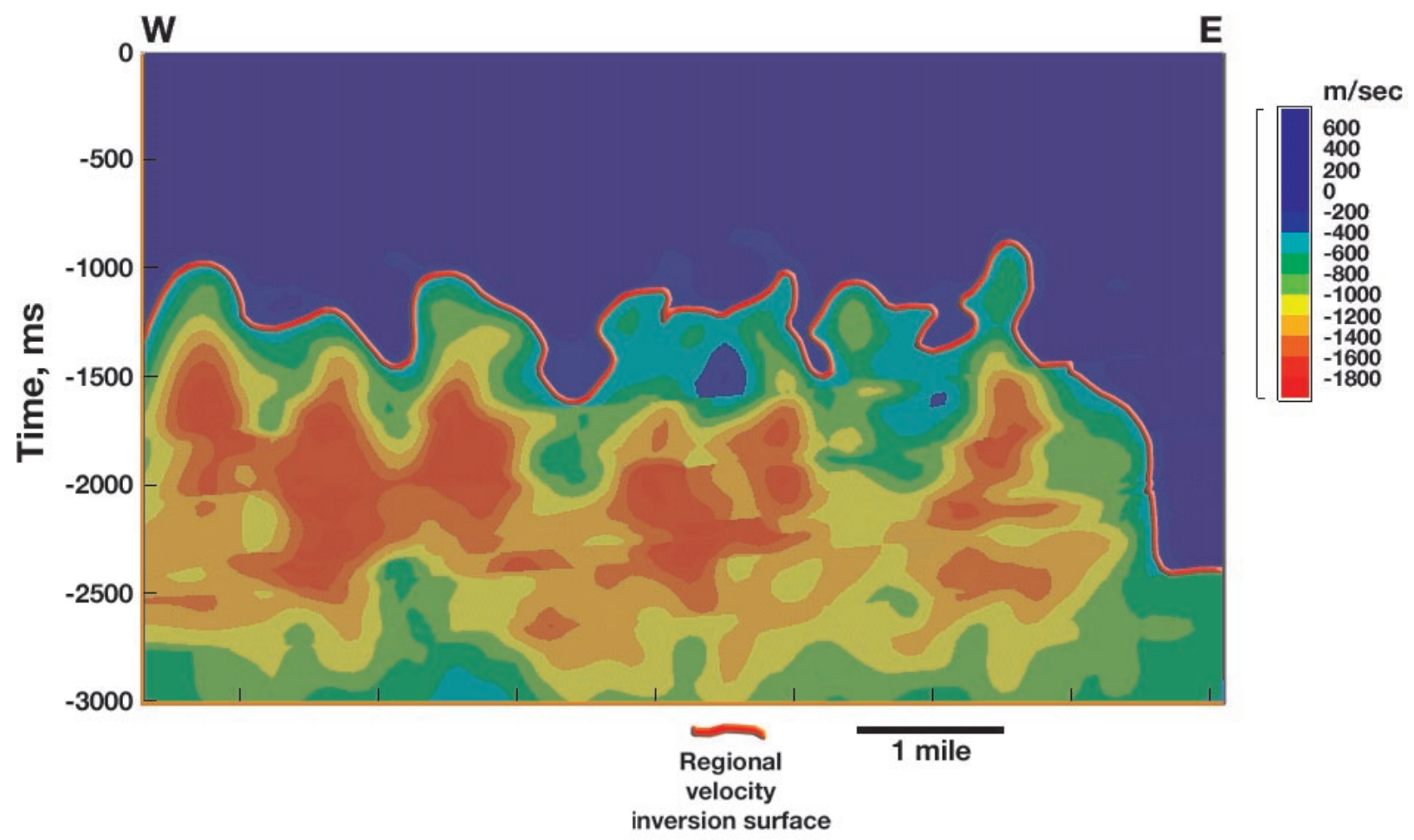

Figure 9. Typical anomalous seismic interval velocity (i.e., slow) panel for the Washakie Basin. Regional velocity inversion surface denoted by red line. The intense anomalous velocity domains (i.e., "highly" gascharged domains) are shown in orange and red.

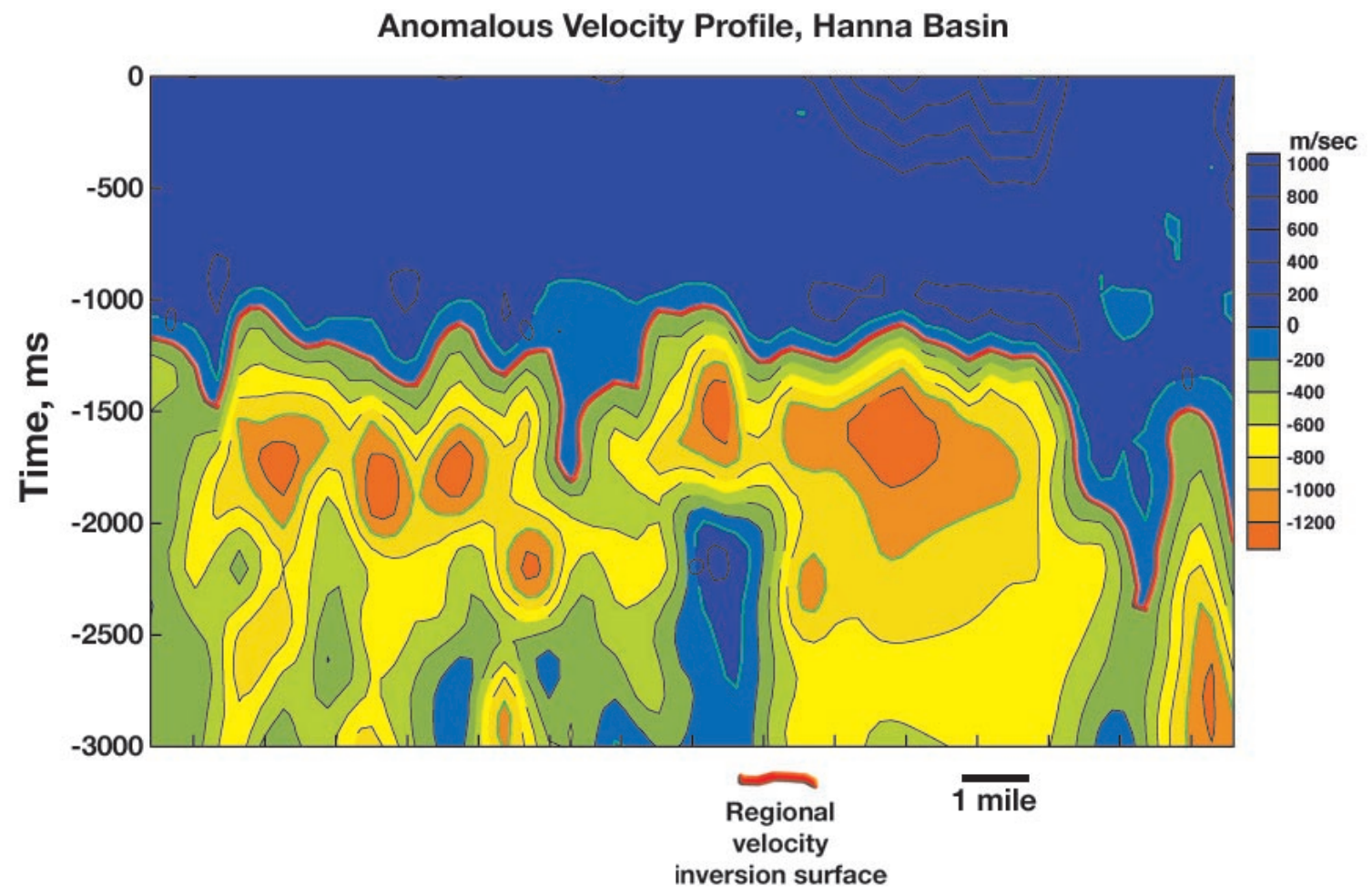

Figure 10. Typical anomalous seismic interval velocity (i.e., slow) panel for the Hanna Basin. Regional velocity inversion surface denoted by red line. The intense anomalous velocity domains (i.e., "highly" gas-charged domains) are shown in orange. 


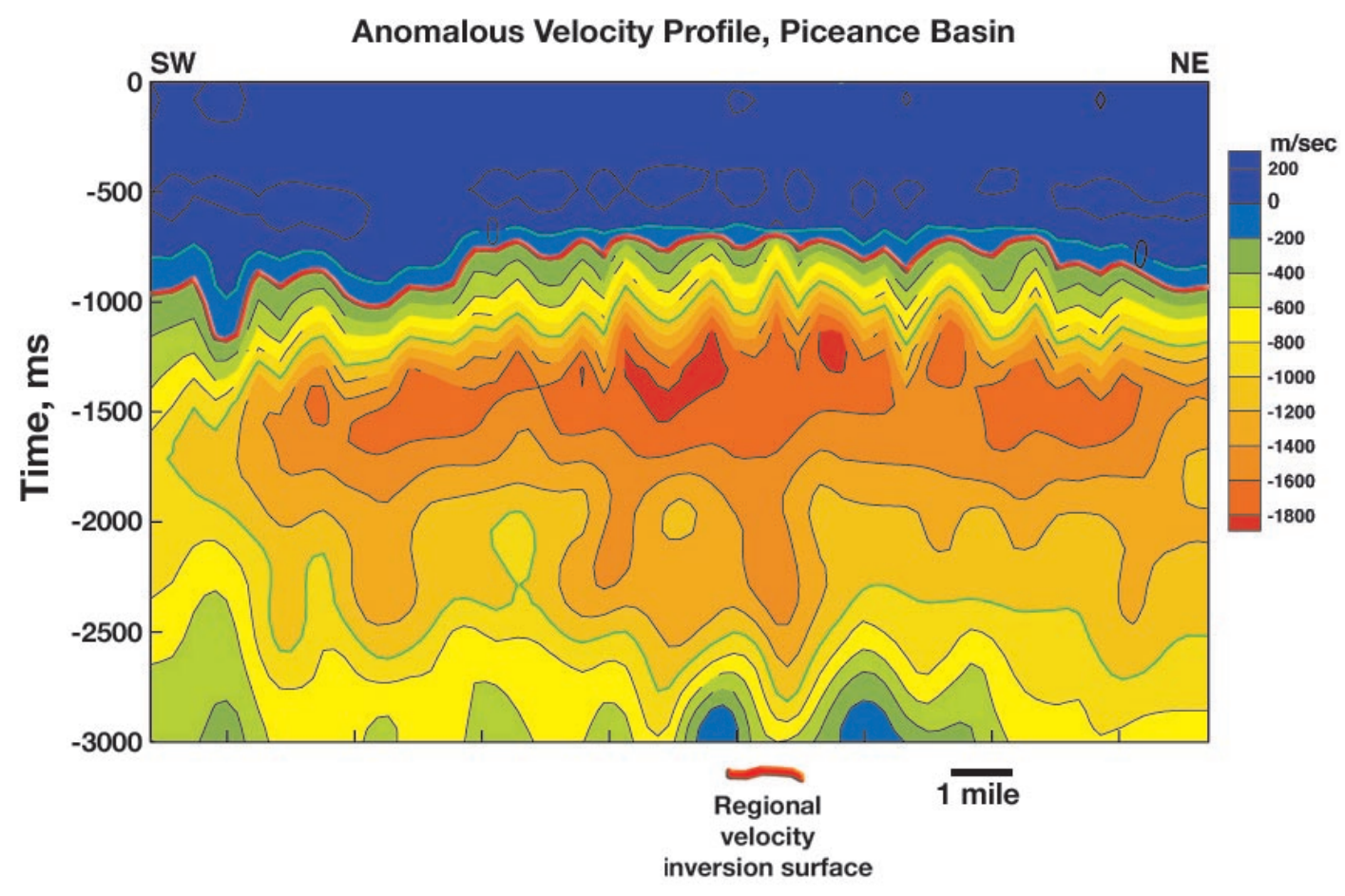

Figure 11. Typical anomalous seismic interval velocity (i.e., slow) panel for the Piceance Basin. Regional velocity inversion surface denoted by red line. The intense anomalous velocity domains (i.e., "highly" gascharged domains) are shown in orange and red.

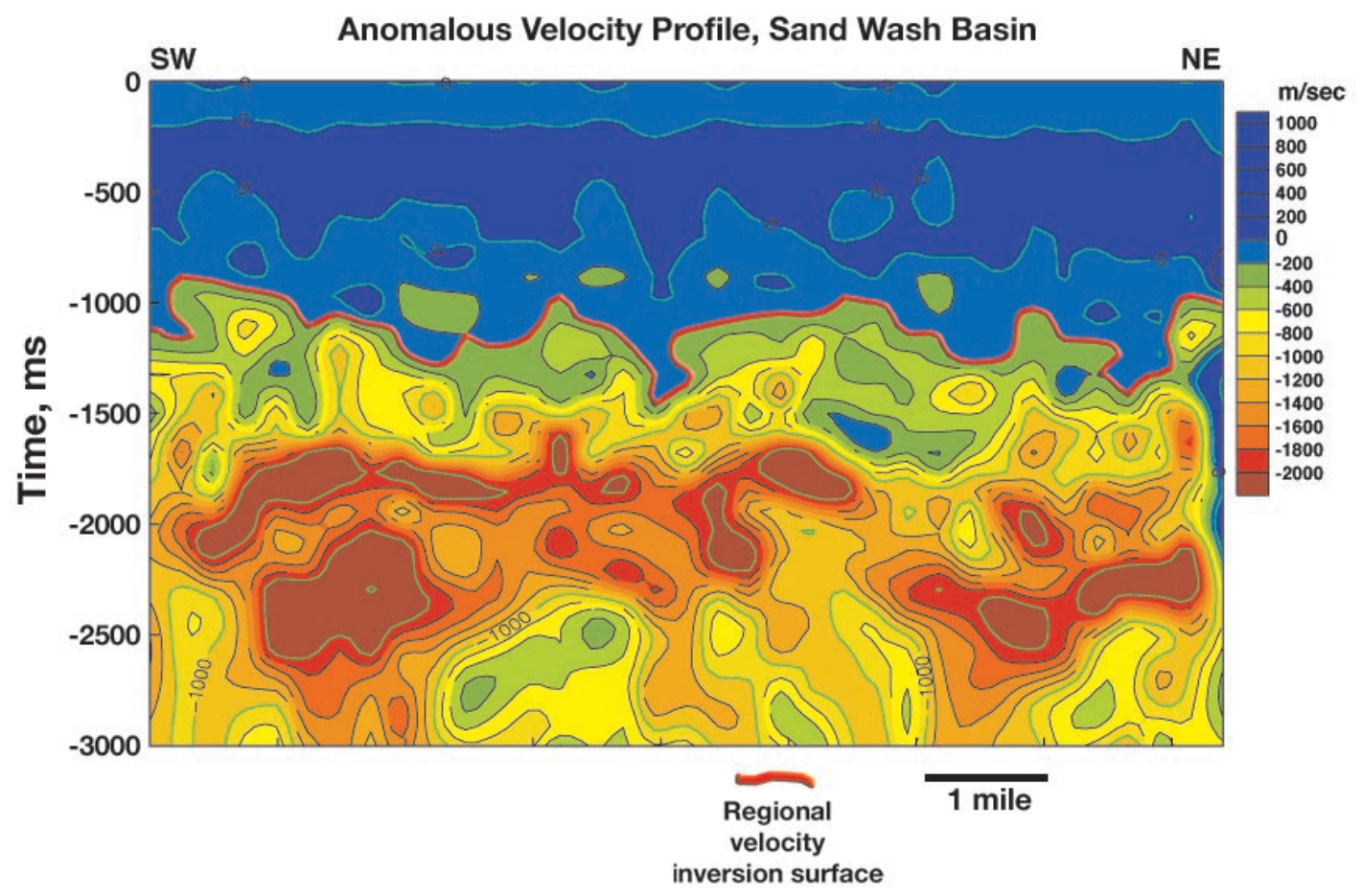

Figure 12. Typical anomalous seismic interval velocity (i.e., slow) panel for the Sand Wash Basin. Regional velocity inversion surface denoted by red line. The intense anomalous velocity domains (i.e., "highly" gascharged domains) are shown in red. 


\section{Anomalously Pressured "Basin-Center" Gas Accumulations Rocky Mountain Laramide Basins}

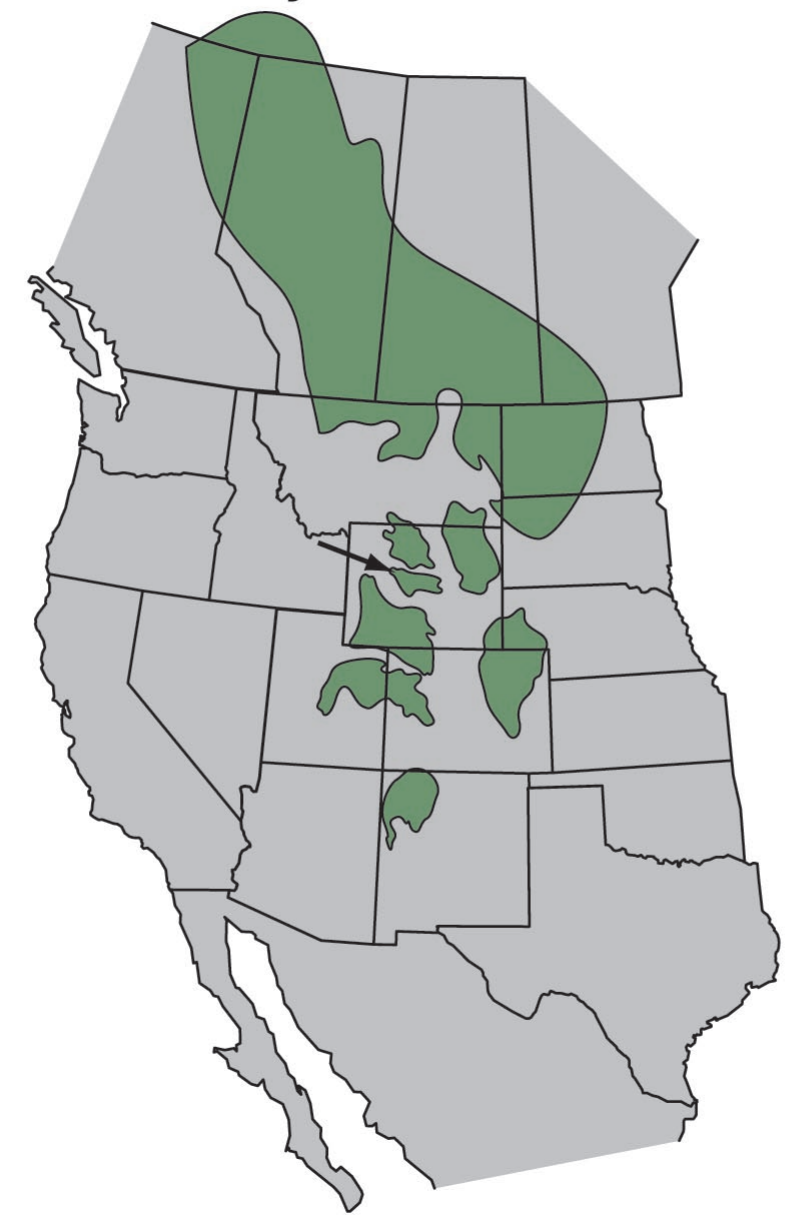

Figure 13. Index map of the Rocky Mountain Laramide Basins (RMLB). Arrow denotes the Wind River Basin. Shown are the Western Canada (Alberta), Powder River (NE Wyoming), Bighorn (N Central Wyoming), Greater Green River (SW Wyoming), Denver-Julesberg (E. Colorado), Piceance (NW Colorado), Uinta (NE Utah), and the San Juan (NW New Mexico) basins.

fold coverage. Generally, the far offset should be close to the depth of interest and the CMP fold coverage should be greater than six.

Using the three-step technique outlined above, the regional velocity inversion surface, regional anomalously slow velocity rock/fluid column, and the intensely slow velocity domains beneath the regional velocity inversion surface have been neatly delineated in Figures 7 through 12 . With regard to the velocity distribution patterns observed in the RMLB, note that if the evaluation is extended deeper into the basin, the observed velocity/depth gradient can return to the ideal velocity/depth gradient (Figure 14). In the Powder River Basin, the return to the ideal velocity/depth gradient occurs at the deepest shales in the Mesozoic; below this stratigraphic level, the fluid-flow regime is characterized by a return of "normal" pressures.

\section{Regional Velocity Inversion Surface}

The regional velocity inversion surface shown in each of the anomalous velocity profiles (Figures 7 through 12) is an extremely important boundary with respect to the fluid-flow and 

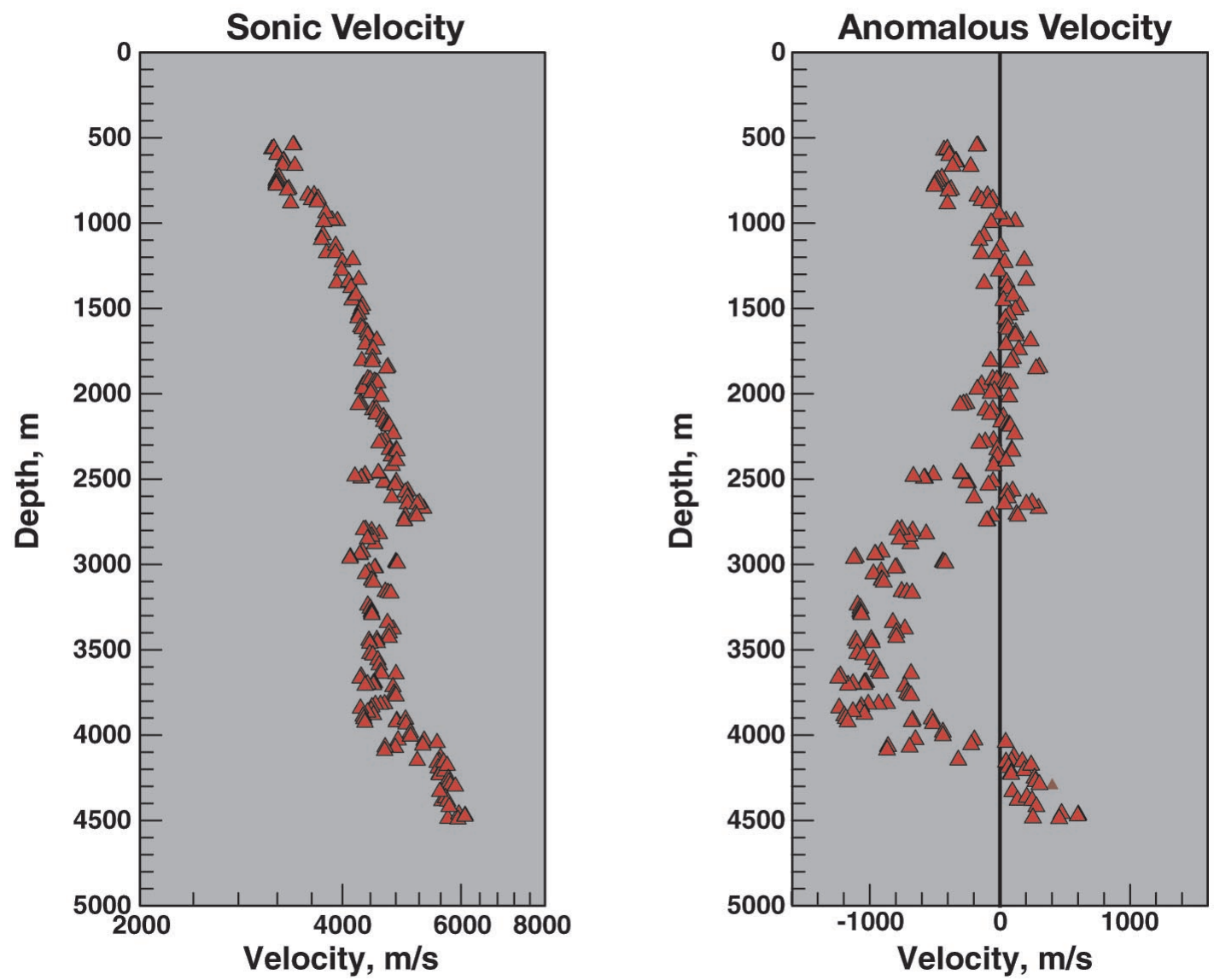

Figure 14. Left panel: typical observed sonic velocity/depth profile in the Powder River Basin. Right panel: anomalous sonic velocity profile. Black vertical line is the ideal regional velocity/depth function. Note that at $4000+m$ depth, the velocity values approach the ideal velocity/depth gradient, suggesting that at this depth, the fluid system is again normally pressured. From 2500 to $4000 \mathrm{~m}$ depth, the velocities are anomalously slow and anomalously pressured (either under- or overpressured or both, but not the same at any depth interval).

rock/fluid regimes. As previously noted, this boundary separates the normally pressured, water-rich (i.e., typically single-phase fluid) fluidflow system above from the anomalously pressured (either under- or overpressured), multiphase, gas-charged fluid-flow system below. This surface also is characterized by a steepening of the $\mathrm{R}_{\mathrm{o}}$ /depth gradient at the boundary (Figure 15), which suggests that there is a significant difference in the thermal regime above and below the regional velocity inversion surface. The surface also is characterized by a significant change in formation water chemistry within individual stratigraphic units (Figure 16), which suggests that an individual marine unit above the boundary is more likely to be flushed with meteoric water than the same unit occurring below the boundary. Other important phenomena occurring beneath the regional velocity inversion surface or boundary include an acceleration of the reaction rate of the smectite-to-illite diagenesis in mixed-layer clays and an increase in bitumen and remnant liquid hydrocarbons (Figure 15).

One of the most important rock/fluid attributes that changes in relation to the regional velocity inversion surface is capillary properties. There is a remarkable increase in capillary displacement pressures across the regional velocity inversion surface (Figure 17). In fine-grained lithologies from individual stratigraphic units, the displacement pressures above this boundary are a few hundred psi, whereas below the boundary they are a few thousand psi (Figure 17). The 

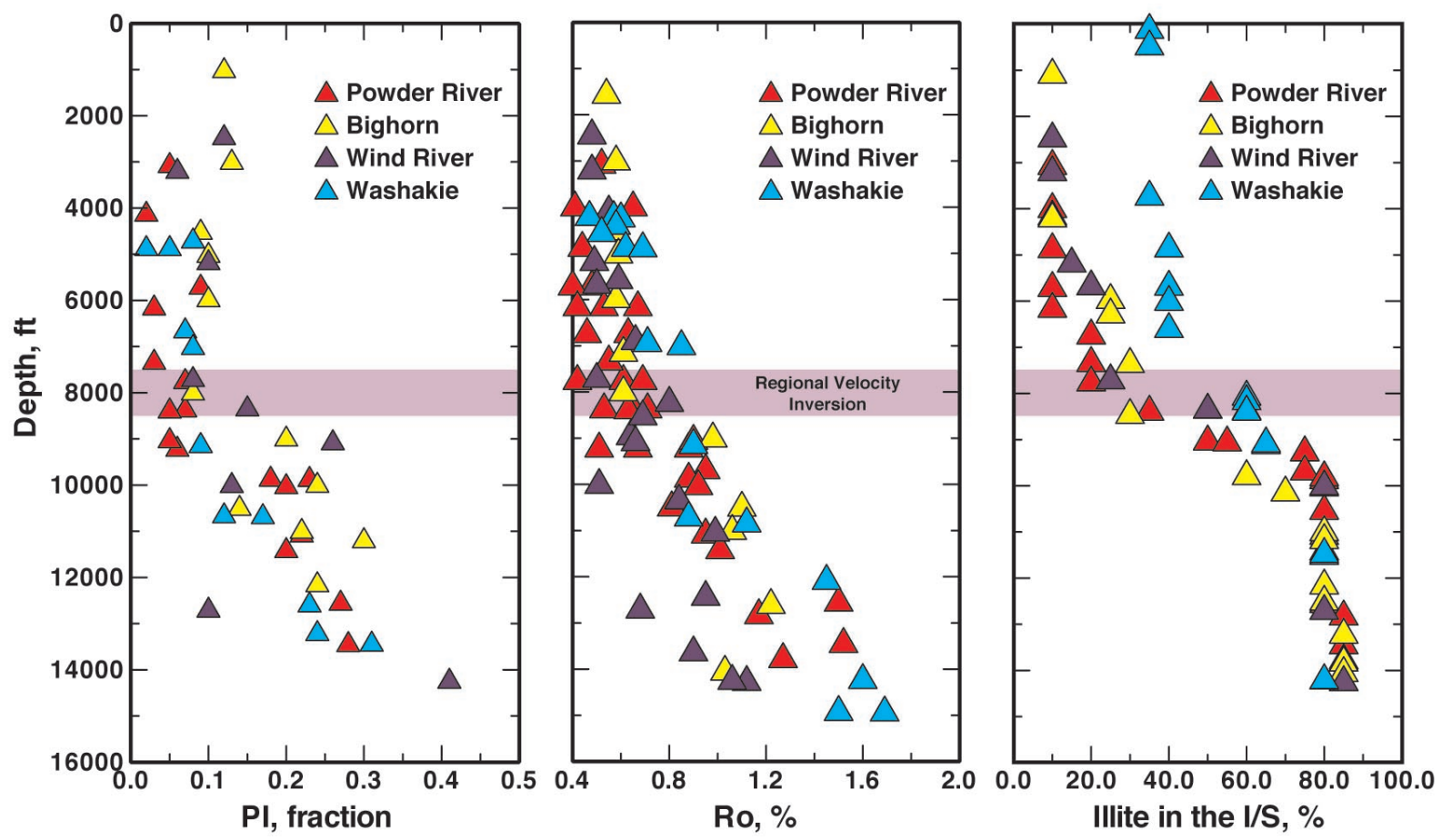

Figure 15. Left panel: Production index (PI) vs. depth for organic-rich rocks from the Powder River, Bighorn, Wind River, and Washakie basins. Middle panel: $\mathrm{R}_{\mathrm{o}}$ vs. depth for the same four basins. Right panel: illite in the mixed-layer clays (illite/smectite) vs. depth for clay-rich lithologies from four RMLB basins. In all panels, the approximate position of the regional velocity inversion surface is noted.

importance of this observation relates to sealing capacity as defined by Sneider et al. (1991). Above the regional velocity inversion surface, certain fine-grained lithologies are capable of supporting gas columns a few hundred feet high, whereas beneath this surface, the same lithologies are capable of supporting gas columns several thousand feet in height (Figure 17). Clearly, the rock/fluid systems below the regional velocity inversion surface are dominated by capillarity, making it more difficult to move fluid across low-permeability boundaries, which increases the potential for compartmentalization of fluid-flow systems. In summary, all of the changes in the rock/fluid characteristics associated with the regional velocity inversion surface are compatible with a very significant reduction in the convection of fluids across this surface or boundary.

Regional velocity inversion surfaces have been detected in 30+ basins (Table 1) around the world using the technique outlined previously in this paper. The most detailed evaluations of lithol- ogies associated with the regional velocity inversion surface have occurred in the RMLB. In each of the RMLB, the regional velocity inversion surface (or "pressure surface boundary") is associated with a low-permeability lithology. Commonly, the lithology associated with the inversion surface is a low-permeability lithology, and commonly with one that has been modified to even lower permeability values through diagenesis (Jiao and Surdam, 1994). In some cases, the inversion surface cuts across stratigraphic boundaries, typically along a near-vertical fault. Where this occurs, the inversion follows the low-permeability stratigraphic unit laterally until it intersects a fault and jumps up or down to another lowpermeability stratigraphic/lithologic unit and once again continues laterally. It is emphasized that the distribution of regional velocity inversion surfaces in the RMLB typically is associated with low-permeability lithologic units such as shales, paleosols, and diagenetically and pedogenetically modified siltstones and sandstones, among others. Topographic relief on the regional velocity inver- 


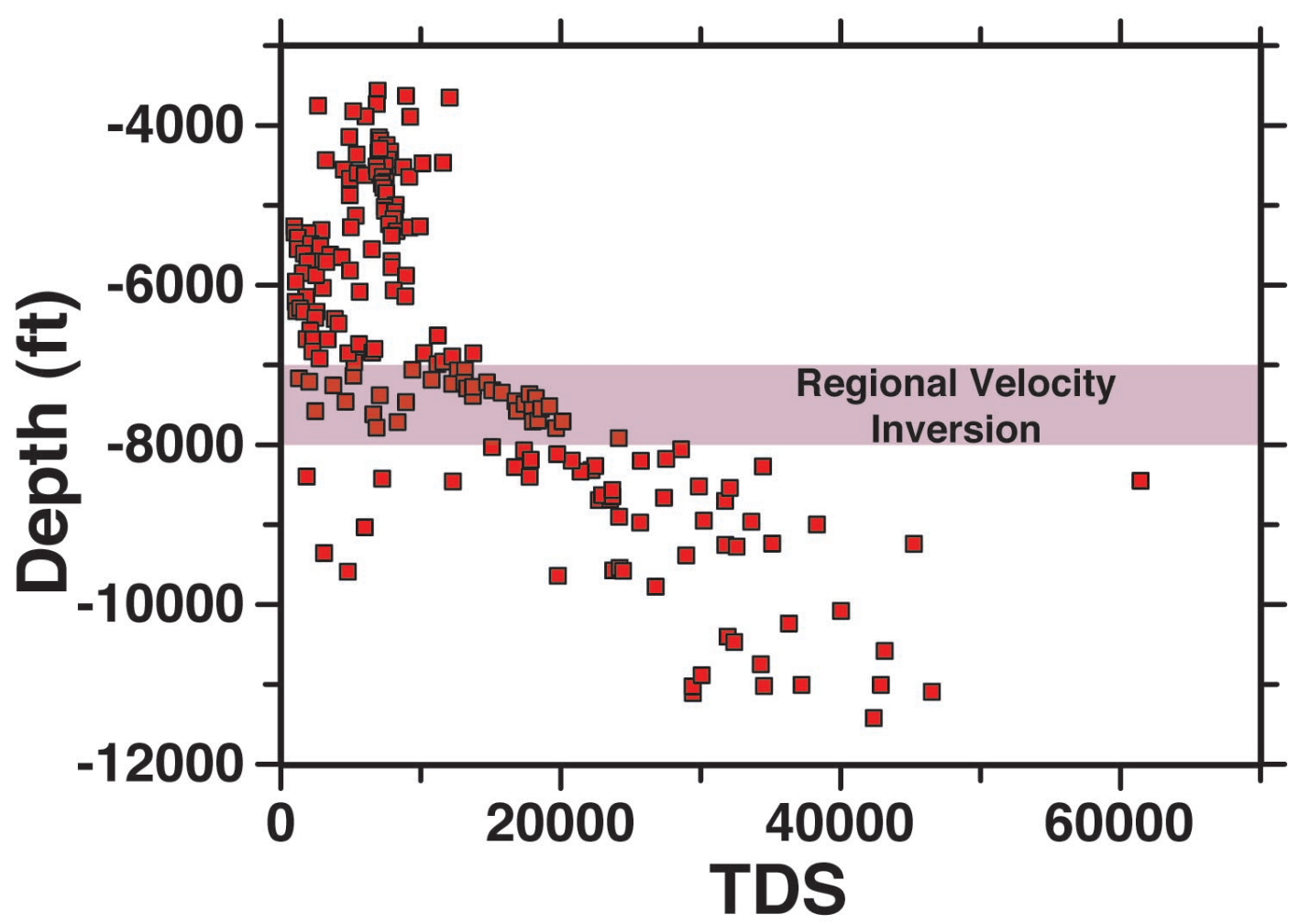

Figure 16. Total dissolved solids (TDS) in formation water from the Muddy Sandstone vs. depth in the Powder River Basin, Wyoming. The approximate position of the regional velocity inversion surface is shown. Above this surface, the marine connate waters in the Muddy Sandstone have been diluted; below the surface, there is significantly less, and in most samples, no dilution of the original formation water.
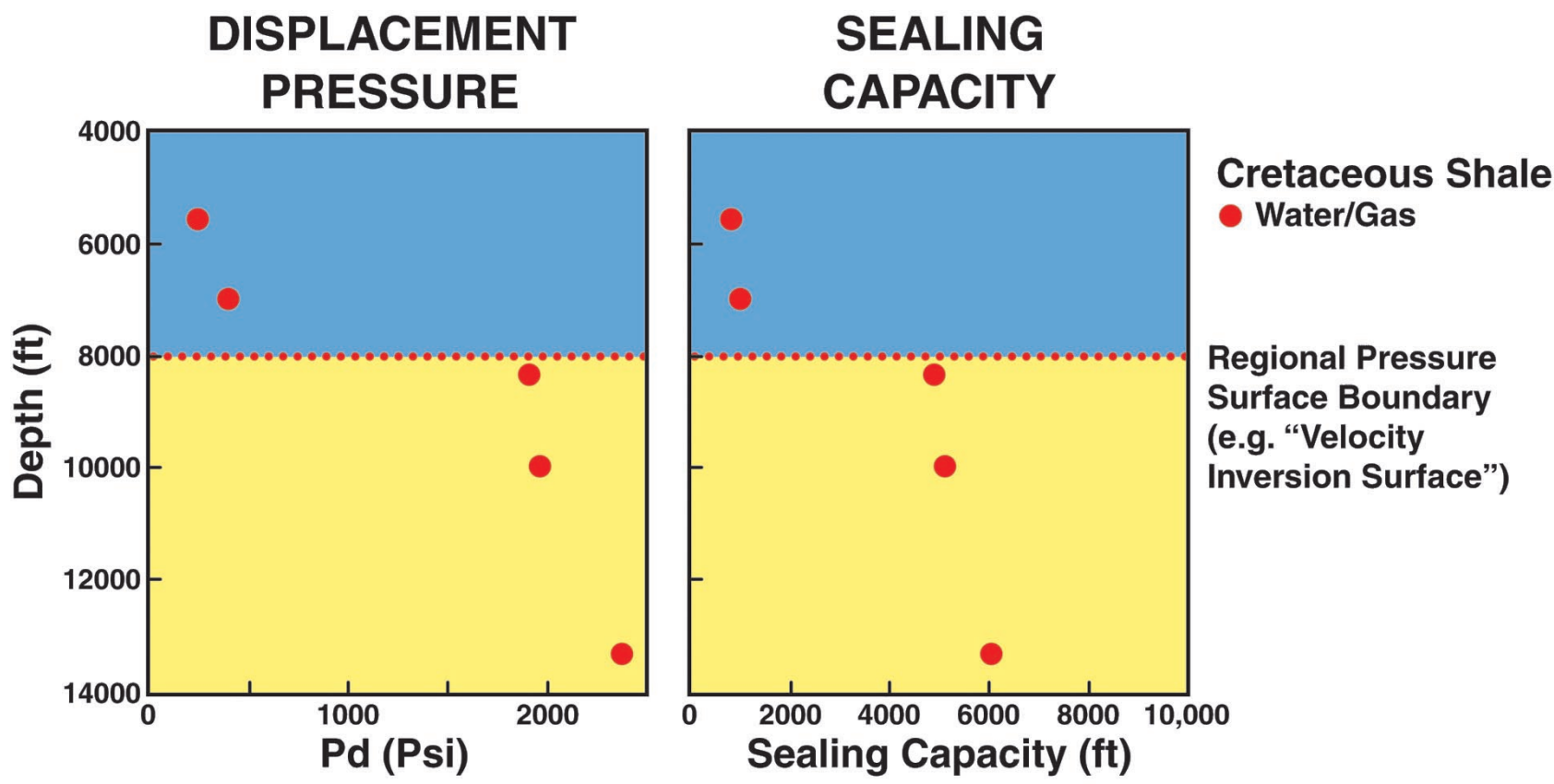

Figure 17. Left panel: displacement pressure vs. present-day depth for samples from the Cretaceous Mowry Shale from the Powder River Basin. Right panel: sealing capacity (as defined by Sneider et al., 1991) vs. present-day depth. The position of the regional velocity inversion surface is shown. 
sion surface can occur along faults, fracture swarms, stacked sandstones, or other stratigraphic/structural elements that result in permeability chimneys.

\section{Gas-Charged Domains}

Another feature of the fluid-flow system that can be detected and its distribution delineated includes those domains beneath the regional velocity inversion surface that are intensely gascharged (Figures 7 through 12). These domains are characterized by anomalous velocity values greater than $1000 \mathrm{~m} / \mathrm{sec}$. An anomalous velocity value of $-1000 \mathrm{~m} / \mathrm{sec}$ indicates that, at that point, the velocity falls $1000 \mathrm{~m} / \mathrm{sec}$ below or slower than the velocity predicted for that depth by the ideal regional velocity/depth function (minus sign on the anomalous velocity value simply indicates that the velocity is anomalously slow). Variations in anomalous velocity values can exist in comparisons between regions due to variations in seismic acquisition parameters and overall seismic data quality.

The intensely slow velocity domains are interpreted to be those domains where the probability of high gas saturations is the highest. In the RMLB, these intensely slow velocity (gascharged) domains tend to be highly compartmentalized (Figures 7 through 12). While in some cases, these intense, anomalously slow velocity domains occur in particular stratigraphic intervals (e.g., the Lance Formation in Figure 7), typically they are laterally discontinuous. The variations in distribution patterns of the intense, anomalously slow velocity domains in the RMLB is nicely

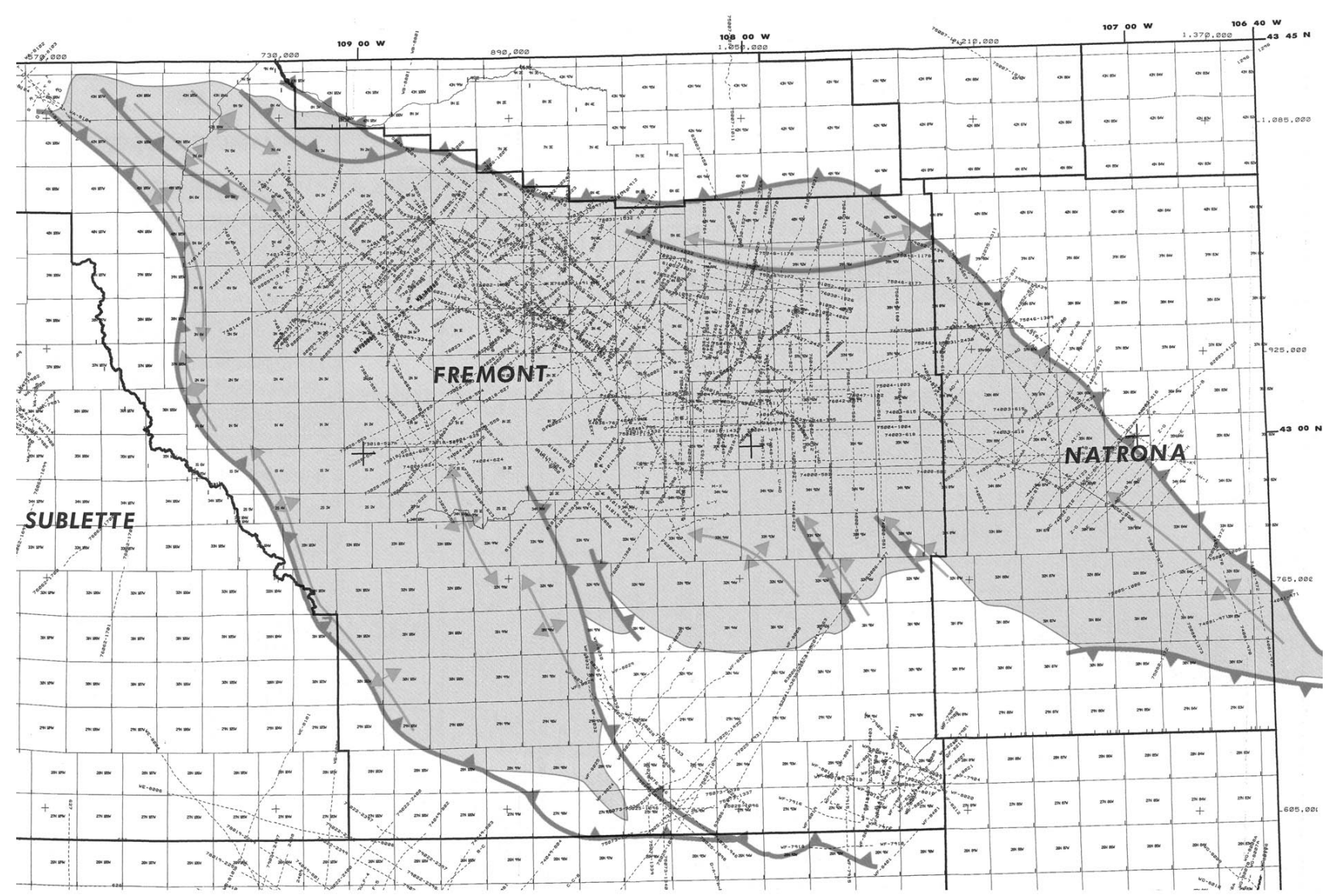

Echo 2-D seismic database for Wind River Basin.

Figure 18. Index map from the distribution of the Echo Geophysical Co. Wind River seismic data set. The total area of the Wind River Basin is $\sim 8500 \mathrm{mi}^{2}$. 


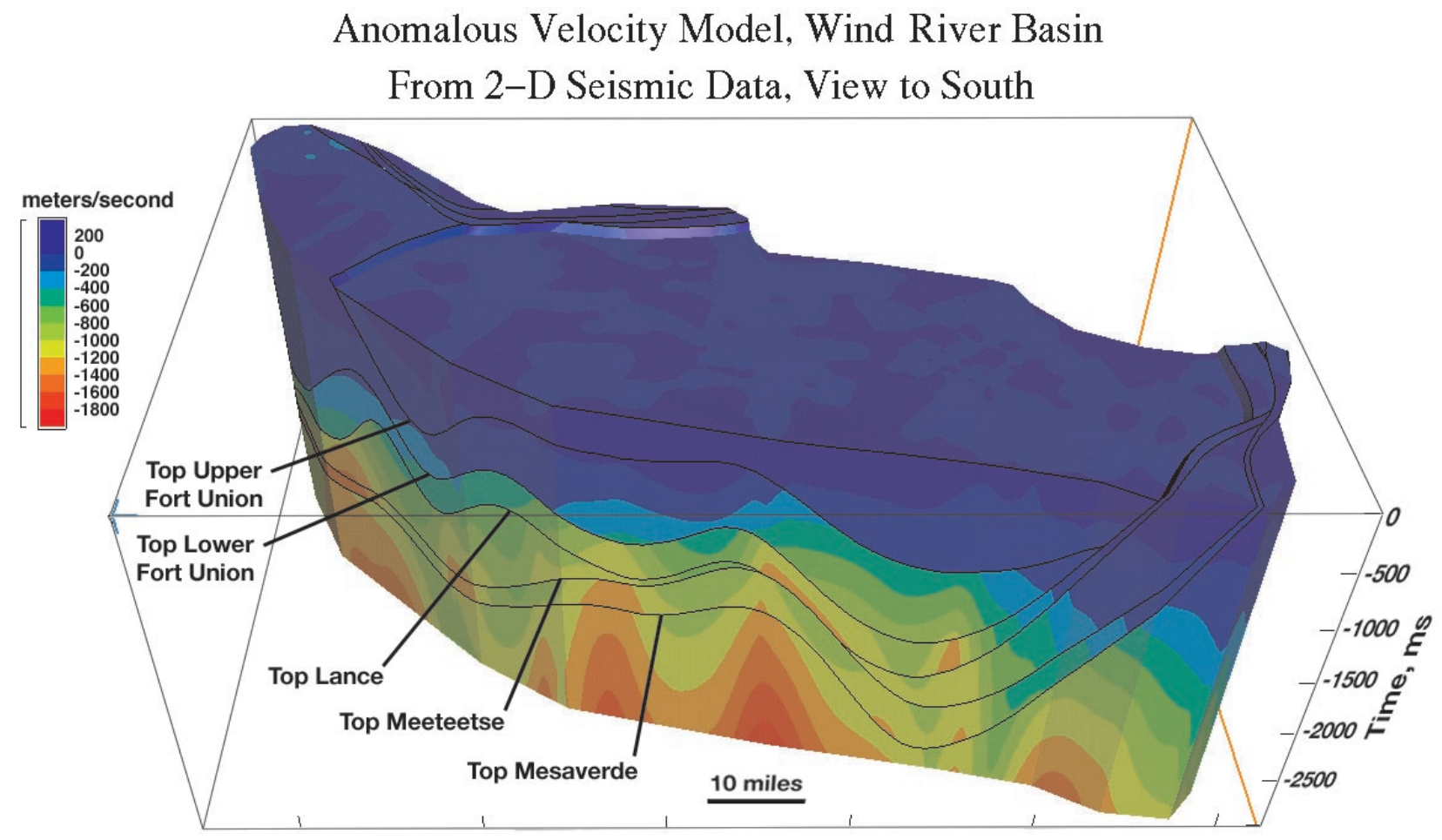

Figure 19. anomalous velocity model constructed for the Wind River Basin from 2000+ mi of 2-D seismic data and 175 sonic logs. View of the model is to the south. The stratigraphic tops for the Upper and Lower Fort Union and Lance, Meeteetse, and Mesaverde units are noted.

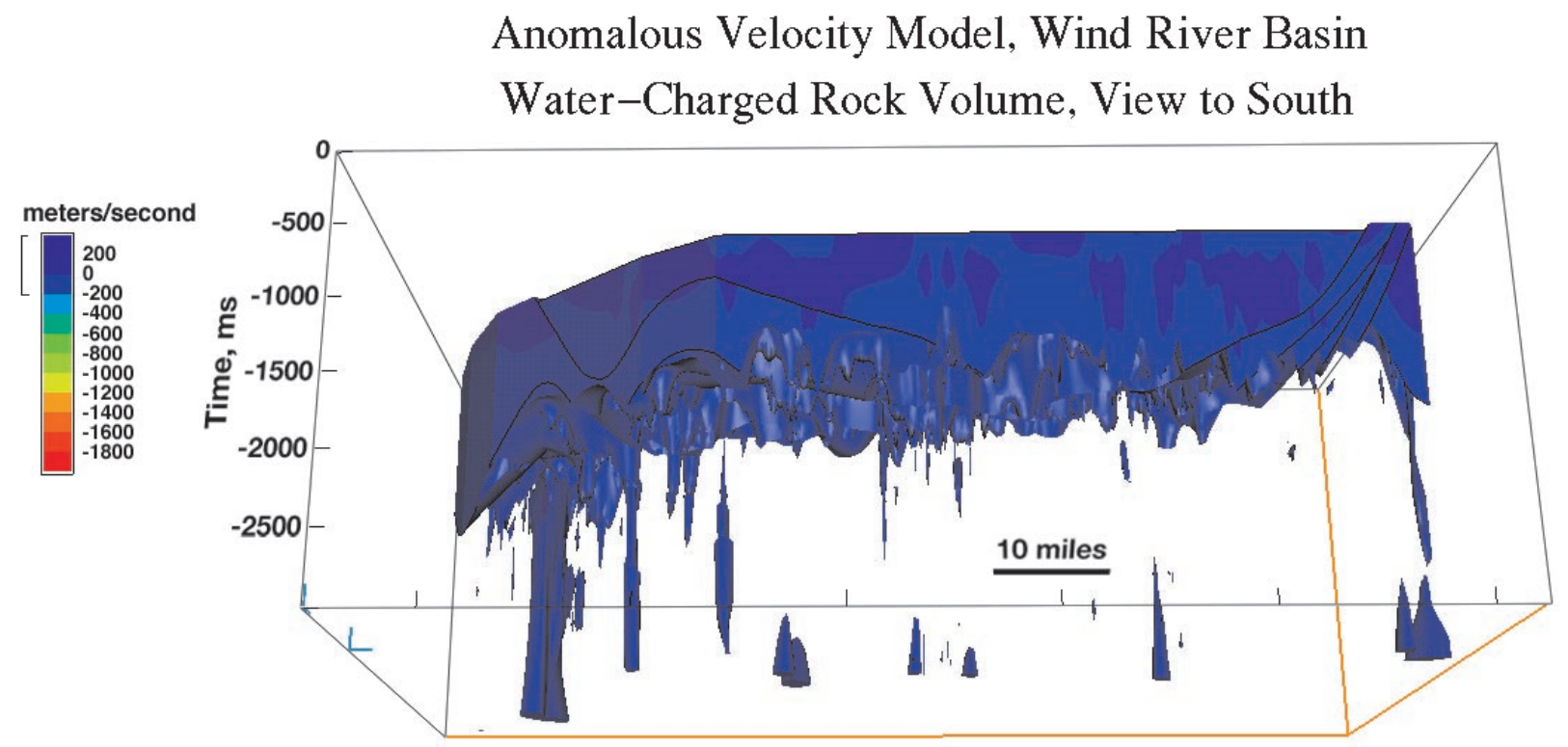

Figure 20. The portion of the velocity model for the Wind River Basin that falls on the ideal regional velocity/depth trend. In this volume (blue), the rock/fluid systems are characterized by normal pressure (i.e., fall on the hydrostatic gradient) and a dominantly single-phase, water-rich fluid. View is to the south. 


\section{Anomalous Velocity Model, Wind River Basin \\ Top of Anomaly, View to South}

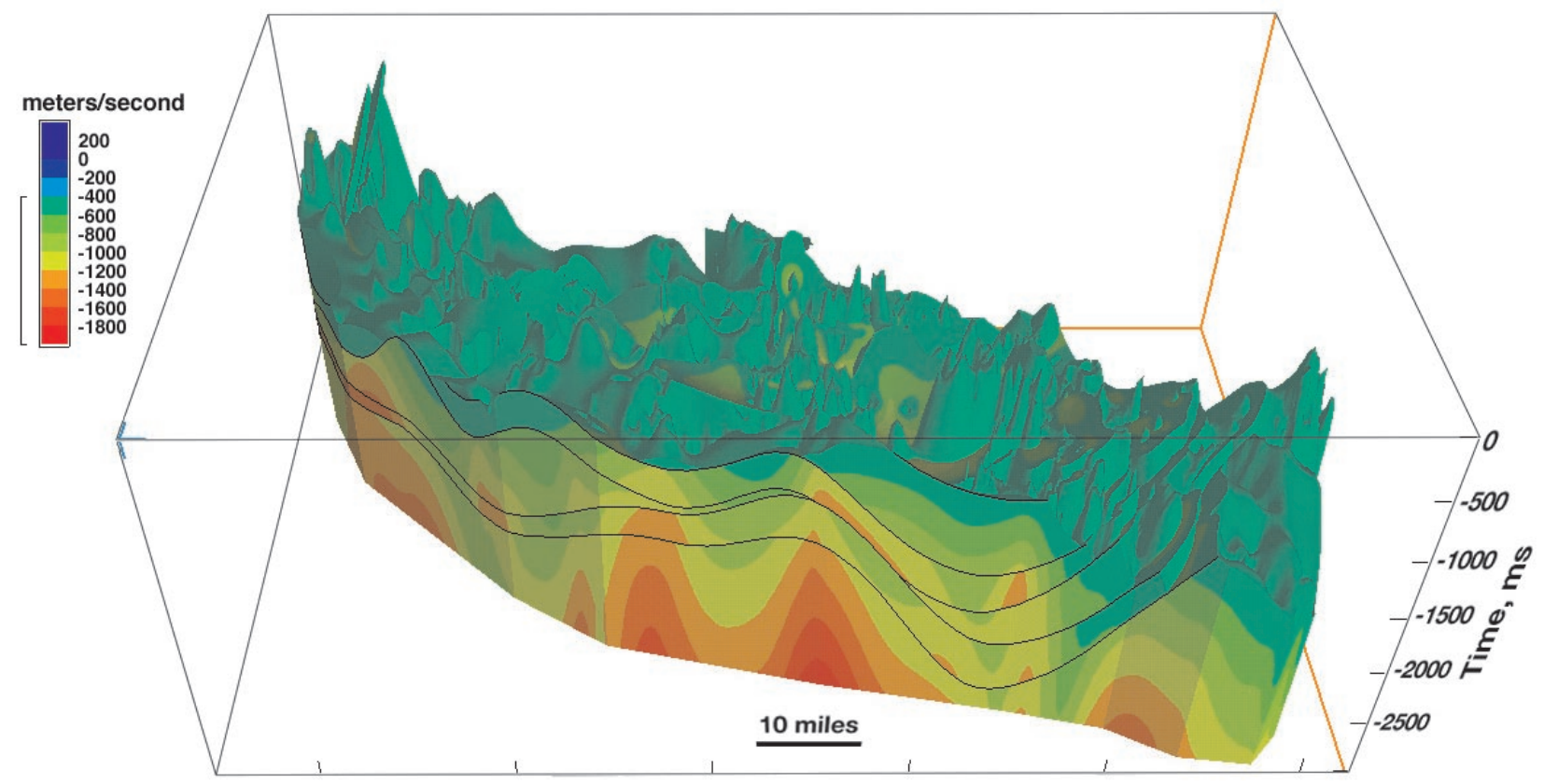

Figure 21. Inclined view of the top of the regional velocity inversion surface and the anomalously slow velocity portion or the Wind River Basin anomalous velocity model. There is over $3000 \mathrm{ft}$ of relief on the regional velocity inversion surface. The rock/fluid systems beneath the regional velocity inversion surface down to at least a depth equivalent to $3.0 \mathrm{sec}$ TWTT are anomalously pressured and the fluid-flow regime is multiphase (i.e., water-gas-oil). View is to the south.

illustrated in Figures 7 through 12.

\section{Basinwide Rock/Fluid Systems: Wind River Basin}

Using the procedures outlined above, it is possible to construct an anomalous velocity volume, or more correctly stated, an anomalous velocity model, for an area, or even a whole basin if a sonic log and seismic data set with basinwide coverage is available. Such a sonic $\log$ and 2-D seismic data set is available for the Wind River Basin (Figure 18); thus, an anomalous velocity model (Figure 19) was constructed for the whole basin $\left(\sim 8500 \mathrm{mi}^{2}\right)$. This anomalous velocity model (Figure 19) is based on $2000 \mathrm{mi}$ of 2-D seismic data and 175 sonic logs, for a total of 132,000 velocity/depth profiles. The model consists of the following two parts: (1) the upper volume shown in blue, which is characterized by rock/fluid systems falling on the ideal velocity/ depth gradient and which is typically under strong meteoric water drive (Figure 20) and (2) the lower portion below the regional velocity inversion surface, which is characterized by a regional, anomalously slow velocity "volume" that contains highly compartmentalized, intense anomalously slow velocity domains (i.e., gas-charged domains; Figure 21).

To gain additional insight into the internal fabric of the anomalous velocity model of the Wind River Basin, five stratigraphic volumes have been extracted for the Upper Fort Union, Lower Fort Union, Lance, Meeteetse, and Mesaverde formations (Figures 22 through 26). In Figures 22 through 26, blue areas indicate fluid systems under meteoric water drive, whereas green to red areas designate gas-charged, multiphase fluid-flow systems. The intense, anomalously slow velocity domains are shown in red in Figures 22 through 26. 
Anomalous Velocity Model, Wind River Basin

Upper Fort Union, View to South

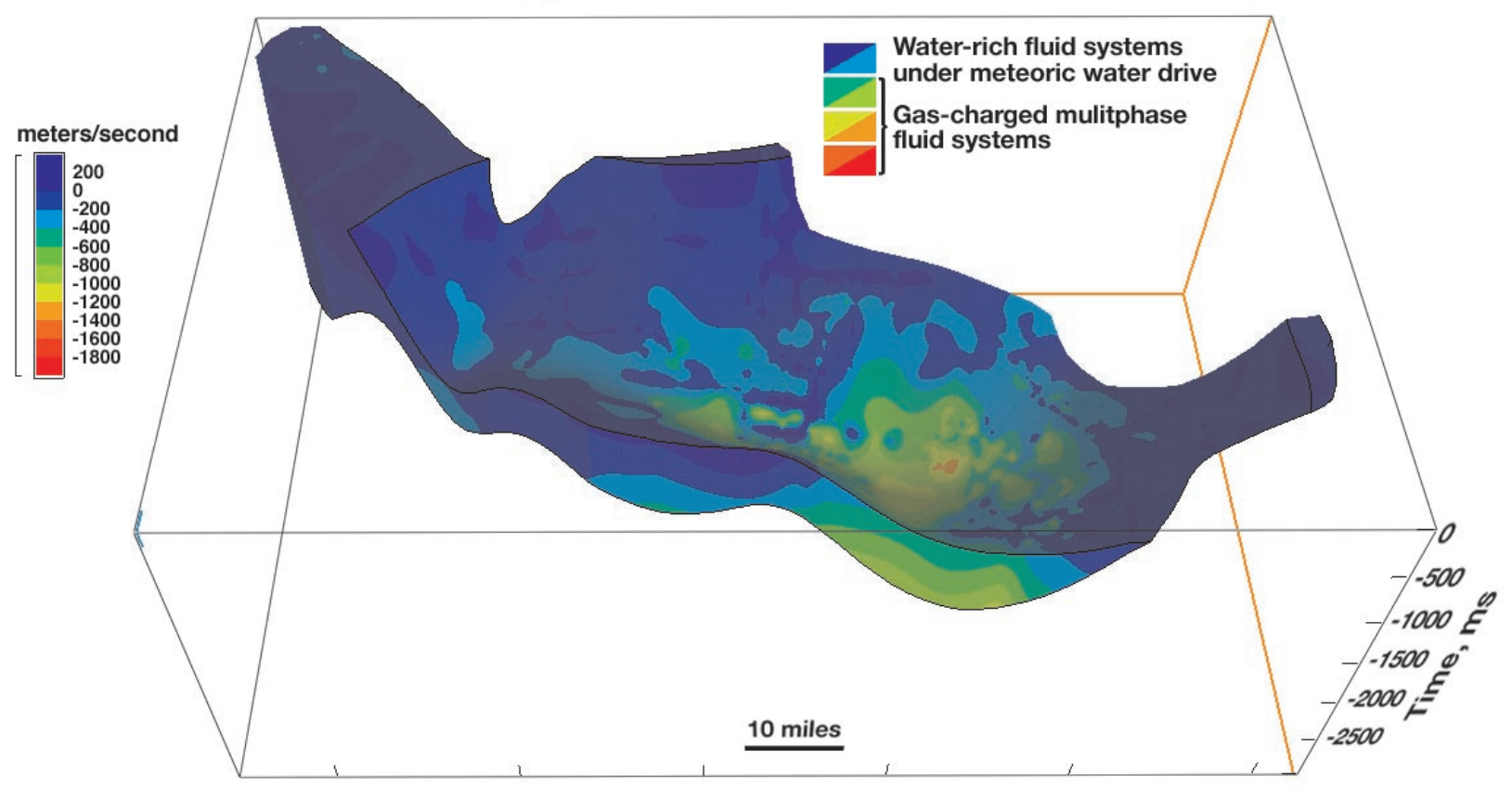

Figure 22. Inclined view of a 3-D anomalous velocity model for the Upper Fort Union stratigraphic volume. View is to the south.

Anomalous Velocity Model, Wind River Basin Lower Fort Union, View to South

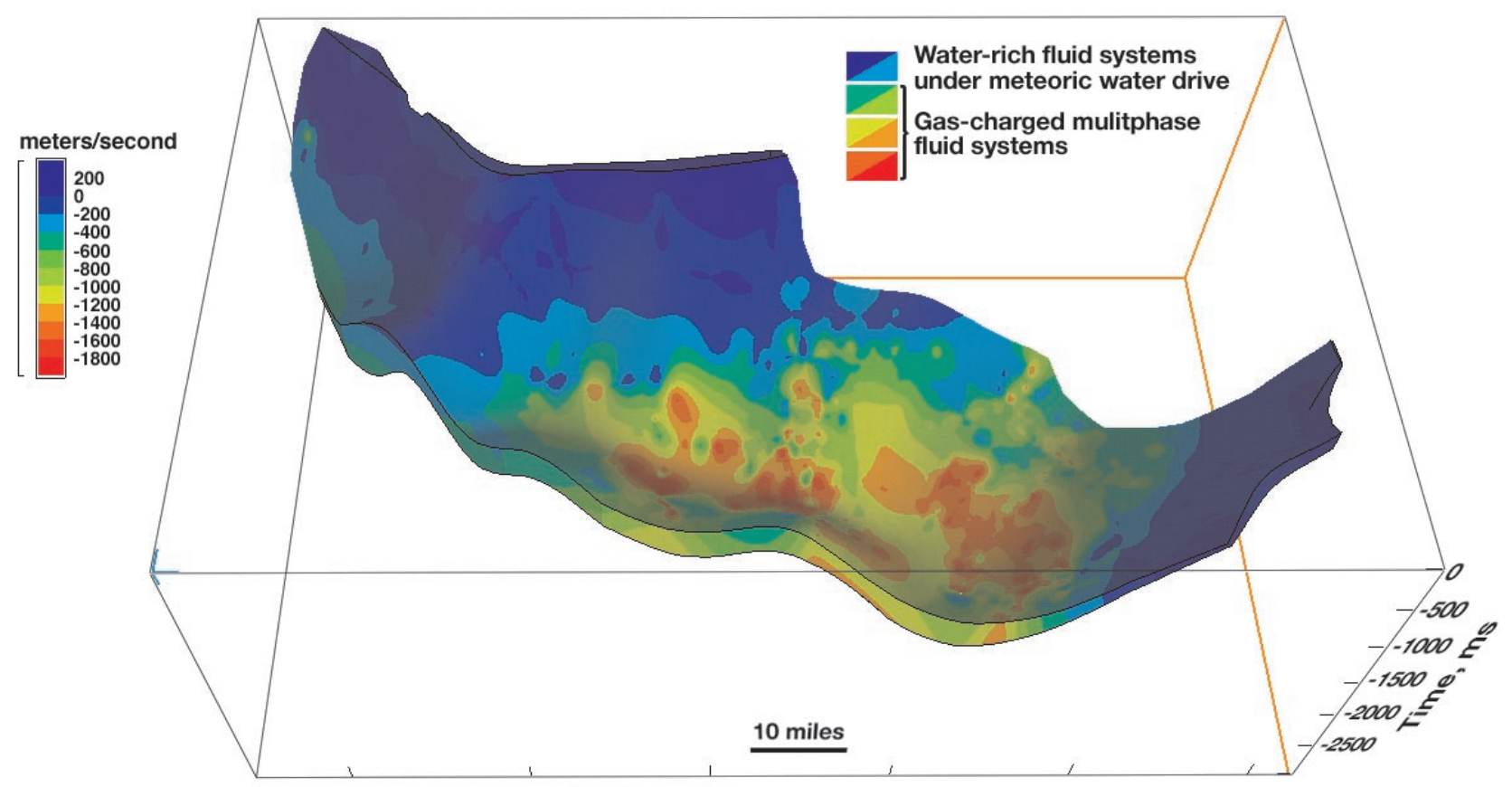

Figure 23. Inclined view of a 3-D anomalous velocity model for the Lower Fort Union stratigraphic volume. View is to the south. 


\section{Anomalous Velocity Model, Wind River Basin}

Lance, View to South

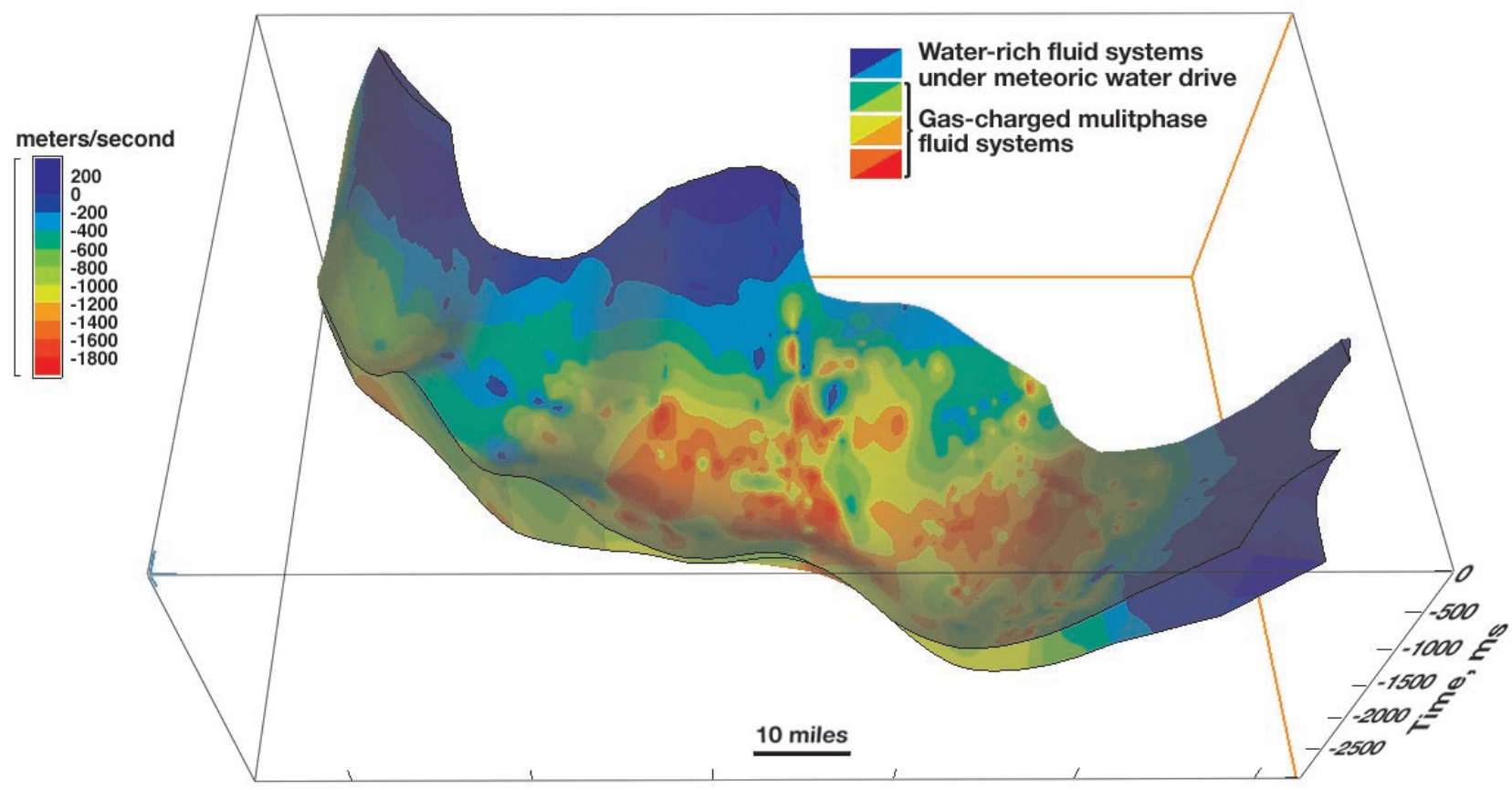

Figure 24. Inclined view of a 3-D anomalous velocity model for the Lance stratigraphic volume. View is to the south.

\section{Anomalous Velocity Model, Wind River Basin Meeteetse, View to South}

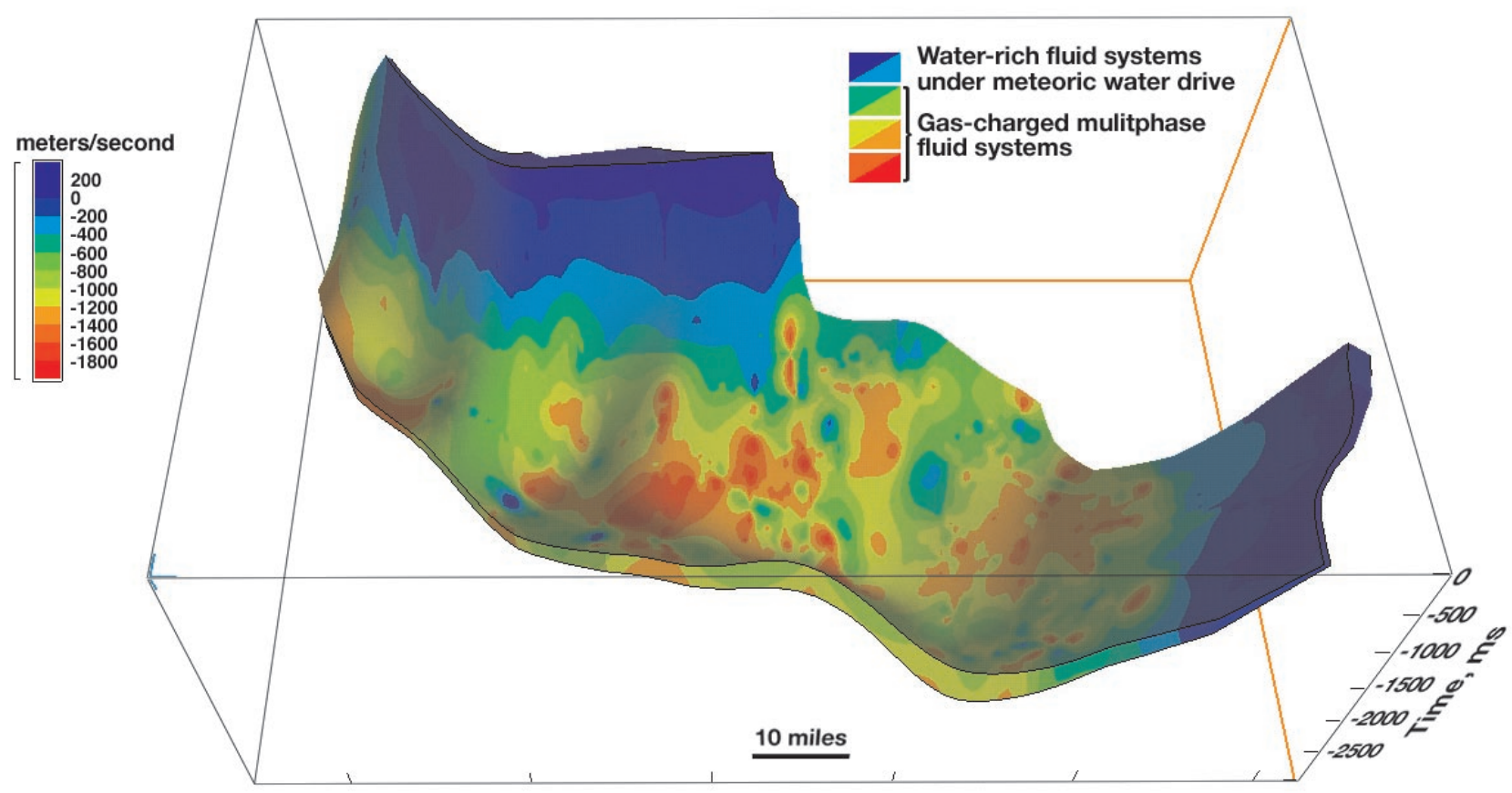

Figure 25. Inclined view of a 3-D anomalous velocity model for the Meeteetse stratigraphic volume. View is to the south. 


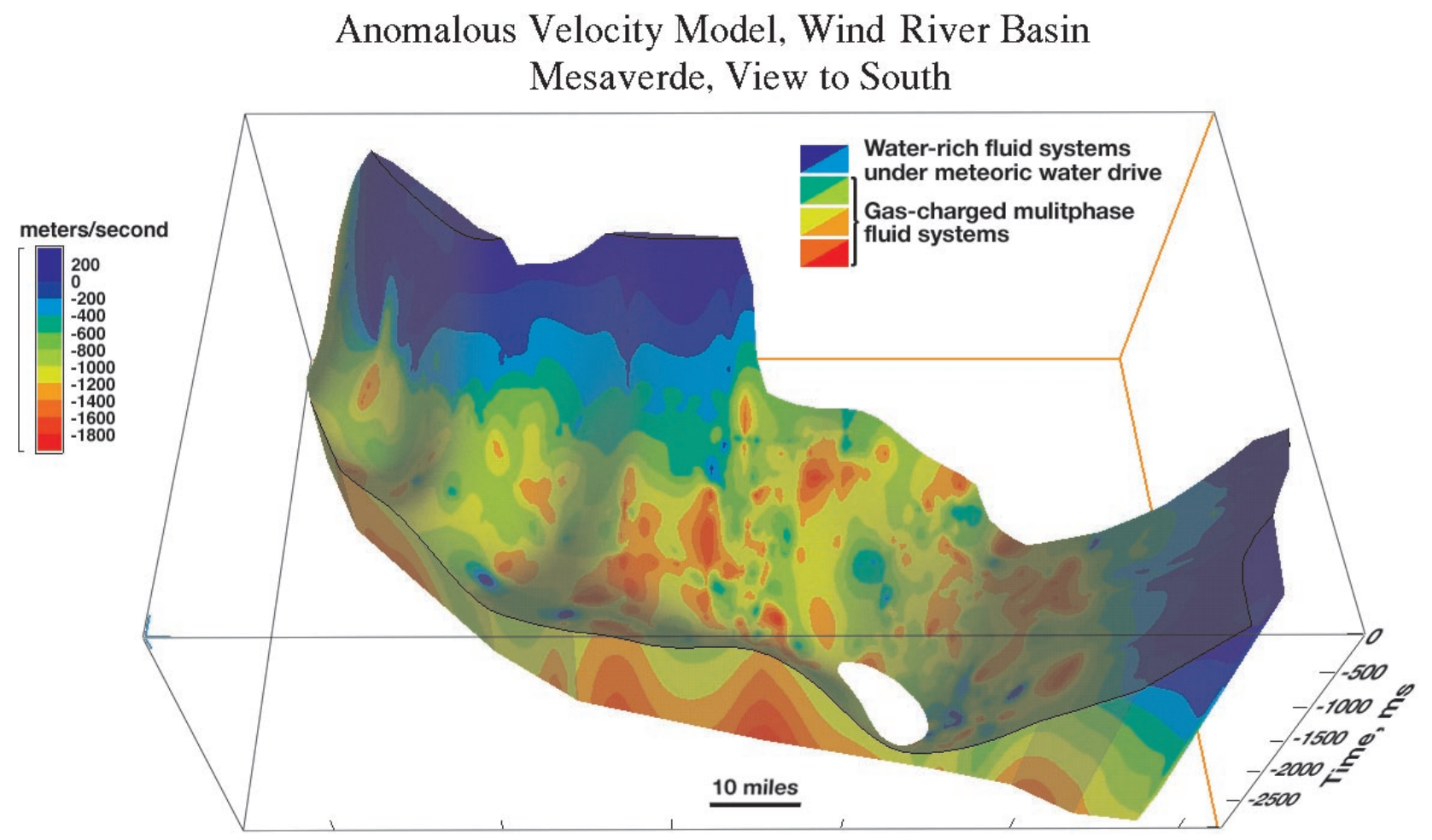

Figure 26. Inclined view of a 3-D anomalous velocity model for the Mesaverde stratigraphic volume. View is to the south.

\section{Validity of the Technique}

The diagnostic technology applied in this study was tested by constructing 10 cross sections through the anomalous velocity model that were coincident with known gas fields (for the sake of illustration, six of the ten cross sections are shown in Figures 27 through 32). In each of the cross sections (Figures 27 through 32) a strong and intense anomalously slow velocity domain coincided with a gas productive rock/fluid interval; there were no exceptions. Because of limitations placed on the study by the far offsets and CMP fold coverage of the 2-D seismic data, the illustrated cross sections only extend down to depths equivalent to $3.0 \mathrm{sec}$ TWTT; therefore, the known gas fields chosen for the test produced from the lower Fort Union and Lance formations (Figures 27-32).

\section{Wind River Basin Fluid-Flow System}

In the Wind River Basin, it is likely that significant vertical migration of gas (see positive relief on Figure 21) has occurred. Many of the topographic highs on the regional velocity inversion surface in the Wind River Basin are $3000 \mathrm{ft}$ higher than the surrounding areas (Figure 21 ), and each of the topographic highs represents the vertical migration of gas (i.e., gas chimney). Thus, these areas represent conduits characterized by enough permeability to allow vertical gas migration.

Note that some locations in the Wind River Basin have 5,000+ ft-thick columns of rock/fluid systems that are characterized by continuous, anomalously slow velocities (Figure 21); this suggests that the areas containing 5,000+ ft-thick rock/fluid columns in this basin have no connection to meteoric water. In other words, the velocity analysis strongly suggests that there are regionally significant fluid-flow compartments which have a gas-charge in the fluid phase that are isolated from meteoric water recharge. However, this configuration does not eliminate the possibility that there is trapped water (Figure 20), perhaps even substantial, smaller, water-dominated 


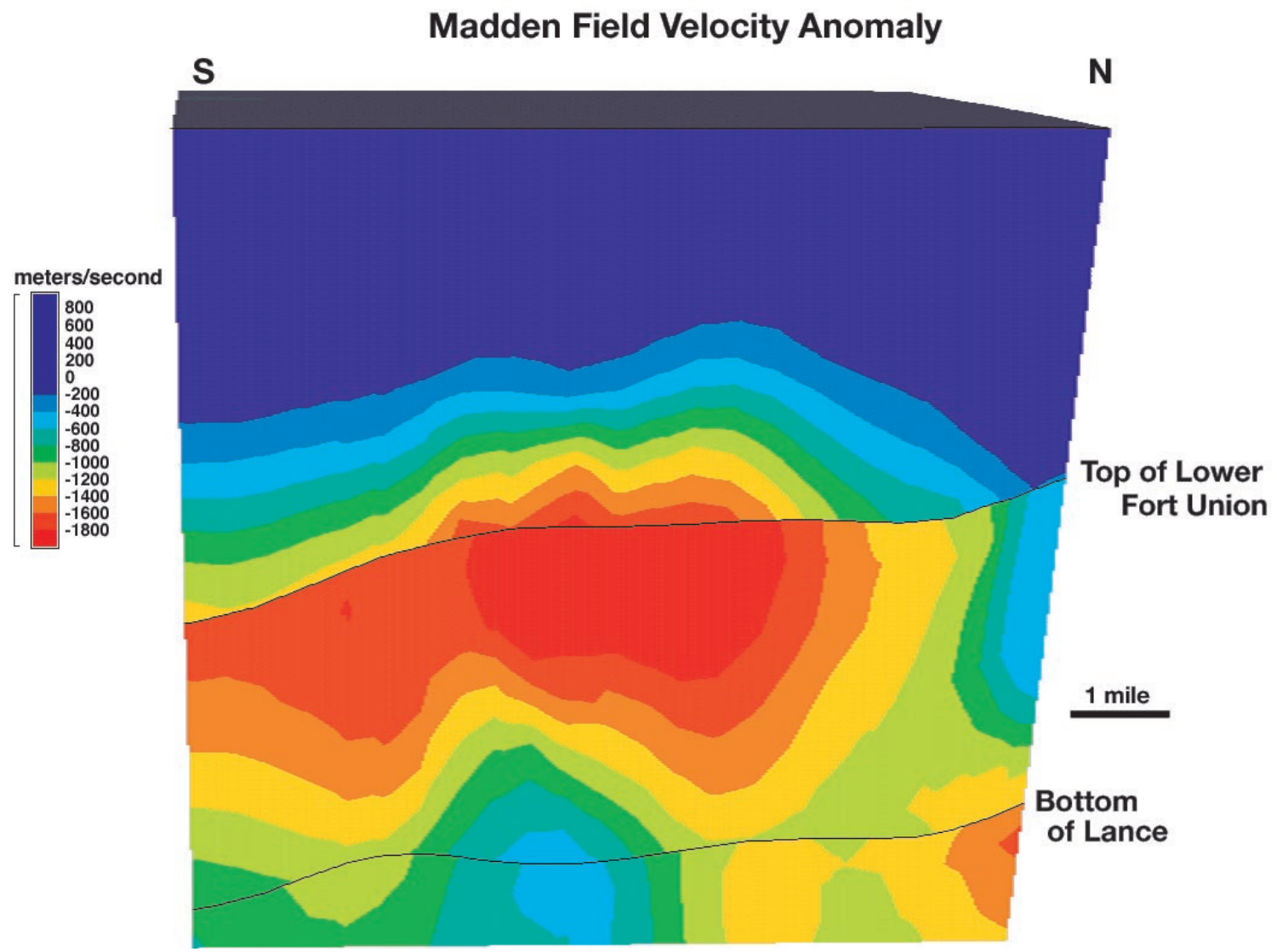

Figure 27. N-S anomalous velocity profile through the Upper Cretaceous portion of the Madden gas field.

\section{Frenchie Draw Field Velocity Anomaly}

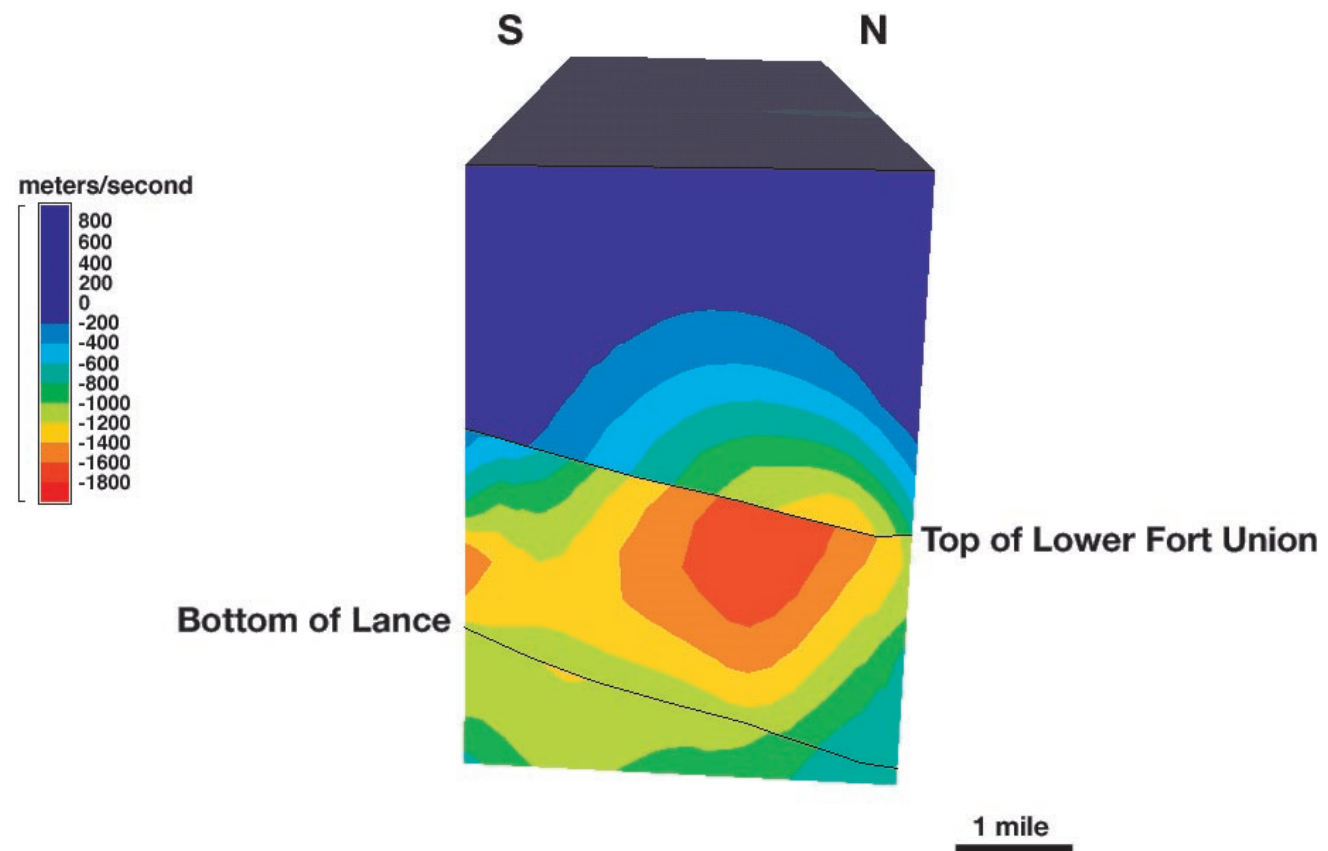

Figure 28. N-S anomalous velocity profile through the Frenchie Draw field. The top of the Lower Fort Union and bottom of the Lance formations are shown. 


\section{Dinty Moore Field Velocity Anomaly}

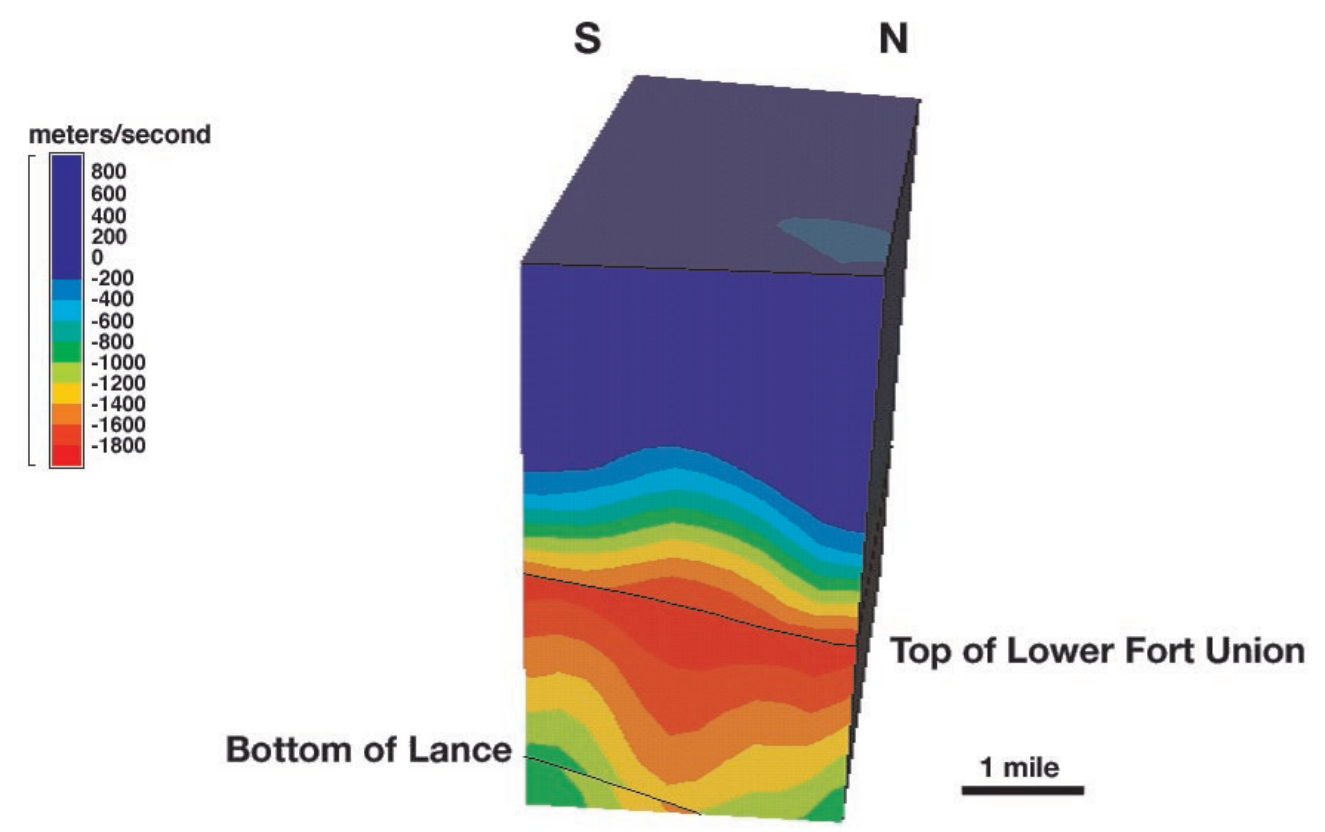

Figure 29. N-S anomalous velocity profile through the Dinty Moore field. The top of the Lower Fort Union and bottom of the Lance formations are shown.

\section{Squaw Butte Field Velocity Anomaly}

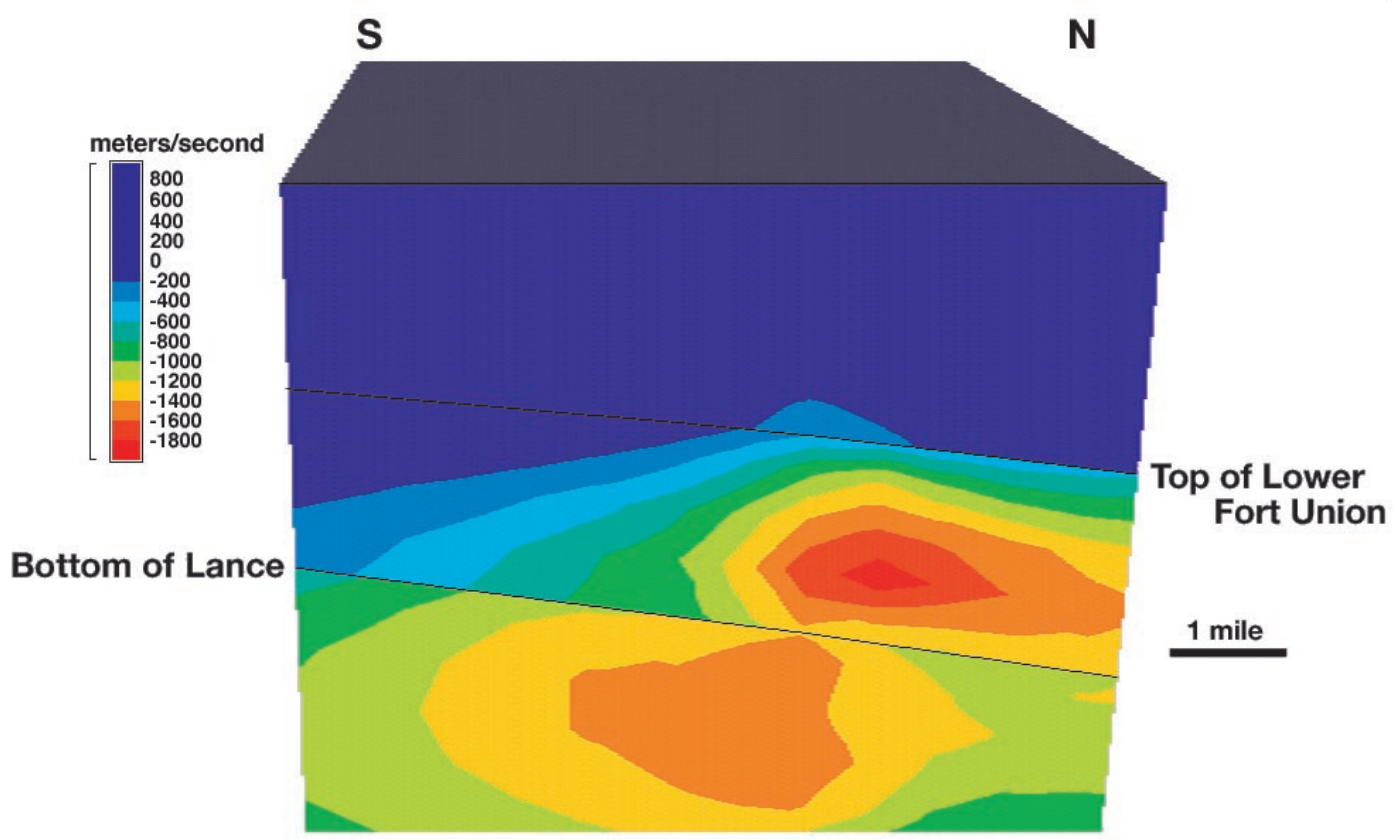

Figure 30. N-S anomalous velocity profile through the Squaw Butte field. The top of the Lower Fort Union and bottom of the Lance formations are shown. 


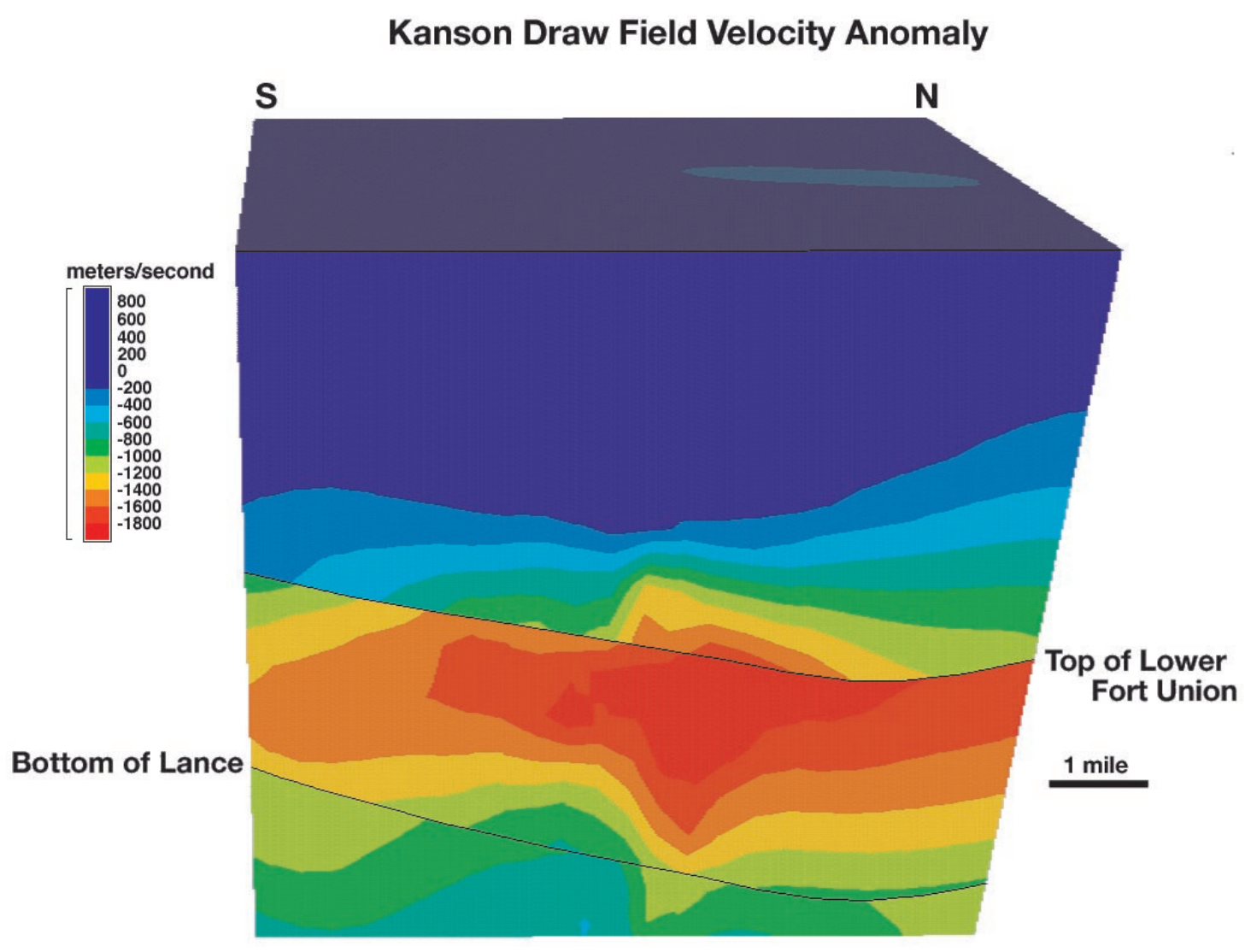

Figure 31. N-S anomalous velocity profile through the Kanson Draw field. The top of the Lower Fort Union and bottom of the Lance formations are shown.

\section{Pavillion Field Velocity Anomaly}

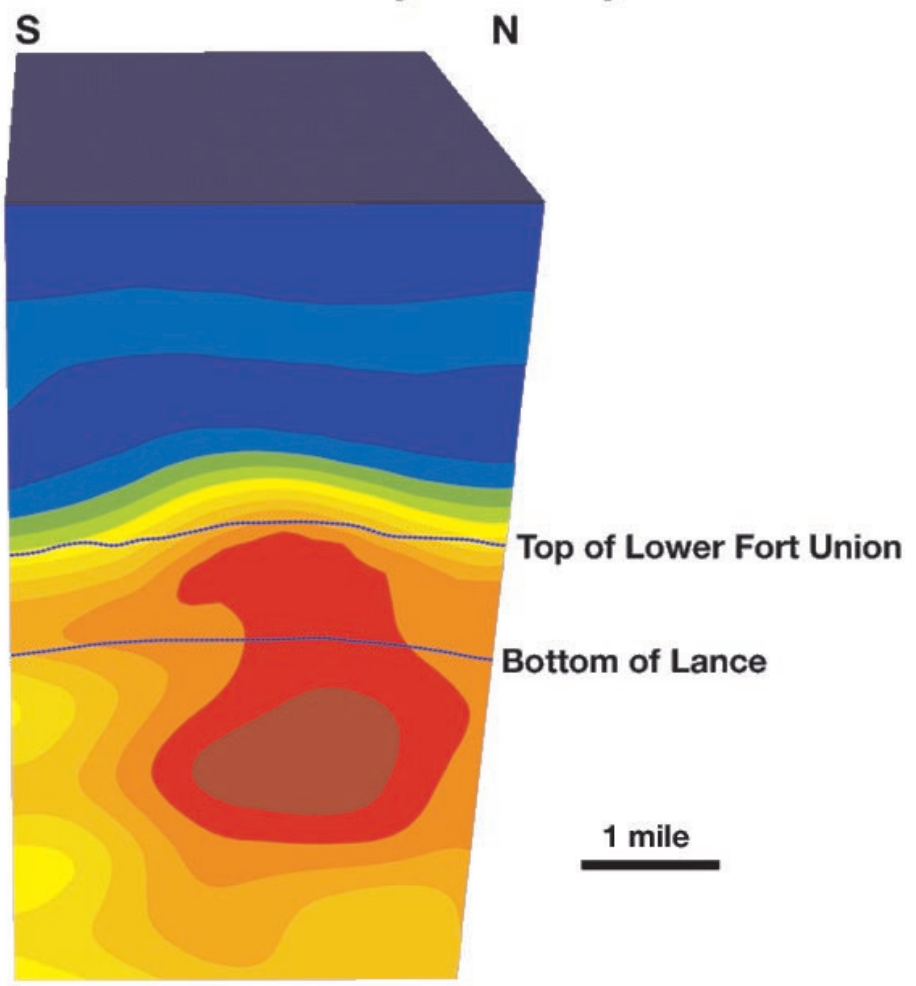

Figure 32. N-S anomalous velocity profile through the Pavillion field. The top of the Lower Fort Union and bottom of the Lance formations are shown. 
domains within the large, regional, gas-charged compartments. If such water-rich, single-phase fluid domains exist, they are not currently being recharged from the meteoric water system. For example, in the lower Fort Union, Lance, Meeteetse, and Mesaverde units, relatively small, discontinuous, water-rich, isolated domains may occur away from the basin margins (Figure 20).

It should be emphasized that anomalously slow velocities do not exclude the presence of water. The most significant decrease in velocity occurs when the gas phase reaches approximately 15 to $20 \%$ (Timur, 1987). Thus, in the anomalously slow velocity domains, even though a significant gas phase exists (i.e., a gas-charged, multiphase fluid flow system), the fluid is a gas-water system. However, any water present is isolated from the meteoric water flow system. Note that gas production from reservoir intervals characterized by intense, anomalously slow velocity domains in the RMLB commonly have very low initial water production.

The Wind River Basin on a regional scale is divided into at least two regionally prominent fluid-flow compartments separated by a velocity inversion surface. The upper compartment is water-dominated, probably under strong meteoric water drive (Figure 20), whereas the lower compartment is gas-charged, isolated, and anomalously pressured (Figure 21). The lower boundary of the regionally gas-charged compartment was not observed in the work described herein, but generally it must be at a depth equivalent to 3.0 sec TWTT or greater $(15,000+\mathrm{ft}$ depth). Based on earlier work in the Powder River Basin, there is a strong possibility that the lower boundary of the regional gas-charged compartment in the Wind River Basin will be associated with the lowermost organic-rich shale in the Mesozoic section (Surdam et al., 1994).

Judging from cross sections through the anomalous velocity model, numerous fluid-flow subcompartments occur within the regionally prominent gas-charged compartment beneath the regional velocity inversion surface. The geom- etries and boundaries of these subcompartments are controlled by faults, other structural elements, low-permeability rocks resulting from the stratigraphic framework (i.e., sandstone distribution and petrophysical character), depositional setting, and diagenetic history.

Determining the distribution of gas-charged and water-charged domains can significantly reduce exploration uncertainty in the Wind River Basin and other RMLB. While in the RMLB significant gas accumulations below the regional velocity inversion surface are characterized by significant anomalously slow velocity domains, not all velocity anomalies yield commercial gas production. More exploration uncertainty (risk) reduction can be achieved in the RMLB by determining where targeted reservoir intervals characterized by enhanced porosity and permeability intersect and penetrate anomalously slow velocity domains (Figure 33). Using well log data and seismic attributes, it should be possible to evaluate the distribution of sandstone-rich intervals within targeted reservoir units (i.e., stratigraphic units with commercial gas production potential) within the Wind River Basin. This evaluation is the focus of the next section.

\section{COMMERCIAL GAS-CHARGED RESER- VOIR TARGETS}

The next step in the exploration evolution in the Wind River Basin is to determine if the delineated gas-charged domains (i.e., intensely anomalously slow velocity volumes) intersect reservoir intervals characterized by enhanced porosity and permeability. If any of the gas-charged domains are penetrated by reservoir intervals with enhanced storage and deliverability, the intersections between the gas-charged domains and reservoir intervals should be considered good drilling prospects.

\section{Distribution of Potential Reservoir Intervals}

In this study of the Wind River Basin, the targeted potential reservoir intervals are the lower 


\section{Gas Production Target Delineation}

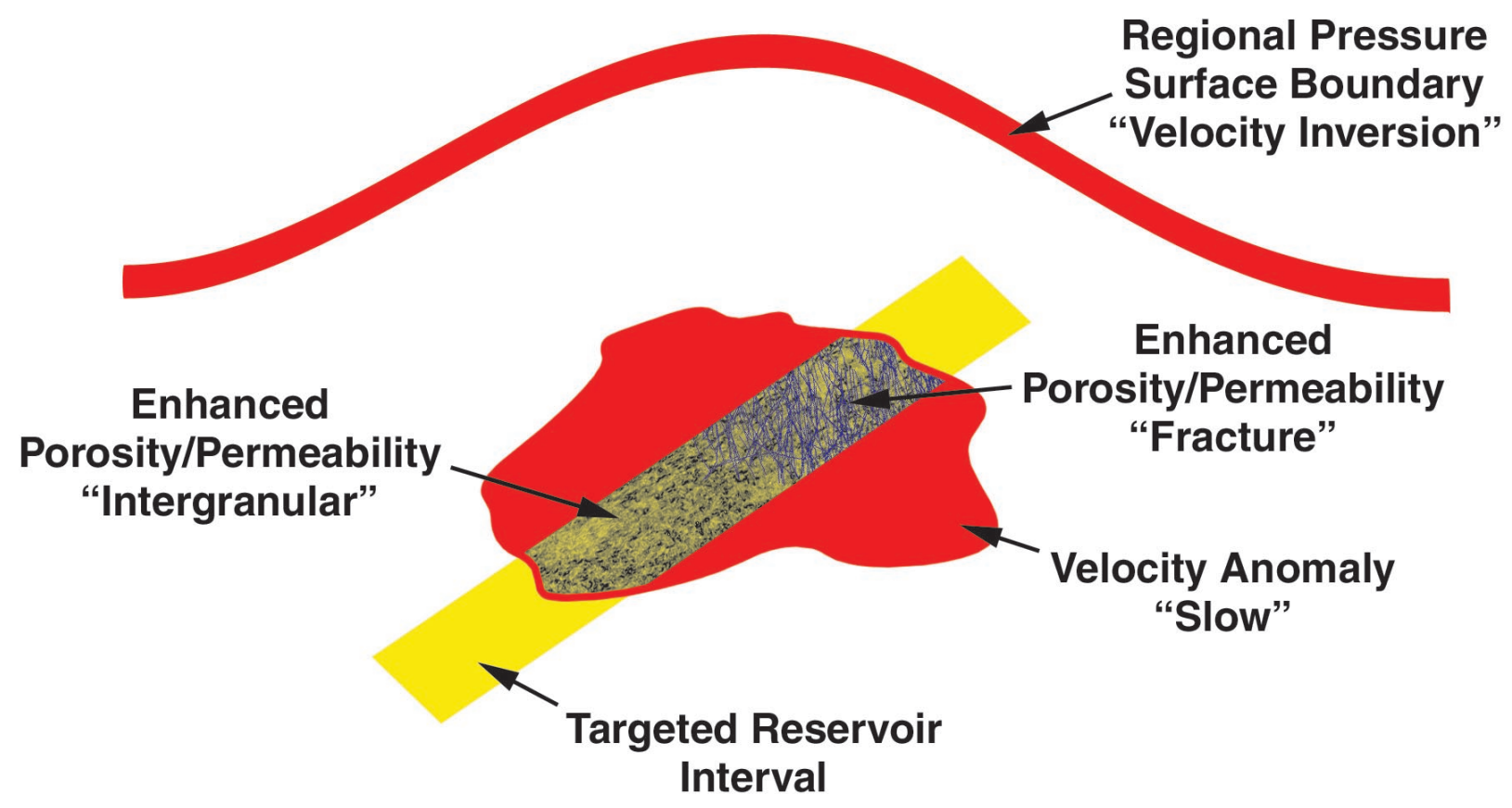

Figure 33. Schematic diagram illustrating that gas production sweet spots typically are defined spatially by the intersection of gas-charged fluid domains with reservoir rock domains characterized by enhanced porosity and permeability (i.e., commercial reservoir storage and deliverability).

Fort Union, Lance, Meeteetse, and Mesaverde stratigraphic units. These stratigraphic intervals were chosen because they typically occur in a depth window below the regional velocity inversion surface and at a depth equivalent to 3.0 TWTT. In addition, historically in the Wind River Basin and other RMLB, these units are known to be gas-producing units.

All of the targeted stratigraphic units consist of complex sedimentologic packages including various combinations of fluvial, deltaic, and marginal marine lithologies. In all of these potential reservoir units, it is important to be able to detect and delineate the distribution of sandstone-rich intervals within the individual depositional complexes. Presently, the best existing information available for evaluating the regional distribution of sandstones of the Lower Tertiary/Upper Cretaceous stratigraphic units in the Wind River Basin are net sandstone isolith maps constructed by Boswell et al. (2002), but these isolith maps are based on only $\sim 60$ well logs. Thus, while the net sandstone isolith maps of Boswell et al. (2003) are valuable, they have limited application for the purposes of defining and targeting the intersection of sandstone-rich and gas-charged domains. The depositional setting of the units of interest are far too complex (i.e., patchy intermingling of fluvial channel and overbank, coal, lagoonal, beach, tidal channel, shoreface, and nearshore marine bar deposits, among others) to be modeled by net sandstone isolith maps based on only $\sim 60$ wells in a basin covering $8500 \mathrm{mi}^{2}$.

Considering the availability of seismic data, a diagnostic technique such as acoustic impedance would be useful in reaching the level of lithologic resolution required to delineate the targeted intersections. However, the well control necessary to generate an accurate $a$ priori estimate of the impedance model, as well as the seismic source wavelet information required for inversion, is not available in the 1970 to 1990 vintage 2-D seismic and well log data. 
Seismic Frequency and Lithologic Correlations

Preliminary work at Innovative Discovery Technologies, LLC, suggests that seismic frequency offers a quick and robust alternative to acoustic impedance, particularly with respect to the type of regional seismic and well log data readily available in the RMLB.

A problem of particular interest in the RMLB is the separation of shale-rich and sandstone-rich stratigraphic intervals. It has been long recognized that sandstone-rich intervals can be defined on a seismic section by regions of relatively low seismic frequency. Sandstone-rich intervals typically consist of a more isotopic fabric, whereas shale-rich intervals consist of a much more strat- ified media, which explains in part why frequency can be useful in distinguishing between sandstones and shales. Multiple interference of reflected seismic energy within the stratified shale-rich sections is a possible reason for their relative higher seismic frequency, as compared to sandstone-rich intervals.

In preliminary work on the seismic frequency content of the Tertiary/Upper Cretaceous section in the Wind River and Green River Basins, strong initial correlations between seismic frequency and sandstone content, as determined from gamma-ray logs, have been achieved (Figure 34) and suggest that seismic frequency can be used to dis-

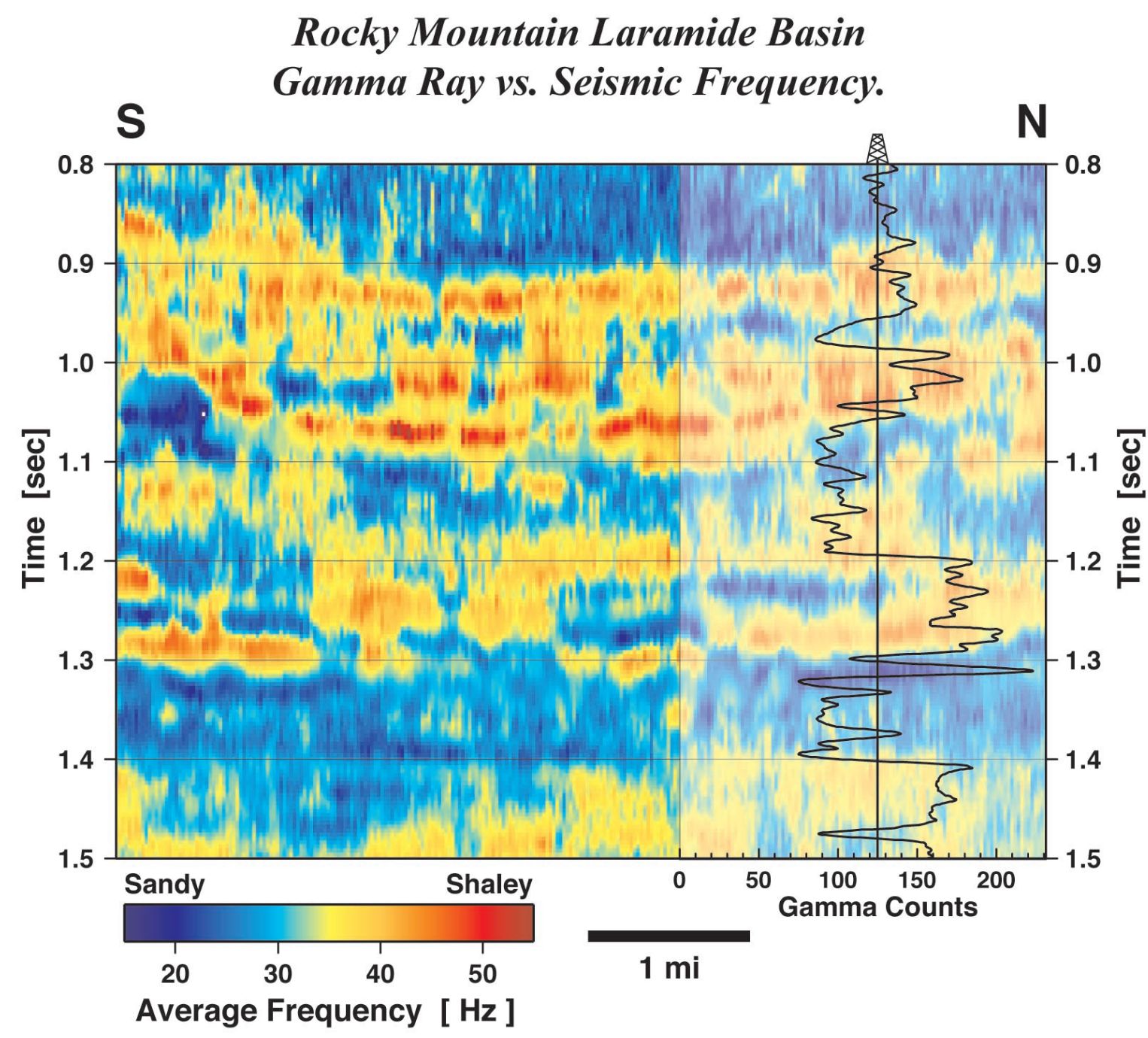

Figure 34. N-S seismic frequency panel from the Greater Green River Basin. The color palette relating average frequency to lithology is based on the gamma ray log trace from a well situated very close to the seismic line. 
tinguish sandstone-rich intervals from shalerich sequences. In addition, the presence of coal-rich sequences also can be separated from sandstone-rich sequences because coalrich sequences have even lower seismic frequency characteristics. To further evaluate the potential of using seismic frequency/lithology correlations as a diagnostic tool in the RMLB, the relationship was tested in an area where there is good control on both seismic frequency and lithologic distribution.

This test of the seismic frequency/lithology correlation was done at the Frenchie Draw field in the Wind River Basin (Figure 35). Fortunately, in this field, the seismic data through the field are of reasonable quantity and quality and there is reasonably good well log control, both of which have facilitated further testing of the diagnostic tool. Also, Frenchie Draw gas field serves as a good illustration of the difficulties associated with detecting and delineating gas assets beneath the regional velocity inversion surface in the RMLB. Originally, the field was drilled because of stratigraphic traps on a north-plunging structural nose (Cardinal et al., 1989). The stratigraphic aspect of the trap consisted of lenticular fluvial sandstone in the lower Fort Union/ Lance stratigraphic interval. The trapping mechanism and gas distribution pattern have proven to be complex and the exploitation of this gas asset by conventional technologies has been fraught with significant risk, as is commonly the case in many gas fields in the Wind River Basin. Figure 35 demonstrates the correlation between seismic
Frenchie Draw Unit 14

Seismic Frequency vs. Gamma Ray data

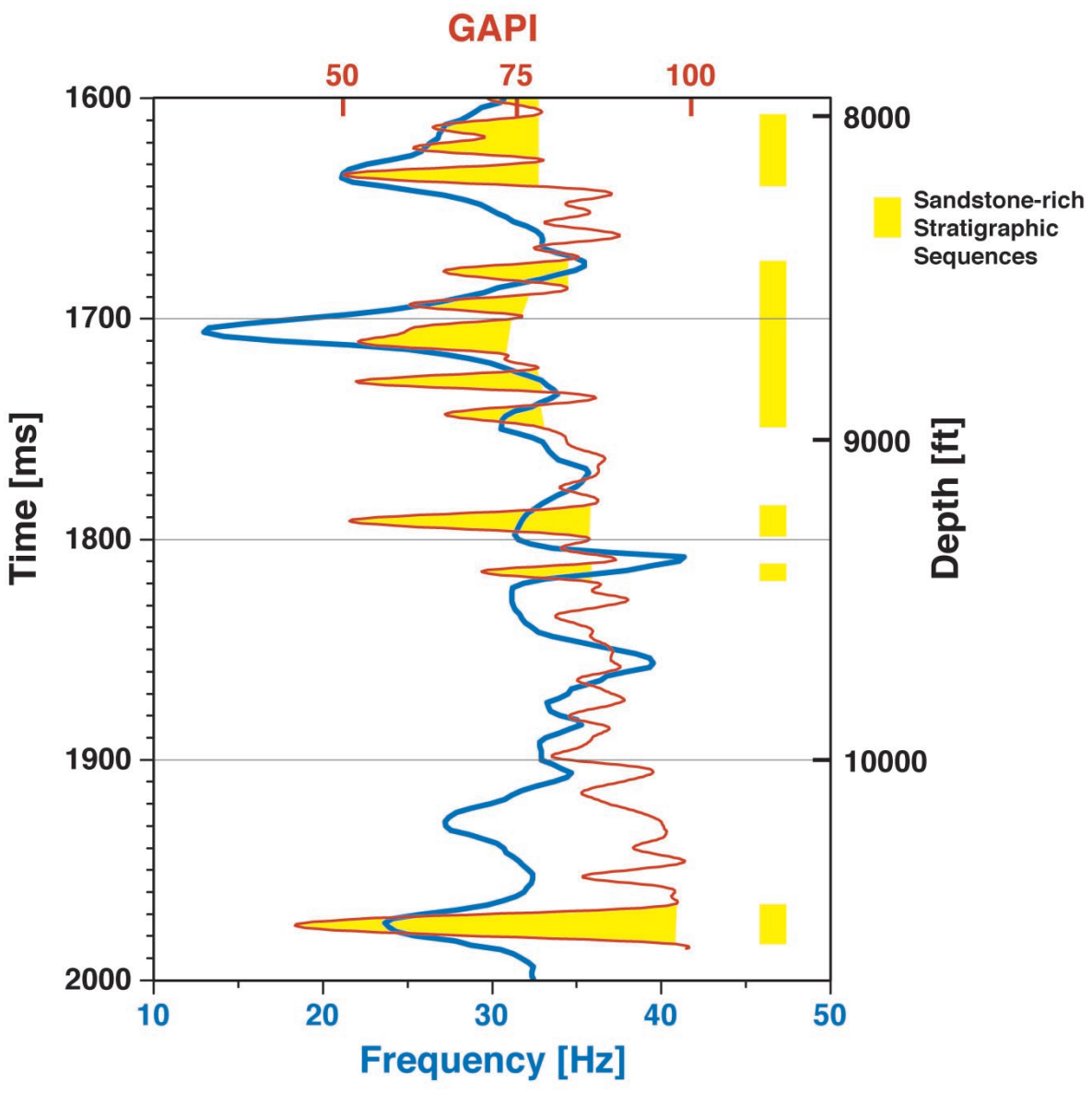

Figure 35. Panel showing both a frequency/depth profile (blue) and a gamma ray log trace/depth profile (red) from a nearly coincident seismic CMP and a well log from within the Frenchie Draw field (Wind River Basin). 
frequency and a gamma ray $\log$ (i.e., lithology) through the lower Fort Union/Lance stratigraphic interval at Frenchie Draw. Note that the well used for the gamma ray data is $\sim 2000 \mathrm{ft}$ off of the seismic line, so the correlation might improve if the gamma ray was from a well in the plane of the seismic line. Nonetheless, the correlation between seismic frequency and lithology in Figure 35 is good, so it is concluded that seismic frequency can be used to distinguish sandstone-rich from shale-rich stratigraphic intervals in the vicinity of the Frenchie Draw field in the Wind River Basin.
Based on the results of the seismic frequency/lithologic correlation demonstrated in Figure 35, a north-south seismic frequency panel was constructed through the Frenchie Draw field (Figure 36). A color palette is included as part of this illustration so that the seismic frequency can be correlated with lithology. Figure 36 clearly shows that not only is there a northplunging structural nose in this area, but at the boundary between the Upper and Lower Fort Union stratigraphic units (near the upper limit of gas production), there is a shale-rich sequence (orange) that serves as a regional seal. In addi-

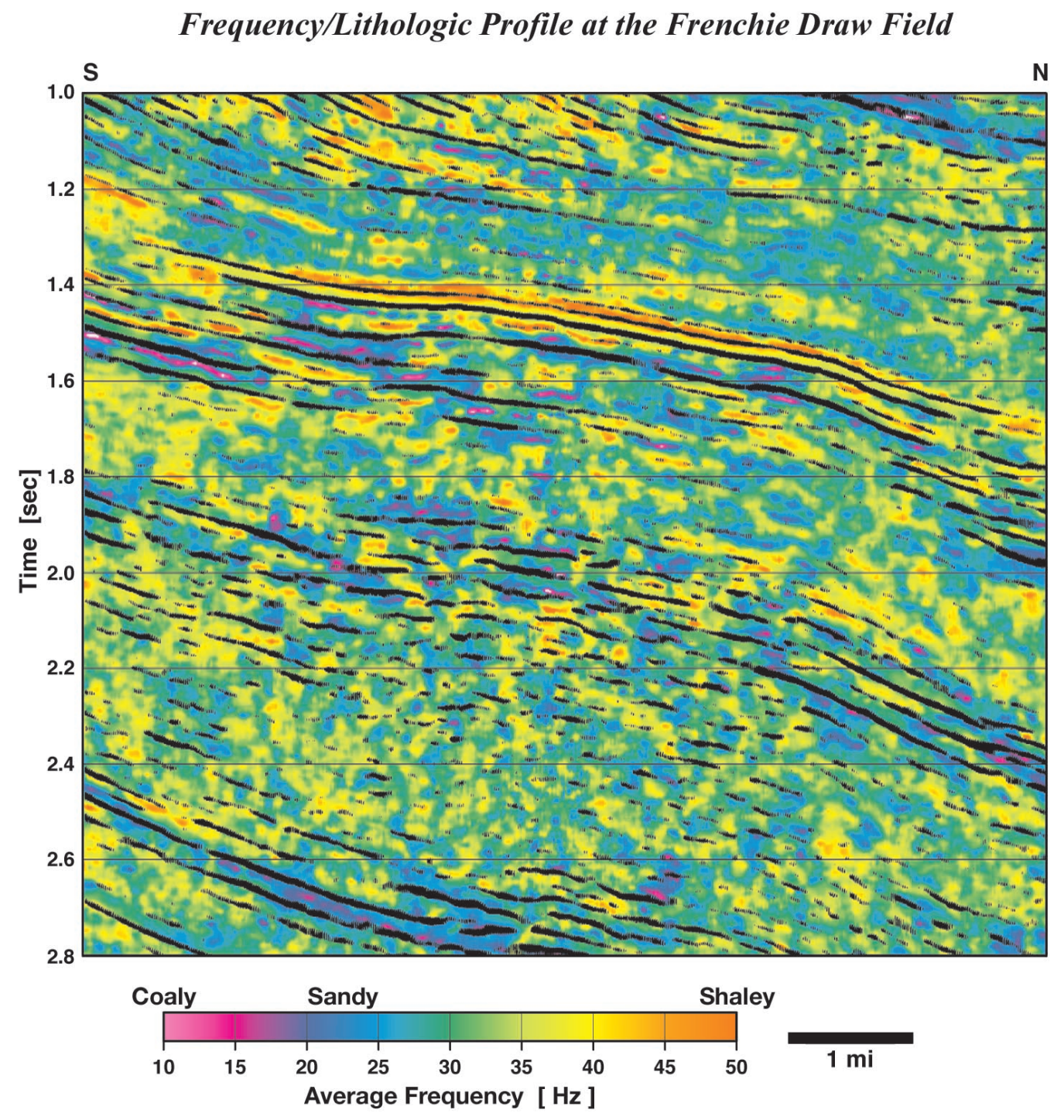

Figure 36. N-S seismic frequency panel through the Frenchie Draw field. The lithologic correlations are based on frequency/gamma ray/lithology logs, and information such as that shown in Figure 35. Some of the seismic reflections are shown to expedite structural interpretation. 
tion, the distribution of sandstone-rich intervals (blue) stands out in contrast to the shale-rich intervals (orange, yellow, and green). The lenticular aspect of the fluvial sandstone-rich intervals is also very apparent. In conclusion, the distributional pattern of lithologies shown in Figure 36 corresponds very well with the initial interpretation by the geologists and geophysicists who discovered the field.

\section{Intersection of Gas-Charged Domains and Sandstone-Rich Reservoir Intervals}

Figure 36 clearly shows that the spatial distribution of fluvial sandstone-rich intervals in the Lower Fort Union and Lance stratigraphic units are patchy and complex, and that the depositional systems that formed these stratigraphic units were characterized by heterogeneity. Therefore, detection of intersections of sandstone-rich and gasrich domains at a useful level within the Lower Fort Union and Lance formations requires new diagnostic tools, such as the seismic frequency/ lithology correlations (Figure 36). After construction of a profile delineating the distribution of sandstone-rich depositional packages (Figure 36 ), it is possible to combine it with a coincident anomalous velocity (i.e., gas-charged) profile (Figure 37).

Figure 38 shows the distribution of sandstone-rich intervals (blue areas, denoted by red arrows and outlined by white dots), which are

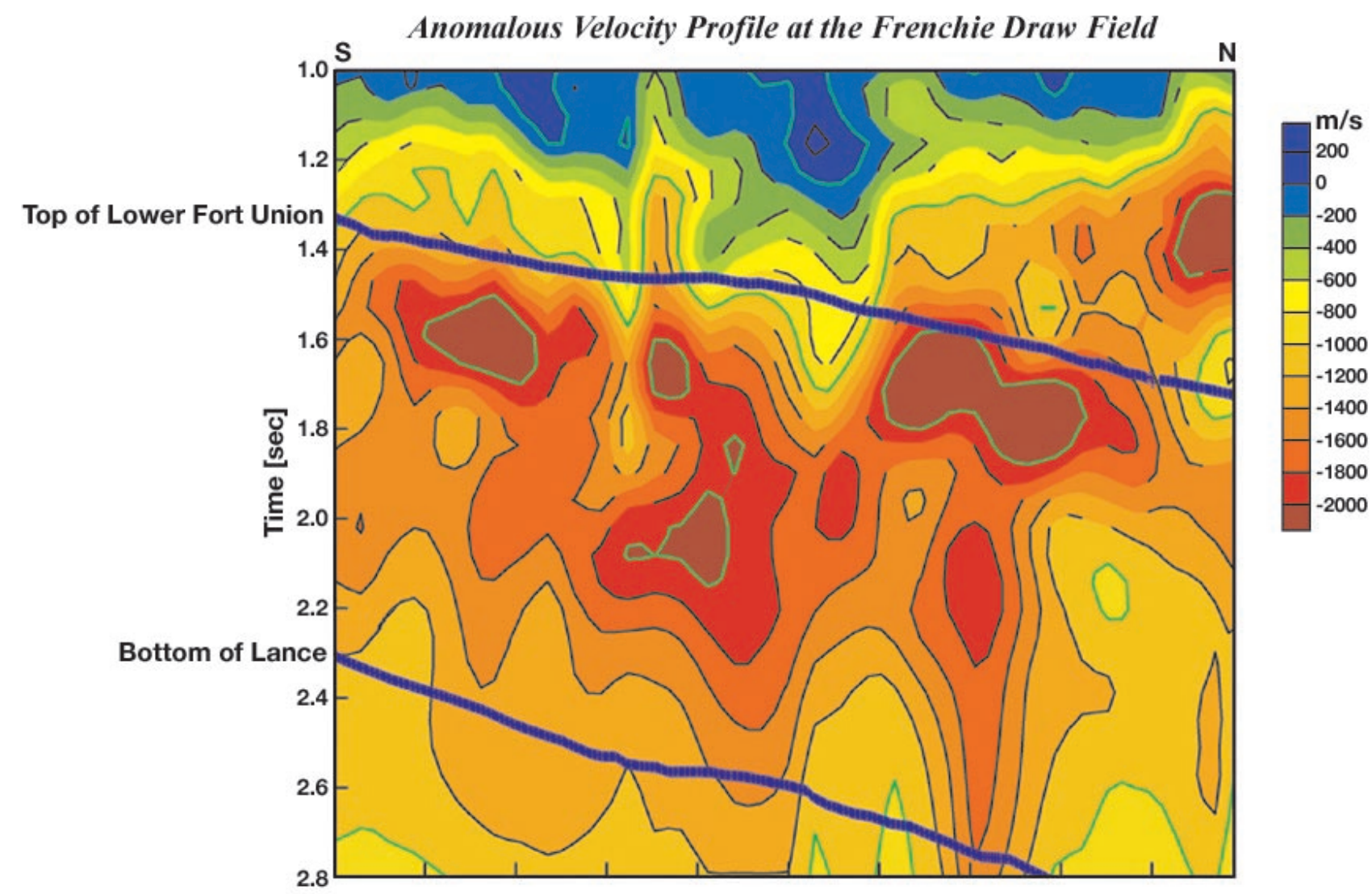

1 mile

Figure 37. N-S anomalous velocity panel for the same seismic data as those shown in Figure 38. The top of the Lower Fort Union and bottom of the Lance formations are shown. The regional velocity inversion surface is at the boundary between the blue and green colors. 
characterized by low seismic frequency, within the Lower Fort Union/Lance stratigraphic section that intersect the intense anomalously slow velocity domain (shaded area and outlined by red dots) below the regional velocity inversion surface (red line) within the Frenchie Draw gas field in the Wind River Basin. This example illustrates the complex nature of compartmentalization of production potential within anomalously slow velocity, gas-charged domains. The distribution of production sweet spots (red arrows) in the Frenchie Draw example is controlled not only by the stratigraphic framework, but also by the structural framework (i.e., faults/fractures and a plunging nose), and also likely by the diagenetic history of the sandstones, all below a regional velocity inversion surface and within the regionally anomalously slow velocity volume (Figure 38). This example nicely illustrates the complex interactions within the rock/fluid system that control the distribution of commercial and noncommercial hydrocarbons in RMLB, "basin-center" petroleum systems. Note that the results of the Frenchie Draw demonstration (Figure 38) correctly predict the gas production patterns and distribution as determined by drilling.

To further confirm the observations made at the Frenchie Draw field, consider a second demonstration, which is characterized by the following attributes:

\section{Frequency Stack/Anomalous Velocity Overlap at the Frenchie Draw Field}

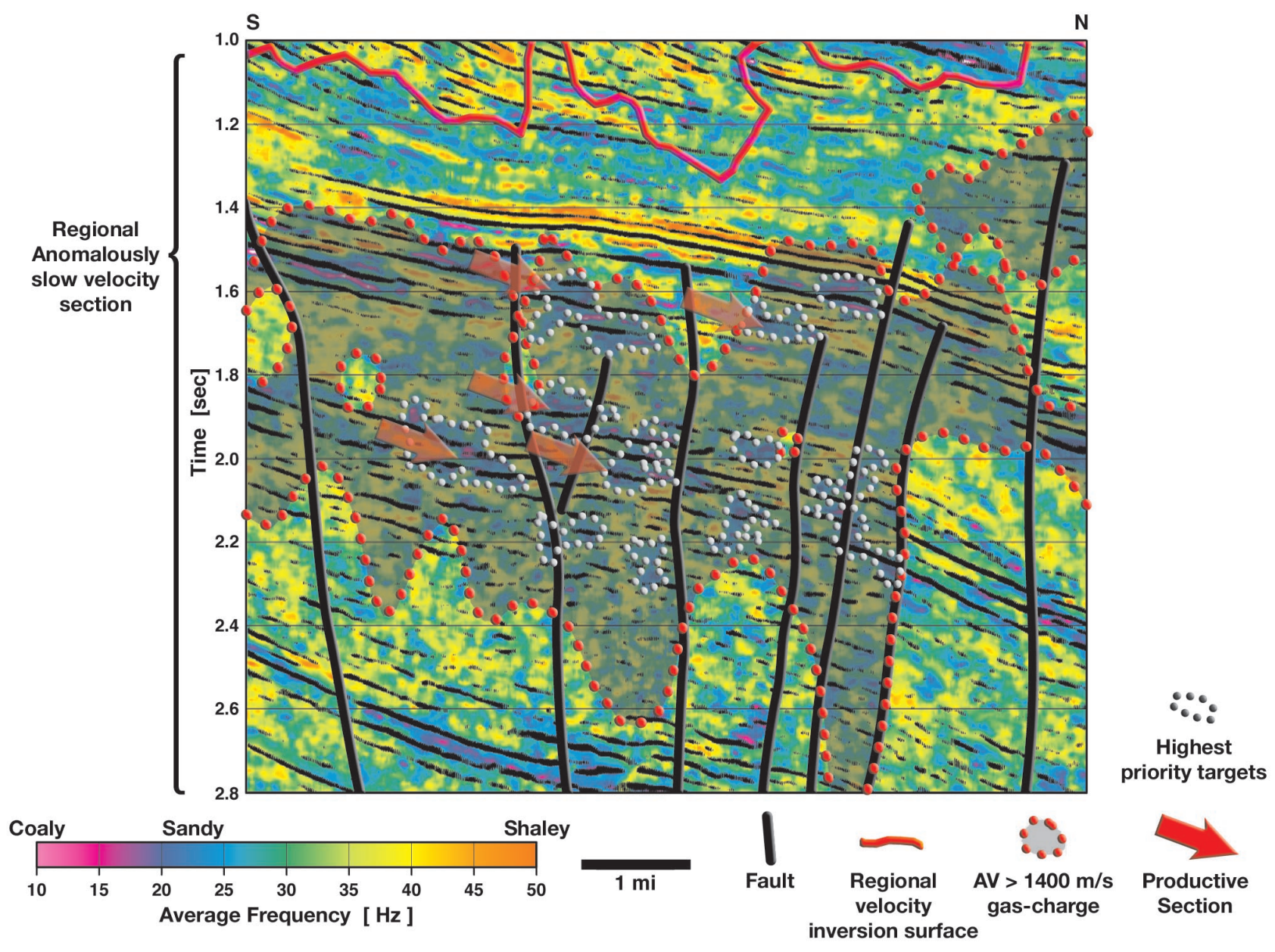

Figure 38. Seismic data display showing the results of superimposing Figure 36 (seismic frequency attributes) and 37 (anomalous velocity profile). Shaded region shows the distribution of intense anomalous velocity overlap. Black regions represent sandstone-rich intervals and highest priority areas are outlined in white dots. Productive areas are indicated by red arrows. 
1. Anomalous velocity domain comparable to known gas fields in the Wind River Basin (i.e., both in size and intensity);

2. Spatial setting (i.e., structural, stratigraphic, and temporal) analogous to a known gas field;

3. Location at a significant distance from the nearest known gas field; and

4. Intersection of the sandstone-rich reservoir intervals with gas-charged domains.

Figure 39 is the seismic frequency/lithology profile through the Lower Fort Union/Lance strati- graphic interval in the test area. In some ways, the structural setting here is similar to that in the Frenchie Draw area, although structural closure, if present, is more subtle. The sandstone-rich intervals within the Lower Fort Union/Lance section appear to be laterally more continuous than in the Frenchie Draw area (Figure 39). Figure 40 is the anomalously slow velocity domain characterizing the area. The tops of the Lower Fort Union and bottom of the Lance formations are shown in Figure 40. Note that the intense, anomalously slow velocity domain is beneath the regional velocity inversion surface, and contained almost completely within the Lower Fort Union/Lance stratigraphic interval. Figure 41 is an integration

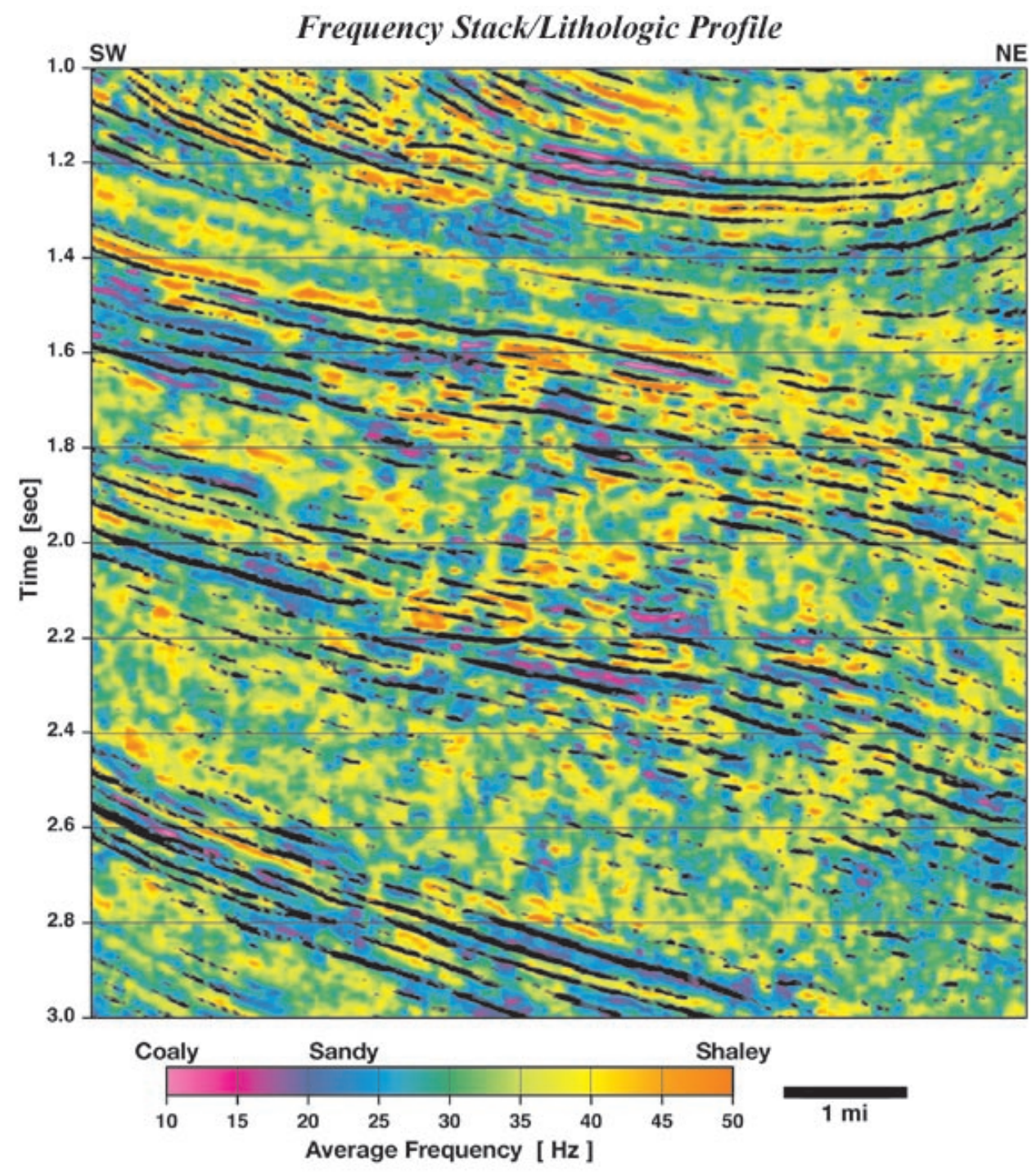

Figure 39. Seismic frequency attribute panel for a prospective area in the Wind River Basin. 


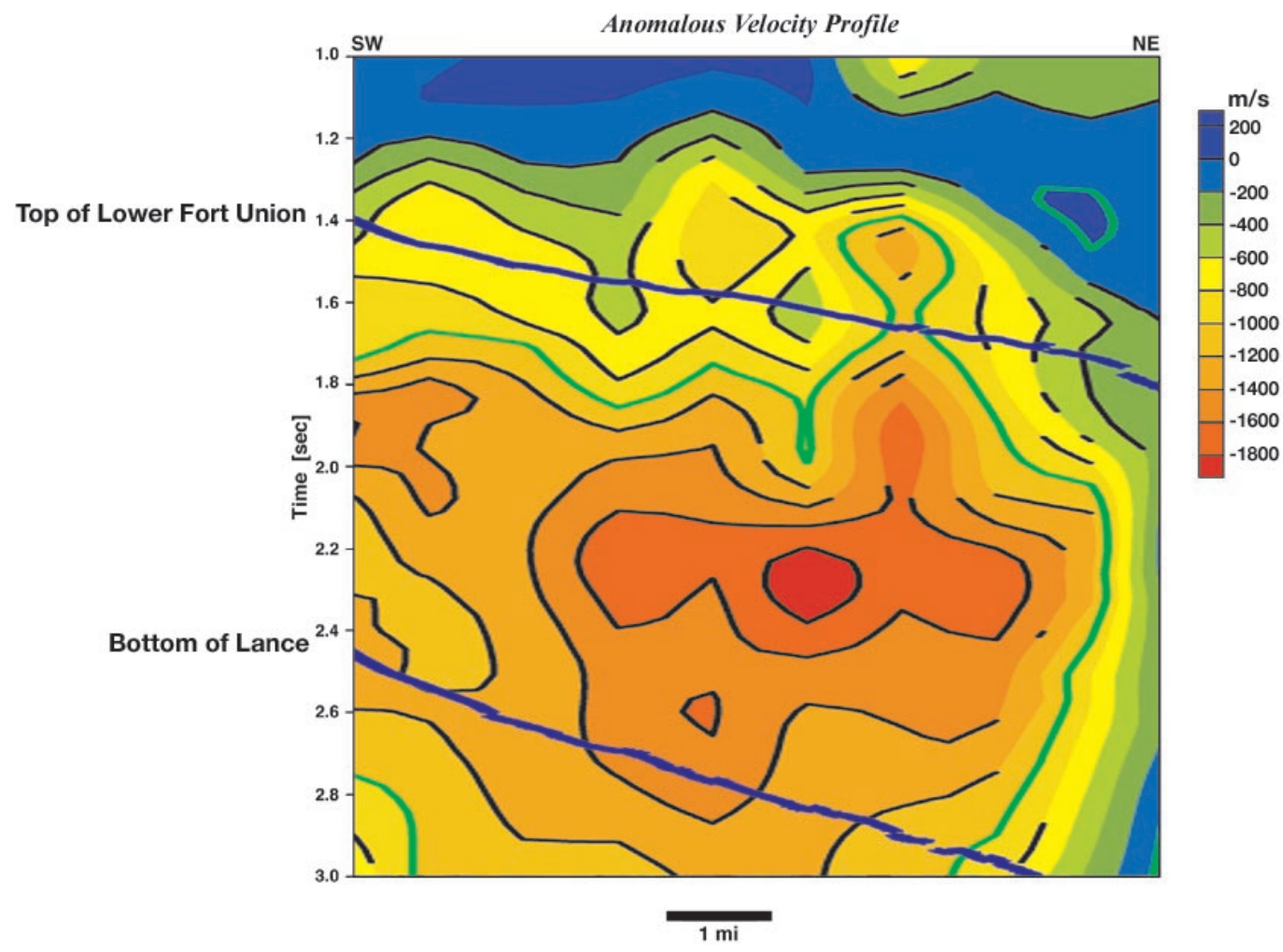

Figure 40. anomalous velocity panel for the same seismic data as those shown in Figure 39. The top of the Lower Fort Union and the bottom of the Lance formations are shown.

of sandstone-rich stratigraphic intervals, or potential reservoir intervals (shown here in blue and outlined by white dots) and gas-charged domains, or intense, anomalously slow areas (shown here as shaded areas and outlined by red dots); the regional velocity inversion surface is denoted by a solid red line. Figure 41 can be used to select and prioritize those sandstone-rich intervals that have the highest probability of being gas-charged. As with the Frenchie Draw area, in this example, those areas with the highest probability of containing gas-charged, sandstone-rich intervals are fault bounded. Again, this example (Figure 41) demonstrates the complex nature of reservoir distribution (heterogeneity) and gas distribution, and the interaction between these two important rock/fluid characteristics. It is concluded that optimization of commercial gas production in the RMLB "basin-center" configurations will occur when targeted reservoir intervals characterized by enhanced porosity and permeability intersect significant velocity anomalies (i.e., gas-charged domains).

\section{Pressure Regimes}

Figure 42 shows the combined pressure data for the Fort Union, Lance, and Mesaverde stratigraphic units from the Wind River Basin. These Fort Union Formation pressure data were originally from 297 wells and 1212 tests; the Lance Formation data were from 129 wells and 611 tests; and the Mesaverde Group data were from 132 wells and 323 tests. The data shown in Figure 42 were edited using the following criteria:

1. For the included tests, both the initial shut-in pressure (ISIP) and final shut-in pressure (FSIP) had to be reported or the test was discarded;

2. The ISIP and FSIP values had to agree within $10 \%$ or the test was discarded; and

3. All pressure data characterized by gradients less than $0.1 \mathrm{psi} / \mathrm{ft}$ (i.e., gas gradient) were eliminated. 


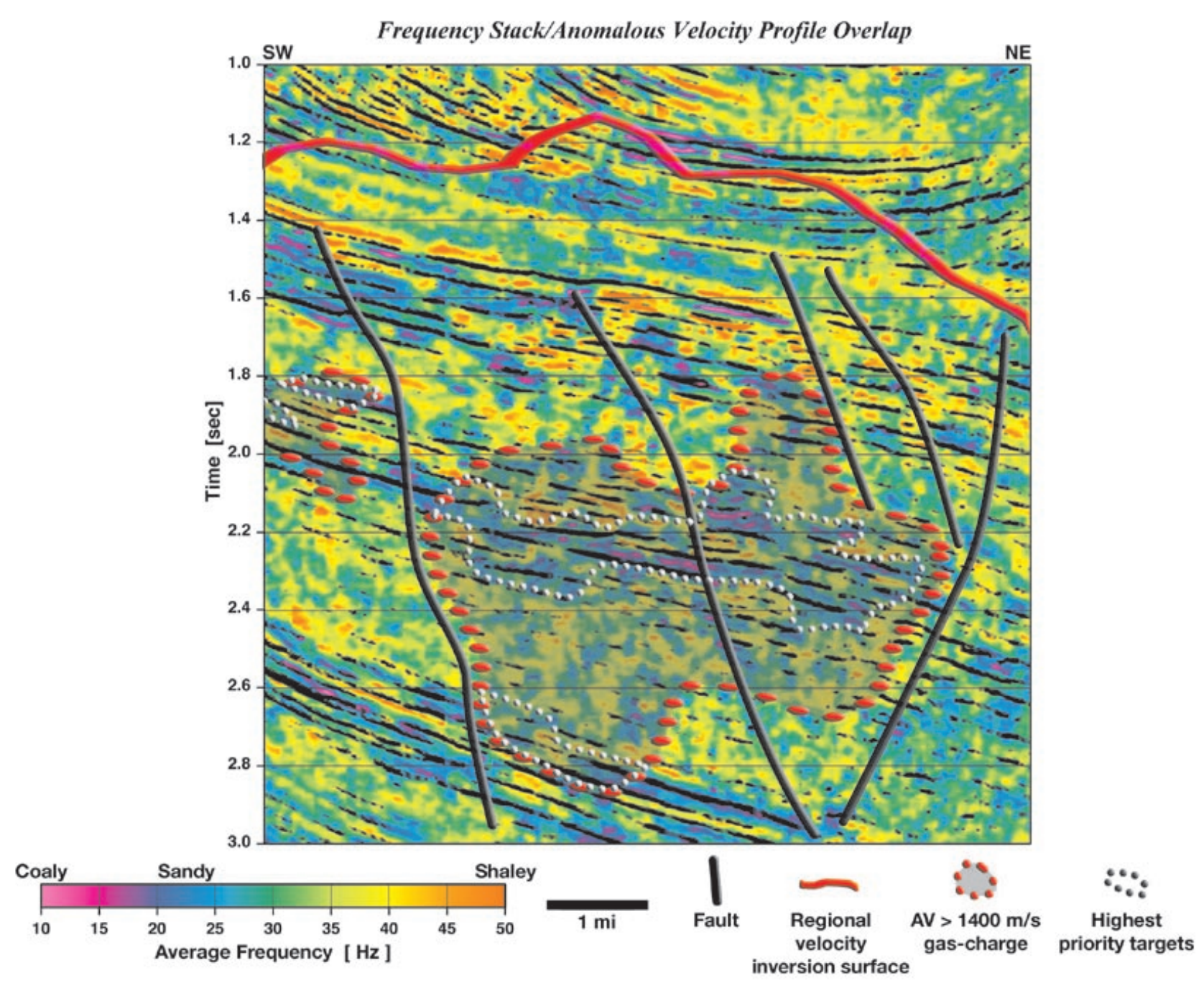

Figure 41. Seismic display illustrating the overlap between the frequency panel (Figure 39) and the anomalous velocity panel (Figure 40 ). The highest potential for regions characterized by gas-charged commercial reservoir distributions are outlined by white dots.

The observed pressure regimes in the lower Fort Union, Lance, and Mesaverde units are nearly identical. For each unit from near surface to $12,000 \mathrm{ft}$ depth, most of the observed pressure measurements are near the hydrostatic gradient (i.e., normal) or are significantly underpressured. Only when these units approach 12,000 $\mathrm{ft}$ present-day depth are significant overpressured values (i.e., significantly $>0.43 \mathrm{psi} / \mathrm{ft}$ ) observed (Figure 42). From the regional velocity inversion surface (typically encountered at 6000 to $8000 \mathrm{ft}$ depth) down to $12,000 \mathrm{ft}$ depth, the observed pressure gradients generally are less than or slightly greater than the regional "hydro- static" pressure gradient (i.e., $\sim 0.43 \mathrm{psi} / \mathrm{ft}$ ). At present, much of the drilling activity for these units in the Wind River Basin is for targets in the 8000 to $12,000 \mathrm{ft}$ depth window.

Judging from the pressure data presented in Figure 42, it appears that substantial evidence exists to indicate that significant portions of the lower Fort Union, Lance, and Mesaverde units are underpressured or normally pressured. These data, when combined with Figure 19, indicate that few of these rocks are in fluid-flow communication with the meteoric water system. The rock/ fluid systems in the lower Fort Union, Lance, 

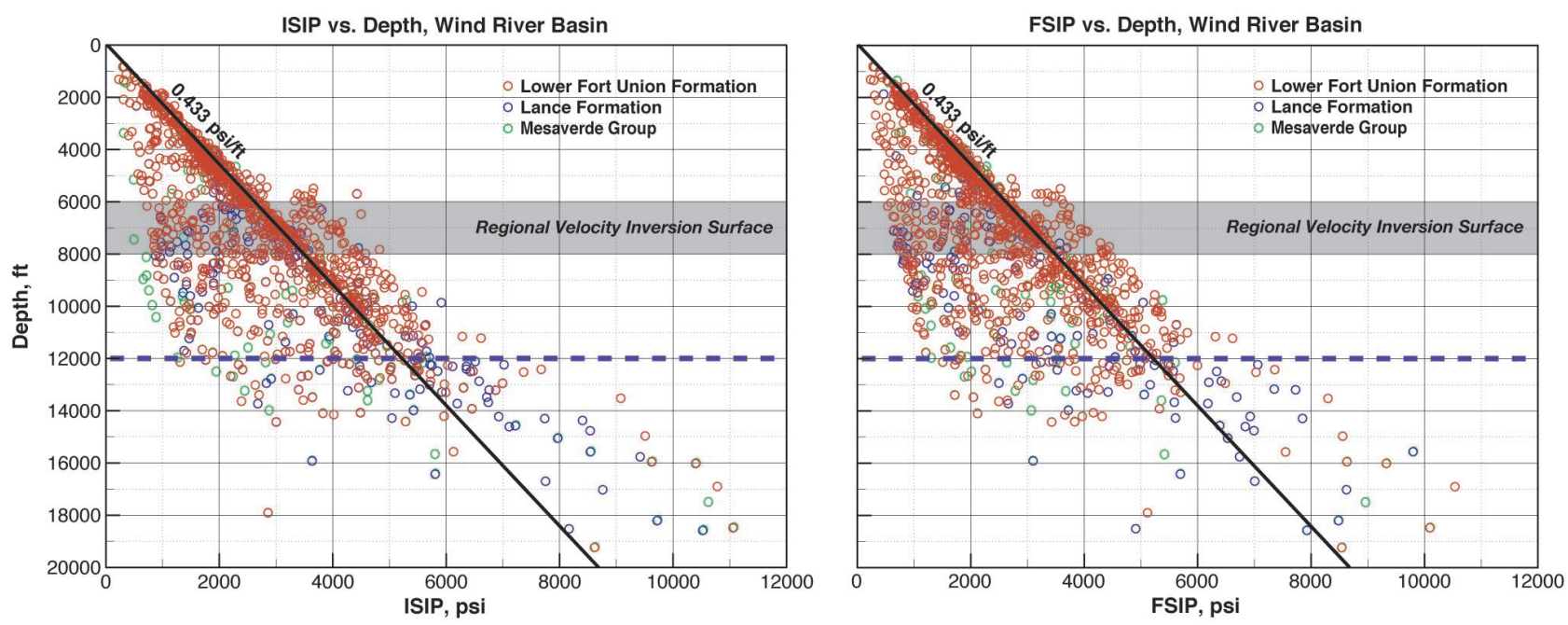

Figure 42. ISIP (left) and FSIP (right) vs. depth for the Lower Fort Union, Lance, and Mesaverde stratigraphic units from the Wind River Basin. For each unit from near surface to 12,000 ft depth, most of the observed pressure measurements are near the hydrostatic gradient (i.e., normally pressured) or significantly underpressured.

or Mesaverde units below the regional velocity inversion surface are not typically under strong water drive. (If there are exceptions to this observation, they would be on a very local, small scale and would not be detectable on the scale of seismic data.). Instead, both the normal and underpressured rock/fluid systems below the regional velocity inversion surface and above $12,000 \mathrm{ft}$ depth are compartmentalized and gas-charged, with multiphase fluid-flow systems dominated by capillarity. Below $\sim 12,000 \mathrm{ft}$ depth, most of the rock/fluid systems for these units will likely be compartmentalized and overpressured.

Commonly, the best gas production in Laramide basins is beneath, but within $2000 \mathrm{ft}$ of the regional velocity inversion surface (i.e., the pressure surface boundary separating normally pressured rock/fluid systems above from anomalously pressured rock/fluid systems below; see Surdam et al., 1997). Typically, reservoir rocks beneath but within $2000 \mathrm{ft}$ of the pressure transition, when compared to reservoir rocks occurring deeper in the anomalously pressured rock/fluid column, have undergone less burial and diagenesis; hence, they have relatively good porosity and permeability. This is why the Lower Fort Union/ Lance section is so important — this section typically occurs just below the regional velocity inversion surface. If a rock/fluid system within this 2000-ft depth interval is underpressured or even near normal pressure, it can be easily bypassed or badly damaged.

Recent work has shown that in all the RMLB, the transition at the velocity inversion surface is commonly from a normally pressured to an underpressured fluid-flow system. The potential for drilling damage to underpressured reservoir rock in the RMLB, and probably elsewhere in the world, is universal, particularly if the underpressured zone or interval is relatively thin, and if it is adjacent to overpressured rock/fluid systems (Figure 43). The potential for yet unrecognized, underpressured gas resources in many of the RMLB is significant (excluding the Alberta and San Juan basins, where huge, underpressured gas resources have been recognized and exploited). Ironically, the underpressured gas resources contain some of the best-quality reservoirs within the anomalously pressured portion of the Wind River Basin and probably most other RMLB.

From the pressure/depth observations summarized from the Wind River Basin and other 
RMLB, a general pressure evolution model for the Laramide basins has been constructed (Figure 44). If this model (Figure 44) is accurate, then both underpressured and overpressured rock/fluid systems are possible in any of the RMLB that have undergone uplift. The relationships among maximum burial, stratigraphic position, and structural setting determine whether an overpressured fluid regime will evolve to underpressured regime in a RMLB. Note that any rock/fluid system evolving from overpressured to underpressured conditions has to pass through a "normal" appearing pressure/ depth gradient, even though the fluid is isolated and is not in contact with the meteoric water system (i.e., hydrostatic pressure gradient).

\section{CONCLUSIONS}

The rock/fluid characteristics of the Rocky Mountain Laramide Basins described in this work determine the potential for significant, relatively unconventional, so-called "basin-center" hydrocarbon accumulations. The rock/fluid systems characterizing the RMLB dictate that if such accumulations occur, they will be characterized by the following critical attributes:

1. Location beneath a regional velocity inversion surface that typically is associated with low-permeability lithologies;

2. Anomalous pressure, both over- and underpressure, and when, less commonly,

\section{Major Cretaceous Gas Reservoir Pressure, Powder River Basin Pressure, psi}

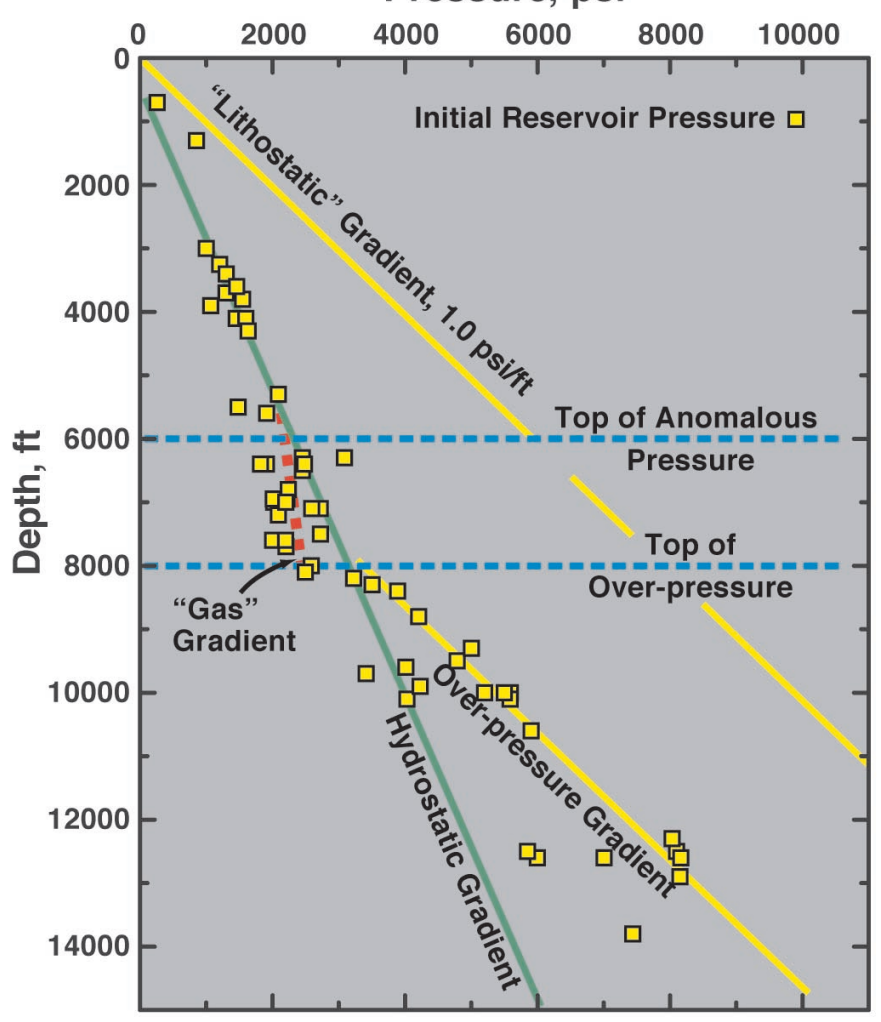

Figure 43. Pressure profile for the major Cretaceous gas reservoirs in the Powder River Basin. Note that at the depth of the regional velocity inversion surface (which is denoted the top of anomalous pressure), the transition is from a normal pressure gradient (i.e., hydrostatic gradient) to an underpressured gradient. At a depth of $8000 \mathrm{ft}$, there is a transition to an overpressured gradient. This type of pressure transition at the regional velocity inversion surface is typical in many RMLB. 


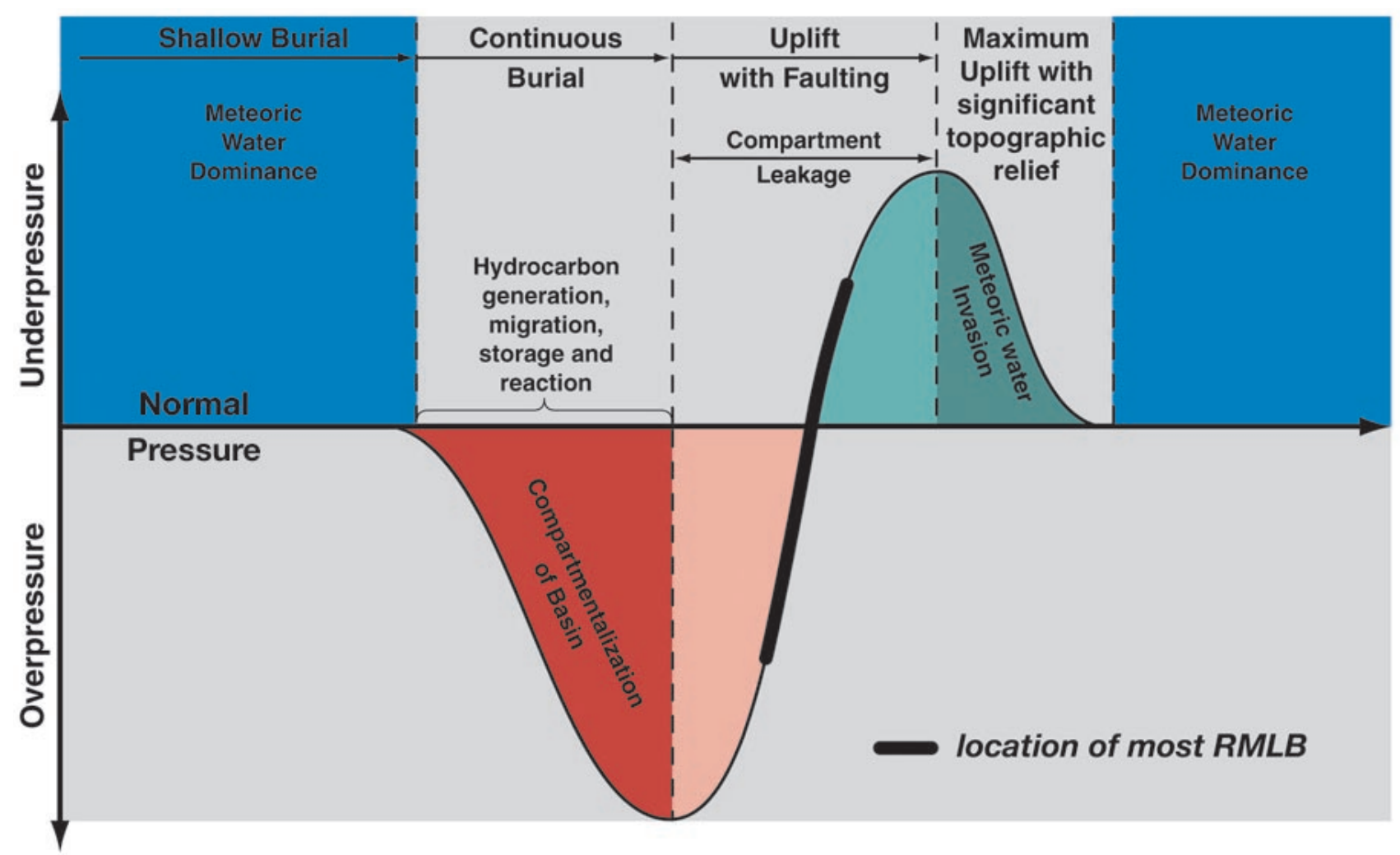

\section{Pressure Evolution Characterizing Laramide Basins}

Figure 44. Schematic diagram illustrating the typical transition from overpressured to underpressured rock/fluid systems in the RMLB that have undergone regional uplift. Note that to evolve from overpressure (i.e., continuous burial) to underpressure (i.e., uplift), the rock/fluid system has to pass through what would appear to be a "normal" pressure regime. Rock/fluid systems at this point appear to fall on the hydrostatic gradient, but the fluid-flow regime is still compartmentalized and not in contact with the meteoric water flow regime (i.e., water drive).

they appear to be normally pressured, they are not in contact with the meteoric water system;

3. A significant gas component in the regional multiphase fluid-flow system (water-gas-oil) that occurs beneath the regional velocity inversion surface;

4. Domains of intense gas charge (i.e., high gas saturation) within the regional multiphase fluid-flow system;

5. Compartmentalization of the rock/fluid system to a far greater extent beneath the regional velocity inversion surface than above it (i.e., convection of fluids across the regional velocity inversion surface is reduced or eliminated depending on the nature of the capillary properties of the low-permeability rocks associated with the inversion surface);

6. Commercial gas accumulations occurring at the intersection of reservoir intervals characterized by enhanced porosity and permeability and gas-charged domains;

7. Productive intersections of reservoir intervals and gas-charged domains that are controlled by the structural, stratigraphic, and diagenetic elements affecting the rock/fluid system; and

8. No apparent meteoric water connection with the gas accumulations and gas col- 
umns up to several thousand feet in height.

Because some of these critical attributes are not associated with conventional hydrocarbon accumulations, a new set of diagnostic tools are required in order to explore for and exploit these types of gas prospects efficiently and effectively. Some of these new diagnostic tools have been discussed in this report; other have been described elsewhere (Surdam et al., 1994; Heasler et al, 1994; Chen et al., 1994; MacGowan et al, 1994; Surdam et al, 1997; Maucione and Surdam, 1997; Surdam, 1997; Surdam et al, 200; Surdam, 2001a,b,c; and Surdam, $2003 a, b)$. In order to maximize risk reduction, it is recommended when exploring for these types of gas accumulations in the RMLB - or for that matter, anomalously pressured gas accumulations anywhere in the world - that highest priority be given to:

1. Evaluating gas distribution in the fluid system, and

2. Predicting enhanced porosity and permeability in the rock system.

\section{ACKNOWLEDGMENTS}

We gratefully acknowledge the support provided for this work by the Department of Energy under Contract No. DE-FC26-01NT41325 and Gary Covatch, our DOE Project Manager. We thank Echo Geophysical Co. for assisting us with data processing. Lastly, we acknowledge the long-term encouragement provided to us by the energy industry, especially the McMurry Oil Company.

\section{REFERENCES}

Boswell, R.M., A.S.B. Douds, H.R. Pratt, K.K. Rose, J.A. Pancake, J.H. Dean, and K.R. Bruner, 2003, Natural Gas Resources of the Greater Green River and Wind River Basins of Wyoming: An Assessment of Marginal, Sub-Economic, and Unappraised Resources to Support DOE's Natural Gas Program Planning: DOE/NETL-2202/1176, Morgantown, $\mathrm{WV}$, on $\mathrm{CD}$.

Camp, W. K, A.B. Brown, and L.L. Poth, 2003, Basin-Center Gas or Subtle Conventional Traps?: AAPG Annual Meeting, Salt Lake City, UT, Official Program No. 12 with Abstracts, p. A24.

Cardinal, D.F., T. Miller, W.W. Stewart, and J.F Trotter, eds., 1989, Wyoming Oil and Gas Fields Symposium: Bighorn and Wind River Basins: Wyoming Geological Association, Casper, WY, p.175.

Chen, W., A. Park, and P.J. Ortoleva, 1994, Role of pressure-sensitive reactions in seal formation and healing: Application of the CIRF.A reaction-transport code, in $\mathrm{P}$. Ortoleva, ed., Basin Compartments and Seals: American AAPG, Tulsa, OK, Memoir 61, pp. 417-428.

Heasler, H.P., R.C. Surdam, and J.H. George, 1994, Pressure compartments in the Powder River Basin, Wyoming and Montana, as determined from drill-stem test data, in P. Ortoleva, ed., Basin Compartments and Seals: AAPG, Tulsa, OK, Memoir 61, pp. 235-262.

Jiao, Z.S., and R.C. Surdam, 1994, Stratigraphic/ diagenetic pressure seals in the Muddy Sandstone, Powder River Basin, Wyoming, in P. Ortoleva, ed., Basin Compartments and Seals: AAPG, Tulsa, OK, Memoir 61, pp. 297-312.

Knight, R., J. Dvorkin, and A. Nur, 1998, Acoustic signatures of partial saturation: Geophysics, v. 63, no. 1 (January-February 1998), pp. 132-138.

Law, B.E., 1984, Relationships of source-rock, thermal maturity, and overpressuring to gas generation and occurrence in low-permeability upper Cretaceous and lower Tertiary rocks, Greater Green River Basin, Wyoming, 
Colorado, and Utah, in J. Woodard, F.

Meissner, and J. Clayton, eds., Hydrocarbon

Source Rocks of the Greater Rocky Mountain

Region: RMAG, pp. 469-490.

Law, B.E. and W.W. Dickinson, 1985, A conceptual model for the origin of abnormally pressured gas accumulations in low-permeability reservoirs: AAPG Bulletin, v. 69, pp. 1295-1304.

Law, B.E., and C.W. Spencer, 1998, Abnormal pressure in hydrocarbon environments, in B.E. Law, G.F. Ulmishek, and V.I. Slavin, eds., Abnormal Pressures in Hydrocarbon Environments: AAPG Memoir 70, Chapter 1, pp. 1-12.

Law, B.E., 2002, Basin-centered gas systems: AAPG Bulletin, v. 86, no. 11, pp. 1891-1919.

Law, B.E., C.W. Spencer, and N.H Bostick, 1980, Evaluation of organic maturation, subsurface temperature, and pressure with regard to gas generation in low-permeability Upper Cretaceous and lower Tertiary strata in the Pacific Creek area, Sublette County, Wyoming: Mountain Geologist, v. 17, no. 2, pp. 23-35.

Lazaratos, S.K., and B.P. Marion, 1997, Croswell Seismic Imaging of Reservoir Changes Caused $\mathrm{By}_{\mathrm{CO}_{2}}$ Injection: The Leading Edge, SEG, v. 16, no. 7, pp. 1300-1306.

MacGowan, D.B., Z.S. Jiao, R.C. Surdam, and F.P. Miknis, 1994, Formation water chemistry of the Muddy Sandstone, and organic geochemistry of the Mowry Shale, Powder River Basin, Wyoming: Evidence for mechanism of pressure compartment formation, in P. Ortoleva, ed., Basin Compartments and Seals: American Association of Petroleum Geologists Memoir 61, Tulsa, OK, pp. 321-332.

Masters, J.A., 1979, Deep basin gas trap, western Canada: AAPG Bulletin, v. 63, pp. 152-181.

Masters, J.A., ed., 1984, Elmworth — Case
Study of a Deep Basin Gas Field: American Association of Petroleum Geologists Memoir 38, pp.189-204.

Maucione, D.T., and R.C. Surdam, 1997, Seismic Response Characteristics of a Regional-Scale Pressure Compartment Boundary, Alberta Basin, Canada, in R.C. Surdam, ed., Seals, Traps, and the Petroleum System: American Association of Petroleum Geologists, Tulsa, OK, Memoir 67, Chapter 16, pp. 269-282.

McPeek, L.A., 1981, Eastern Green River basin - a developing giant gas supply from deep, overpressured Upper Cretaceous sandstones: AAPG Bulletin, v. 65, pp. 1078-1098.

Sneider R.M., K. Stolper, and J.S. Sneider, 1991, Petrophysical properties of seals: AAPG Bulletin, v. 75, pp. 673-674.

Spencer, C.W., 1985, Geologic aspects of tight gas reservoirs in the Rocky Mountain region: Journal of Petroleum Geology, pp. 1308-1314.

Spencer, C.W., 1987, Hydrocarbon generation as a mechanism for overpressuring in the Rocky Mountain region: AAPG Bulletin, v. 71, pp. 368-388.

Spencer, 1989, Review of characteristics of lowpermeability gas reservoirs in western United States: AAPG Bulletin, v. 73, pp. 613-629.

Shanley K.W., R.C. Cluff, L.T. Shannon, and J.W. Robinson, 2003, Controls on Prolific Gas Production from Low-Permeability Sandstone Reservoirs in Basin-Centered Regions: Implications from the Rocky Mountain Region for Resource Assessment, Prospect Appraisal, and Risk Analysis: AAPG Annual Meeting, Salt Lake City, UT, Official Program No. 12 with Abstracts, p. A156.

Surdam, R.C., 1997, A New Paradigm for Gas Exploration in Anomalously Pressured "Tight Gas Sands" in the Rocky Mountain Laramide 
Basin, in R.C. Surdam, ed., Seals, Traps, and the Petroleum System: American Association of Petroleum Geologists, Tulsa, OK, Memoir 67, Chapter 17, pp. 283-298.

Surdam R.C., 2001a, Anomalously pressured gas resources in Rocky Mountain Laramide Basins: World Oil, v. 222, no. 9, p. 80-82.

Surdam, R.C., 2001b, APG is a Huge, Undeveloped Resource: The American Oil \& Gas Reporter, v. 44, no. 12, pp. 68-71.

Surdam, R.C., 2001c, Sweet Spot of Success: Velocity Analysis Maps Sweets Spots in Tight Gas Reservoirs: New Technology Magazine, v. 7, no. 3, p. 32-33.

Surdam R.C., J. Robinson, Z.S. Jiao, and N.G. Boyd, 2001, Exploration of the giant Jonah Gas Field using sonic and seismic data, Great Green River Basin, Wyoming: Rocky Mountain association of Geologists Special Publication, pp. 1-19.

Surdam, R.C., Z.S. Jiao, and Y. Ganshin, 2003a, Anomalously Pressured Gas Distribution in the Wind River Basin, Wyoming: DOE Topical Technical Progress Report under Contract No. DE-FC26-01NT41325, 22 p.

Surdam, R.C., Z.S. Jiao, and Y. Ganshin, 2003b, Rock/Fluid System Characteristics of the Wind River Basin, Wyoming: DOE Topical Technical Progress Report under Contract No. DE-FC26-01NT41325, 18 p.

Surdam, R.C., Z.S. Jiao, and H.P. Heasler, 1997, Anomalously Pressured Gas Compartments in Cretaceous Rocks of the Laramide Basins of Wyoming: A New Class of Hydrocarbon Accumulation, in R.C. Surdam, ed., Seals, Traps, and the Petroleum System: AAPG, Tulsa, OK, Memoir 67, Chapter 12, pp. 199-222.

Surdam, R.C., J. Robinson, Z.S. Jiao, N.K. Boyd, 2001, Delineation of Jonah Field Using Seismic and Sonic Velocity Interpretations, in D.S. Anderson, J.W. Robinson, J.E. Estes-
Jackson, E.B. Coalson, ed., Gas in the Rockies, Rocky Mountain Association of Geologists, Denver, CO, Chapter 13, pp. 189-208.

Surdam, R.C., Z.S. Jiao, and R.S. Martinsen, 1994, The regional pressure regime in Cretaceous sandstones and shales in the Powder River Basin, in P. Ortoleva, ed., Basin Compartments and Seals: AAPG Tulsa, OK, Memoir 61, pp. 213-233.

Timur, A., 1987, Acoustic logging, in H. Bradley, ed., Petroleum Engineering Handbook: Dallas, TX, Dallas Society of Petroleum Engineers. 